Sylene Coutinho Rampche de CaRvalho

\title{
Avaliação de polimorfismos no gene do fator de crescimento endotelial vascular (VEGF) e da metilenotetrahidrofolato redutase (MTHFR) em pacientes com carcinoma hepatocelular e infecção pelo vírus da hepatite $\mathrm{C}$
}

Tese apresentada à Faculdade de Medicina da Universidade de São Paulo para obtenção do título de Doutor em Ciências Programa de Ciências em Gastroenterologia Orientador: Prof. Dr. Flair José Carrilho

São Paulo 
Dados Internacionais de Catalogação na Publicação (CIP)

Preparada pela Biblioteca da

Faculdade de Medicina da Universidade de São Paulo

Creprodução autorizada pelo autor

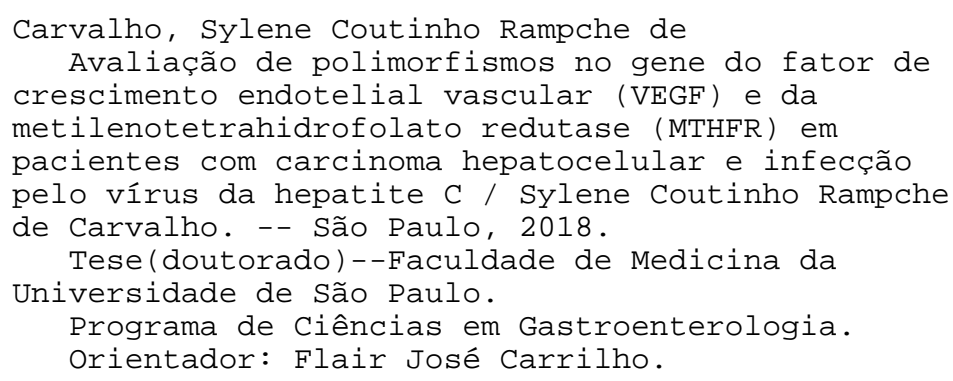

Descritores: 1.Carcinoma hepatocelular 2.Fator A do crescimento do endotélio 3.Polimorfismo genético 4. Hepatite C 5.Fígado 6.Cirrose hepática

$\mathrm{USP} / \mathrm{FM} / \mathrm{DBD}-495 / 18$

Responsável: Erinalva da Conceição Batista, CRB-8 6755 


\section{DEDICATÓRIA}

Aos meus três filhos: Karina, Pedro e Antonio 


\section{AGRADECIMENTOS}

“Gratidão é o ato de reconhecimento de uma pessoa por alguém que lhe prestou um auxílio...em um sentido mais amplo abrange situações e dávidas que a vida lhe proporcionou e ainda proporciona." (Wikipédia)

É chegada a hora de agradecer! Agradecer a todos que de alguma forma estiveram ligados a esta missão.

Agradeço a Deus, Pai de todas as Dávidas desta vida. Foi a Fé que sempre me impulsionou até aqui.

Agradeço aos meus pais e irmãos, base de minha educação, de minha personalidade e exemplos profissional.

Agradeço a Aldo Cezar companheiro de minha jornada e aos meus filhos, pelo incentivo, compreensão, amor e atenção aos detalhes que fazem a diferença.

Agradeço a meu orientador Dr Flair Carrilho e a minha co-orientadora Dra. Claúdia Oliveira. Pela confiança depositada e serem o meu ponto de apoio nesta missão.

Agradeço ao grupo de nódulos do IFP nas pessoas de Dra. Leila Beltrão e Dra. Dayse, por acima de tudo compartilhar e incentivar.

Agradeço a todos os colegas de trabalho por estarem juntos a mim neste processo, do início ao fim. Um agradecimento especial aos diretores do Hospital Universitário Oswaldo Cruz, Professora Doutora Izabel Avelar e do Hospital da Restauração de Pernambuco, Professor Doutor Miguel Arcanjo, pelo estímulo para o crescimento profissional.

Agradeço ao grupo de trabalho do laboratório de cirurgia Experimental LIM-37- setor de biologia molecular da FMUSP pelo cuidado e atenção em realizar o trabalho.

Agradeço a Vilma Libério secretária de pós-graduação em Ciências em gastroenterologia/ FMUSP, por toda atenção e responsabilidade com seu trabalho, e todo carinho dedicado.

E por último, de forma especial, agradeço aos amigos queridos, Luydson Vasconcelos, Fábio Moura, Clarissa Rocha e Gabriela Foinquinos que estiveram ao meu lado, incentivando, escutando, compartilhando, colaborando. Este grupo define amor.

Obrigada a todos sem exceção... 


\section{NORMALIZAÇÃO}

Esta tese está de acordo com as seguintes normas, em vigor no momento desta publicação.

Referências: adaptado de International Committee of Medical Jornal Editors (Vancouver).

Universidade de São Paulo. Faculdade de Medicina. Divisão de Biblioteca e Documentação. Guia de Apresentação de dissertações, teses e monografias. Elaborado por Anneliese Carneiro da Cunha; Maria Júlia de A. L. Freddi; Maria F. Crestana; Marinalva de Souza Aragão; Suely Campos Cardoso; Valéria Vilhena. 3. ed. São Paulo: Divisão de Biblioteca e Documentação; 2011.

Abreviatura dos títulos de periódicos de acordo com List of Journals Indexed in Index Medicus. 


\section{SUMÁRIO}

Lista de abreviaturas e siglas

Lista de figuras

Lista de tabelas

Resumo

Abstract

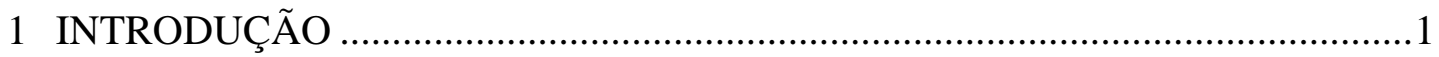

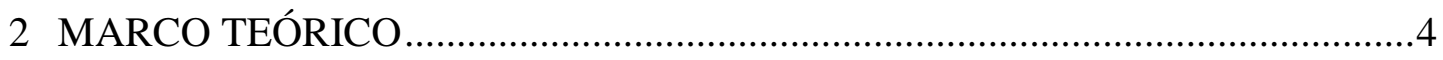

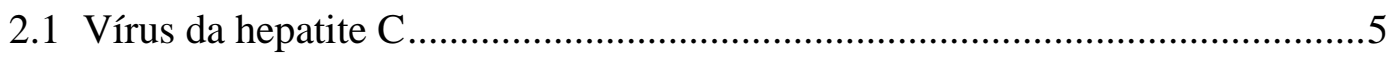

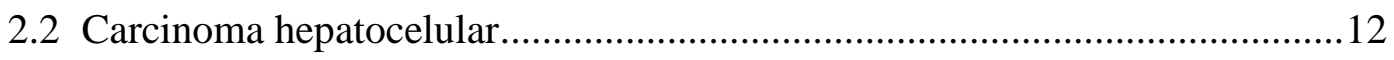

2.2.1 Epidemiologia, prevenção e vigilância do CHC...............................12

2.2.2 Diagnóstico do CHC ....................................................................14

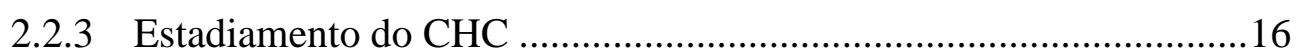

2.2.4 Tratamento do $\mathrm{CHC}$................................................................. 18

2.3 Fator de crescimento endotelial vascular (VEGE) ...................................21

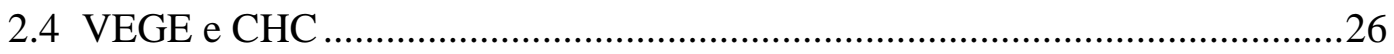

2.5 Metilenotetrahidrofolato redutase (MTHFR) ….........................................27

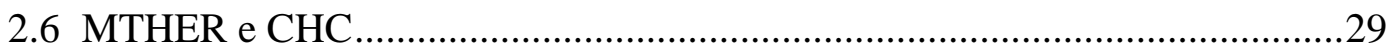

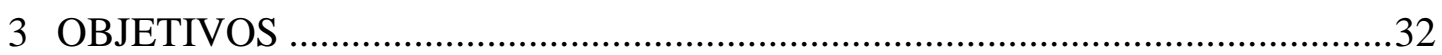

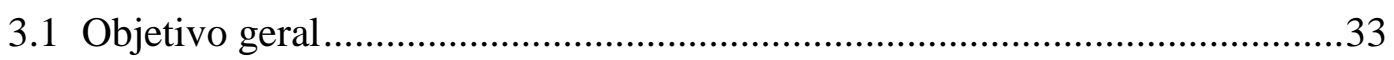

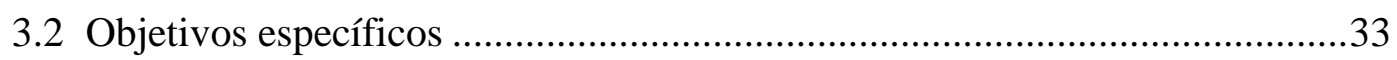

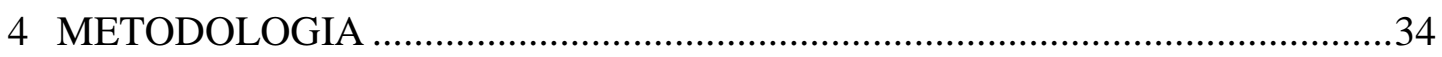

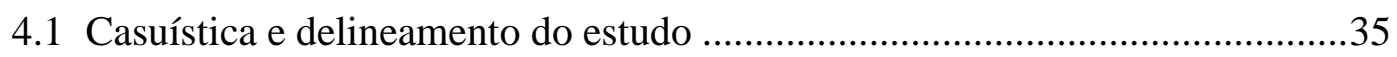

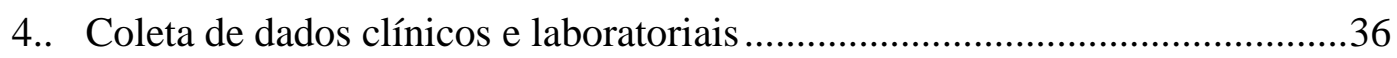

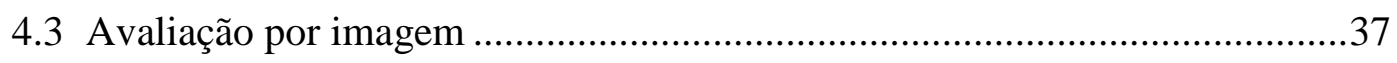

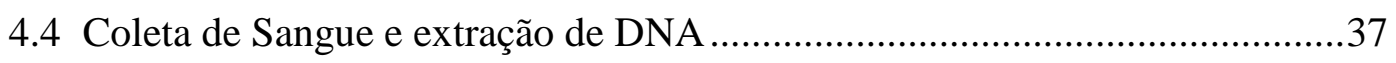

4.5 Seleção dos SNPs (single nucleotide polimorphisms) ...................................39

4.6 Genotipagem por TaqMan $®$ SNP Genotyping Assays .................................40

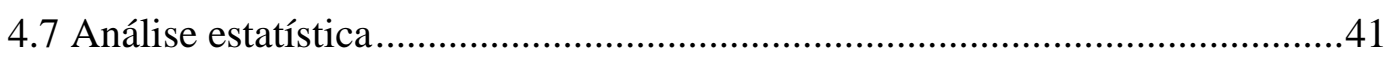

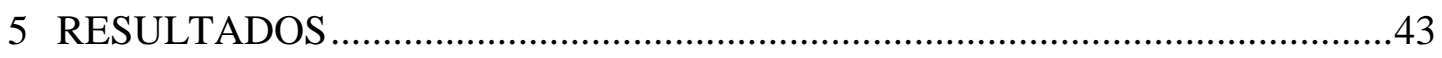

5.1 Características clínicas e laboratoriais ..........................................................44 
5.2 Análise da frequência dos genótipos e distribuição dos SNPs (single nucleotide polimorphisms) nos genes, MTHFR e VEGF em pacientes com $\mathrm{CHC}$ e VHC, e indivíduos controles.

5.3 Análise de associação com os genes MTHFR e VEGF e características do tumor em pacientes com CHC e VHC.

5.4 Análise da frequência alélica dos genes MTHFR e VEGF nas populações de Recife, Europeia e Africana

5.5 Análise de sobrevida dos pacientes com CHC e VHC, estratificados pelos genótipos dos genes MTHFR (rs1801131), MTHFR (rs1801133) e VEGF (rs2010963)

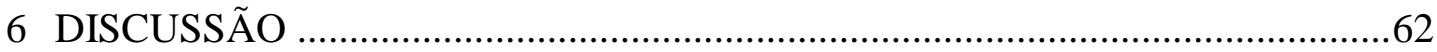

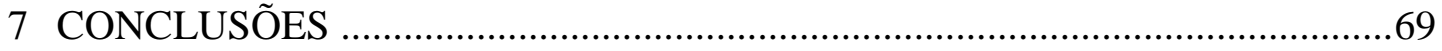

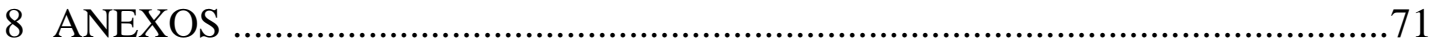

Anexo A- Aprovação do Comitê de Ética em Pesquisa...........................................72

Anexo B- Termo de Consentimento Livre e Esclarecido. ...................................73

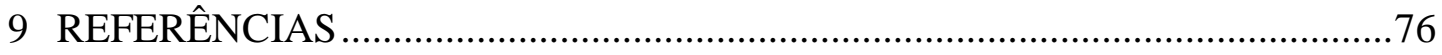




\section{LISTAS}

\section{ABREVIATURAS E SIGLAS}

A

ACR

AFP

AFR

ALT

Ang

AST

BA

BCLC

BT

C

CE

CHC

cm

CRH

dbSNP

DHC

DHGNA

DM

DNA

DP

dUMP

EDTA

EGF

E(HET)

EHW

EUR
Adenina

Colégio Americano de Radiologia

Alfa 1 fetoproteína

Africana

Alanina aminotransferase

Angiopoetina

Aspartato aminotransferase

Bahia

Clinica de câncer de fígado de Barcelona

Bilirrubina total

Citosina

Células endoteliais

Carcinoma hepatocelular

centímetro

cromossomo

Banco de dados de polimorfismos de necleotídeo único

Doença Hepatica Crônica

Doença hepática gordurosa não alcoólica

Diabetes mellitus

Ácido desoxirribonucléico

Desvio padrão

Desoxiuridina monofosfato

Ácido etilenodiaminotetracético

Fator de crescimento endotelial

Frequência relativa esperada nos heterozigóticos

Equilíbrio de Hardy-Weinberg

Europeia 


\begin{tabular}{|c|c|}
\hline FA & Fosfatase alcalina \\
\hline FGF & Fator de crescimento do fibroblasto \\
\hline GGT & Gama glutamil-transferase \\
\hline HIF-1 & Fator induzido por hipóxia \\
\hline HIV & Vírus da imunodeficiência humana \\
\hline HTLV & Vírus T-linfotrópico humano \\
\hline IC & Intervalo de confiança \\
\hline IL & Interleucina \\
\hline IMC & Índice de massa corpórea \\
\hline KG & Kilogramas \\
\hline $\mathbf{M}^{2}$ & Metro quadrado \\
\hline MAF & Frequência do alelo menor \\
\hline MELD & Modelo de estágio final de doença hepástica \\
\hline $\mathbf{m m}$ & milímetro \\
\hline MTHFR & Metilenotetrahidrofolato redutase \\
\hline nm & nanometro \\
\hline NCBI & Centro nacional de informação biotecnológica \\
\hline O(HET) & Frequência relativa observada nos heterozigóticos \\
\hline $\mathbf{O R}$ & Razão de chances \\
\hline PCR & Reação de cadeia de polimerase \\
\hline PDGF & Fator de crescimento derivado de plaquetas \\
\hline PE & Pernambuco \\
\hline REC & Recife \\
\hline $\mathbf{R M}$ & Ressonância Magnética \\
\hline RNA & Ácido ribonucleico \\
\hline RNAm & Ácido ribonucleico mensageiro \\
\hline SAM & $\mathrm{S}$ adenosilmetionina \\
\hline SNP & Nucleotídeo de polimorfismo simples \\
\hline $\mathbf{T}$ & Timina \\
\hline TC & Tomografia Computadorizada \\
\hline TCLE & Termo de consentimento livre e esclarecido \\
\hline THF & Tetrahidrofolato \\
\hline
\end{tabular}




$\begin{array}{ll}\text { TMP } & \text { Timidina monofosfato } \\ \text { TNF } & \text { Fator de necrose tumoral } \\ \text { TNM } & \text { Tumor-nódulo-metástase } \\ \text { US } & \text { Ultrassonografia } \\ \text { VEGF } & \text { Fator de crescimento endotelial vascular } \\ \text { VEGFR } & \text { Receptor do fator de crescimento endotelial vascular } \\ \text { VHB } & \text { Vírus da hepatite B } \\ \text { VHC } & \text { Vírus da hepatite C } \\ \% & \text { Por cento } \\ \leq & \text { Menor ou igual } \\ > & \text { Maior que } \\ \geq & \text { Maior ou igual } \\ < & \text { Menor que }\end{array}$


FIGURAS

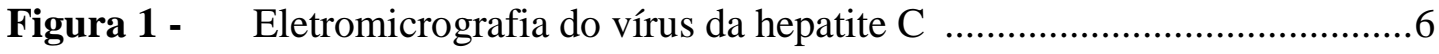

Figura 2 - Organização genômica do VHC …................................................

Figura 3 - $\quad$ Organização do genoma do VHC …..............................................

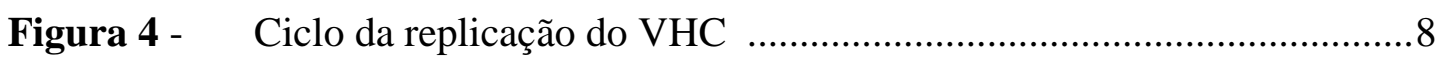

Figura 5 - Árvore filogenética representativa de 129 sequências completas ........9

Figura 6 - Algoritmo de diagnóstico de nódulo em paciente cirrótico ................16

Figura 7 - Algoritmo de estadiamento BCLC e estratégia de tratamento ............18

Figura 8 - Mecanismo da Angiogênese .......................................................24

Figura 9 - Metabolismo da Homocisteína …....................................................28

Figura 10 - Metabolismo do ácido fólico e função da MTHFR ............................30

Figura 11 - Análise de sobrevida de 92 pacientes com CHC infectados pelo vírus da hepatite $\mathrm{C}$ estratificados pelos genótipos do gene MTHFR (rs181133)

Figura 12 - Análise de sobrevida de 92 pacientes com CHC infectados pelo vírus da hepatite $\mathrm{C}$ estratificados pelos genótipos do gene MTHFR (rs181131)

Figura 13 - Análise de sobrevida de 92 pacientes com CHC infectados pelo vírus da hepatite $\mathrm{C}$ estratificados pelos genótipos do gene $V E G F$ (rs2010963) 
TABELAS

Tabela 1 - Características clínicas e laboratoriais relacionadas aos pacientes com CHC e VHC com a classificação do BCLC (Barcelona Clinic Liver Cancer) .46

Tabela 2 - Distribuição dos SNPs em pacientes com CHC e VHC, grupo controle e verificação do equilíbrio de Hardy-Weinberg (EHW) .......48

Tabela 3 - Análise dos SNPs dos genes MTHFR e VEGF em pacientes com CHC e VHC divididos de acordo com a classificação BCLC .49

Tabela 4 - $\quad$ Análise dos SNPs dos genes MTHFR e VEGF em pacientes com CHC e VHC divididos de acordo com o número de tumores

Tabela 5 - $\quad$ Análise dos modelos de associação genética dos genes MTHFR e VEGF em pacientes com CHC e VHC divididos de acordo com o número de tumores

Tabela 6 - Características laboratoriais e do tumor de pacientes com $\mathrm{CHC}$ e VHC em relação aos genótipos dos genes MTHFR (rs18011131 e rs1801133) e VEGF (rs2010963)

Tabela 7 - Análise de regressão logística para predizer ocorrência de tumores multinodulares em 117 pacientes com CHC e VHC .56

Tabela 8 - Frequência alélica dos genes $M T H F R$ e VEGF nas populações de Recife (REC) estudada, Europeia (EUR) e Africana (AFR) .57 


\section{RESUMO}

Carvalho SCR. Avaliação de polimorfismos no gene do fator de crescimento endotelial vascular (VEGF) e da metilenotetrahidrofolato redutase (MTHFR) em pacientes com carcinoma hepatocelular e infecção pelo vírus da hepatite $C$ [tese]. São Paulo: Faculdade de Medicina, Universidade de São Paulo; 2018.

INTRODUÇÃO: A cirrose hepática é fator de risco para o Carcinoma hepatocelular (CHC) e no Brasil, a etiologia de doença hepática crônica mais frequente associada ao CHC é a infecção crônica pelo vírus da hepatite C (VHC). Angiogênese e deficiência de folato podem estar associados ao risco de CHC. Deste modo, os polimorfismos de genes relacionados com esses processos o VEGF e MTHFR em doentes com hepatite $\mathrm{C}$ crónica e $\mathrm{CHC}$ podem conduzir a marcadores genéticos para CHC na infecção por HCV.OBJETIVOS: Avaliar os polimorfismos G634C (rs2010963), C460T (rs833061), C936T (rs3025039) do gene do VEGF e polimorfismos C677T (rs1801133) e C1298A (1801131) da MTHFR, em pacientes brasileiros com CHC e infecção crônica pelo VHC . PACIENTES E MÉTODOS: Foram incluídos 119 pacientes com seguimento de CHC e VHC na clínica de hepatologia do HUOC / UPE e do IFP-PE, Brasil. Este estudo teve aprovação do comitê de ética e os pacientes assinaram o formulário de consentimento. Todos os pacientes tiveram diagnóstico de VHC por PCR e CHC por ressonância magnética e / ou tomografia.RESULTADOS: Dentre os indivíduos com CHC, 70,59\% foram homens. A média de idade dos participantes foi de 62,3 anos. De acordo com a classificação de Child-Pugh, ficaram assim distribuídos: A 60,9\%; B 36,5\%; C 2,6\%. O tamanho do tumor médio foi de $4,4 \mathrm{~cm}$. Sendo que $52,10 \%$ foi multinodular. Foi feita uma análise de associação com os genes MTHFR e VEGF e características do tumor nos pacientes com CHC infectados cronicamente com VHC. Os alelos C da MTHFR (rs1801131) e da VEGF (rs2010963) foram associados com a proteção para o desenvolvimento da forma multinodular, e o alelo T da MTHFR (rs1801133) foi associado a fator de risco para desenvolvimento da forma multinodular $\mathrm{p}=0,04 \mathrm{OR}$ 1,835 IC $(1,0223,297)$. Foram realizadas análises multivariadas, incluindo-se no modelo o sexo masculino e a idade como potenciais fatores de confusão, o gene $V E G F$ genótipo CC (rs2010963) foi um fator independente associado à proteção ao desenvolvimento de tumores multinodulares. Foi também realizada uma análise de sobrevivência estratificada pelos genótipos MTHFR (rs1801131), MTHFR (rs1801133) e VEGF (rs2010963), mas não foram observados resultados significativos. CONCLUSÕES: Foi observado que os genes MTHFR e VEGF tem influência na forma de apresentação uni ou multinodular do tumor.

Descritores: carcinoma hepatocelular; fator A do crescimento do endotélio; polimorfismo genético; hepatite C; fígado; cirrose hepática. 


\begin{abstract}
Carvalho SCR. Polymorphisms in the vascular endothelial growth factor (VEGF) and methylenetetrahydrofolate reductase (MTHFR) gene in patients with hepatocellular carcinoma and hepatitis $C$ virus infection [thesis]. São Paulo: "Faculdade de Medicina, Universidade de São Paulo"; 2018.

BACKGROUND: Hepatic cirrhosis is a risk factor for hepatocellular carcinoma (HCC) and in Brazil, the most frequent chronic liver disease associated with HCC is chronic hepatitis $\mathrm{C}$ virus (HCV) infection. Angiogenesis and folate deficiency may be associated with the risk of HCC. Thus, gene polymorphisms related to such processes VEGF and MTHFR in patients with chronic hepatitis C and HCC may lead to genetic markers for HCC in HCV infection. OBJECTIVES: To evaluate the polymorphisms G634C (rs2010963), C460T (rs833061), C936T (rs3025039) of the VEGF gene and polymorphisms C677T (rs1801133) and C1298A (1801131) of MTHFR, in Brazilian patients with HCC and chronic HCV infection. PATIENTS AND METHODS: A total of 119 patients with HCC and HCV follow-up were included in the HUOC / UPE and IFP-PE hepatology clinic in Brazil. This study was approved by the ethics committee and the patients signed the consent form. All patients had a diagnosis of HCV by PCR and HCC by magnetic resonance and / or tomography. RESULTS: Among the individuals with HCC, $70.59 \%$ were men. The mean age of participants was 62.3 years. According to the Child-Pugh classification, the following were distributed: At $60.9 \%$; B 36.5\%; C 2.6\%. The mean tumor size was $4.4 \mathrm{~cm}$. Being that $52.10 \%$ was multinodular. An association analysis was made with the MTHFR and VEGF genes and tumor characteristics in HCC patients chronically infected with HCV. The C alleles of MTHFR (rs1801131) and VEGF (rs2010963) were associated with developmental protection of the multinodular form, and the MTHFR T allele (rs1801133) was associated with a risk factor for development of the multinodular form $\mathrm{p}=0$, 04 OR 1,835 IC $(1,0223,297)$. Multivariate analyzes, including male gender and age as potential confounders, were performed in the VEGF gene genotype CC (rs2010963), which was an independent factor associated with the protection of the development of multinodular tumors. A survival analysis stratified by the MTHFR (rs1801131), MTHFR (rs1801133) and VEGF (rs2010963) genotypes was also performed, but no significant results were observed. CONCLUSIONS: It was observed that the MTHFR and VEGF genes have influence on the uni or multinodular presentation of the tumor.
\end{abstract}

Descriptors: carcinoma, hepatocellulr; vascular endothelial growth factor A; polymorphism, genetic; hepatitis $\mathrm{C}$; liver; liver cirrhosis. 
1 Introdução 


\section{INTRODUÇÃO}

A infecção crônica pelo vírus da hepatite C (VHC) é uma das principais causas de doença hepática crônica em todo o mundo ${ }^{(1,2)}$, Estima-se que $20 \%$ dos pacientes cronicamente infectados progredirão para a cirrose hepática num período que varia entre 13 a 23 anos e, desse percentual, de 1 a $4 \%$ ao ano, desenvolverão o carcinoma hepatocelular $(\mathrm{CHC})^{(1,3)}$.

Os locais mais frequentes de câncer no ser humano são pulmão, mama e coloretal. Por outro lado, as causas mais frequentes identificadas de morte por câncer são pulmão e fígado ${ }^{(4)}$.

Os fatores mais frequentes associados ao $\mathrm{CHC}$ incluem as hepatites virais crônicas (B e C), ingesta de álcool e exposição a aflatoxina. Na África e no leste da Ásia, a causa mais frequente é devido a hepatite B (60\%), enquanto no mundo ocidental, apenas $20 \%$ dos casos são atribuídos a infecção pelo vírus da hepatite B (VHB), sendo a hepatite C crônica o maior fator de risco ${ }^{(5)}$. Todas as etiologias que levam a cirrose podem complicar com a formação de tumor, mas o risco é maior em pacientes com hepatite viral. Um terço dos pacientes cirróticos irão desenvolver o CHC durante sua vida ${ }^{(2)}$. Aproximadamente $1-8 \%$ ao ano dos pacientes com cirrose desenvolvem $\mathrm{CHC}$, sendo aproximadamente $2 \%$ em pacientes cirróticos infectados pelo VHB e $3-8 \%$ em pacientes cirróticos infectados pelo $\mathrm{VHC}^{(6)}$.

No Brasil, o CHC tem sido associado à cirrose hepática em $98 \%$ dos casos e a etiologia da doença hepática crônica (DHC) associada ao CHC mais frequente é o VHC presente em 54\% dos casos. As demais etiologias de doença hepática associada ao CHC são o VHB em $16 \%$ dos casos, em 14\% o álcool é a única etiologia, 3\% 
associada a doença hepática gordurosa não alcoólica, $3 \%$ criptogênica, $1 \%$ hemocromatose e $4 \%$ associada a outras causas incluindo hepatite autoimune e cirrose biliar primária ${ }^{(7,8)}$.

O Câncer é uma doença resultante da combinação de efeitos relacionados a suscetibilidade genética e elementos externos tais quais estilo de vida e inflamação ${ }^{(9)}$.

O VHC, é na nossa população, uma importante etiologia para a cirrose hepática culminando com o CHC. O mecanismo de carcinogênese no CHC, como em outros tipos de câncer permanece ainda não muito claro. Embora o CHC ocorra em fígados que são afetados pela doença de base como cirrose pela infecção crônica com VHC, acredita-se que alterações genéticas sejam a base desta patologia. Alguns estudos vêm sendo conduzidos para investigar a associação entre polimorfismos genéticos e o risco de CHC, mas os resultados são controversos.

Alguns fatores como a angiogênese e a deficiência de folato, parecem estar associados ao risco de $\mathrm{CHC}$ em alguns grupos étnicos. Porém o papel dos polimorfismos da VEGF e da MTHFR em pacientes com VHC em nossa região são desconhecidos. 
2 Marco Teórico 


\section{MARCO TEÓRICO}

\subsection{Vírus da hepatite $\mathrm{C}$}

A infecção pelo VHC é considerada um problema de saúde de proporção global. O VHC é responsável pela hepatite C crônica, uma das etiologias de cirrose hepática que na sua evolução culmina com o surgimento do CHC. No mundo a estimativa de pessoas infectadas com o VHC é de aproximadamente 200 milhões de indivíduos, sendo estimado uma taxa de 3-4 milhões de novos casos por ano ${ }^{(10)}$. O VHC foi reconhecido em 1970 e chamado de vírus da hepatite não A e não B, quando em 1989 foi finalmente identificado por Choo et al. (1989) ${ }^{(11)}$. É um membro da família Flaviviridae, do gênero Hepacivirus, possui RNA de fita simples de polaridade positiva de 9,6 quilobases de extensão ${ }^{(12)}$, e mede em torno de 50 a 60 $\mathrm{nm}$ de diâmetro e contém um envoltório lipídico de aproximadamente $7 \mathrm{~nm}$ de espessura que envolve o nucleocapsídeo de morfologia esférica. Quando visualizado pela microscopia eletrônica apresenta um tamanho em torno de 30 a 35 nm ${ }^{(13)}$ (Figura 1). 


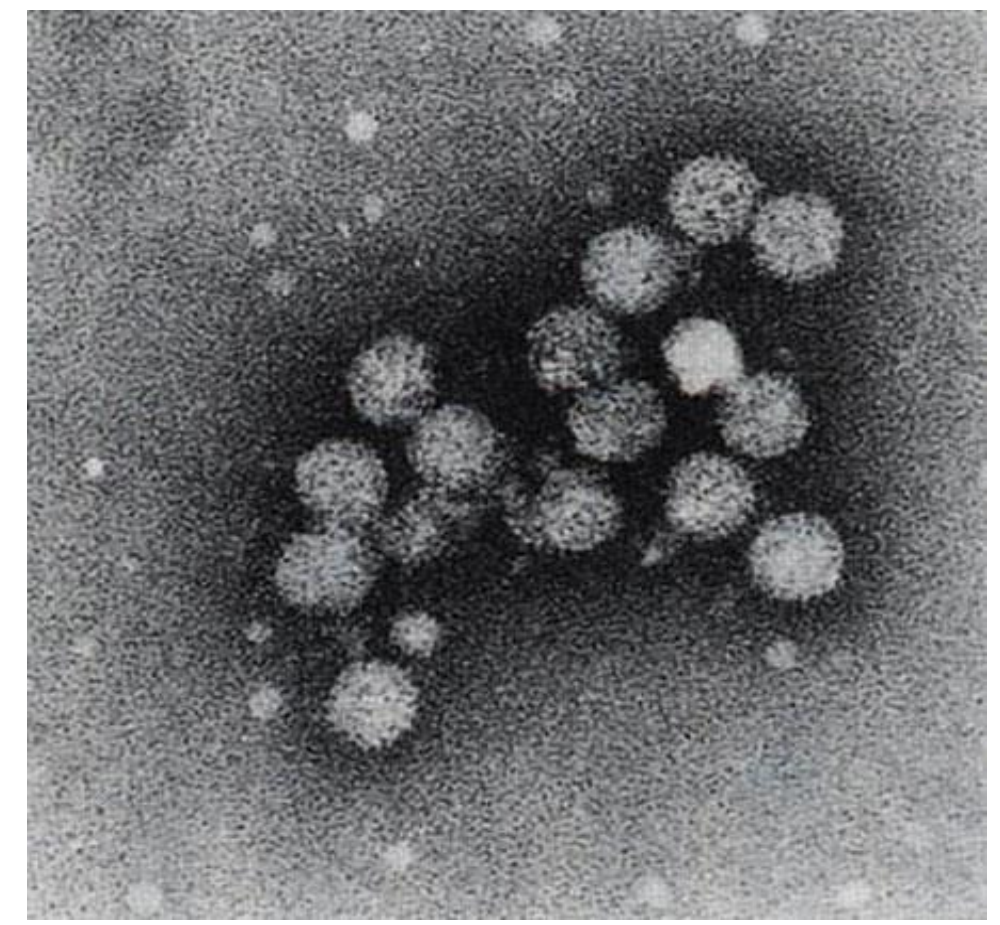

FONTE: Penin et al., $2004^{(14)}$.

Figura 1 - Eletromicrografia do vírus da hepatite C

$\mathrm{O}$ vírus codifica uma única poliproteína longa que é processada em 10 proteínas individuais: as proteínas denominadas estruturais, codificadas por genes localizados próximo à região $5^{\prime} \mathrm{NCR}$, que são as proteínas do nucleocapsídeo, glicoproteínas de envelope E1, E2 e a proteína p7, e as proteínas denominadas não estruturais NS2, NS3, NS4A, NS4B, NS5A e NS5B ${ }^{(12)}$, que são codificadas por genes situados próximo a região 3'NCR e estão envolvidas na replicação e maturação do vírus ${ }^{(14,15)}$ (Figuras 2 e 3). 


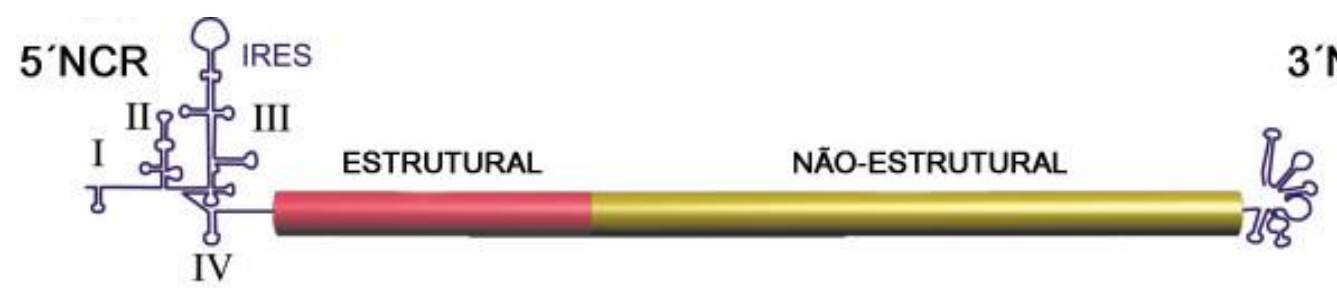

FONTE: Penin et al., $2004^{(14)}$.

Figura 2 - Organização genômica do VHC.
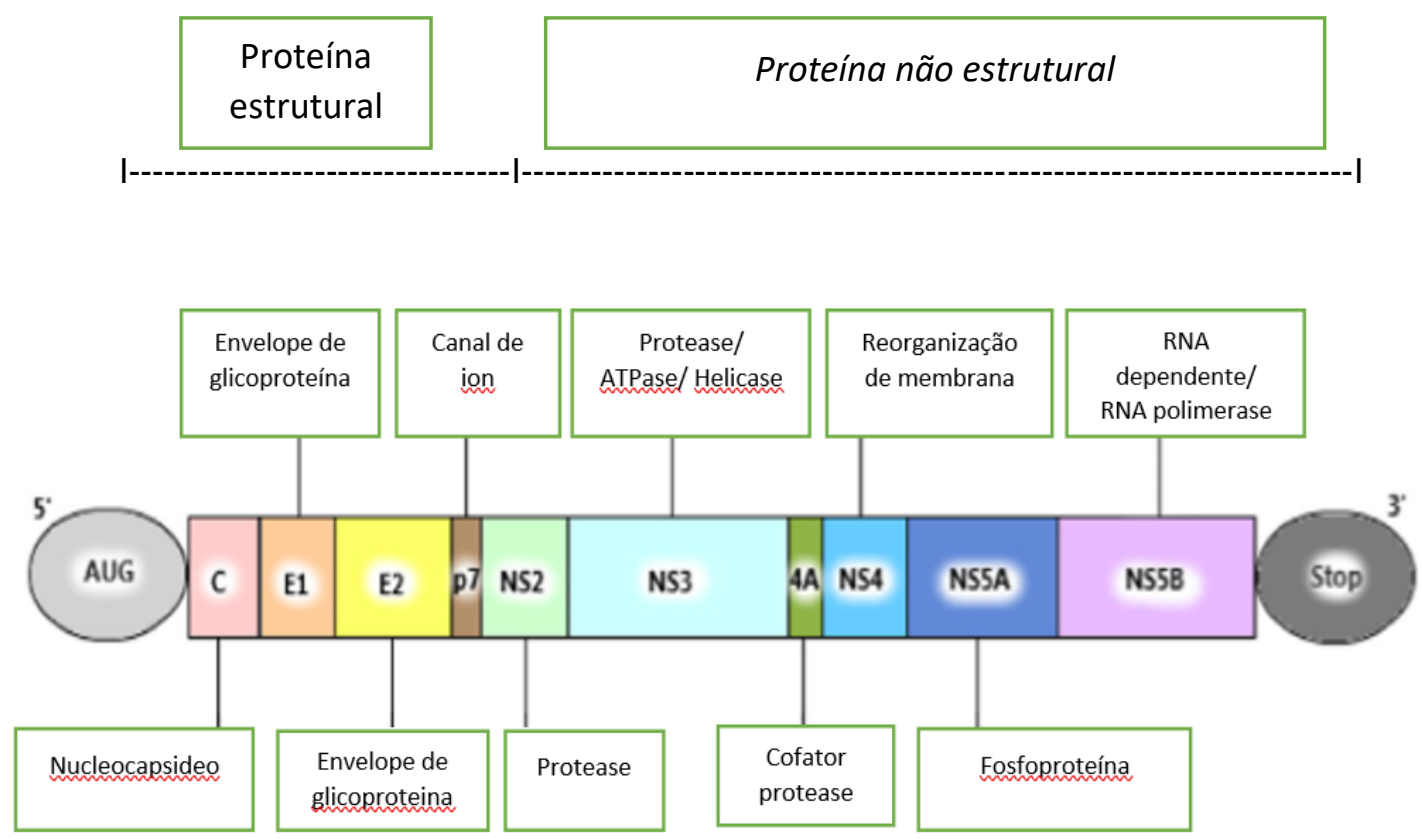

FONTE: Adaptado de Jing et al., $2017^{(15)}$.

Figura 3 - Organização do genoma do VHC

A 5'NCR é formada por 340 nucleotídeos, sendo esta a porção do genoma escolhida para amplificação pela reação em cadeia da polimerase (PCR) e caracterização dos diversos genótipos do $\mathrm{VHC}^{(14)}$. 
A NS5B é uma RNA polimerase RNA dependente que desempenha um papel central na replicação do genoma viral ${ }^{(16)}$ (Figura 4). Já as proteínas do envelope do VHC estão envolvidas na ligação com receptores, entrada e fusão do vírus. A função da proteína p7 ainda não é conhecida ${ }^{(17)}$ e as proteínas do nucleocapsídeo interagem com várias proteínas celulares e afetam algumas funções das células do hospedeiro como a transcrição gênica, o metabolismo dos lipídeos, apoptose e várias vias de sinalização celular $^{(14)}$.

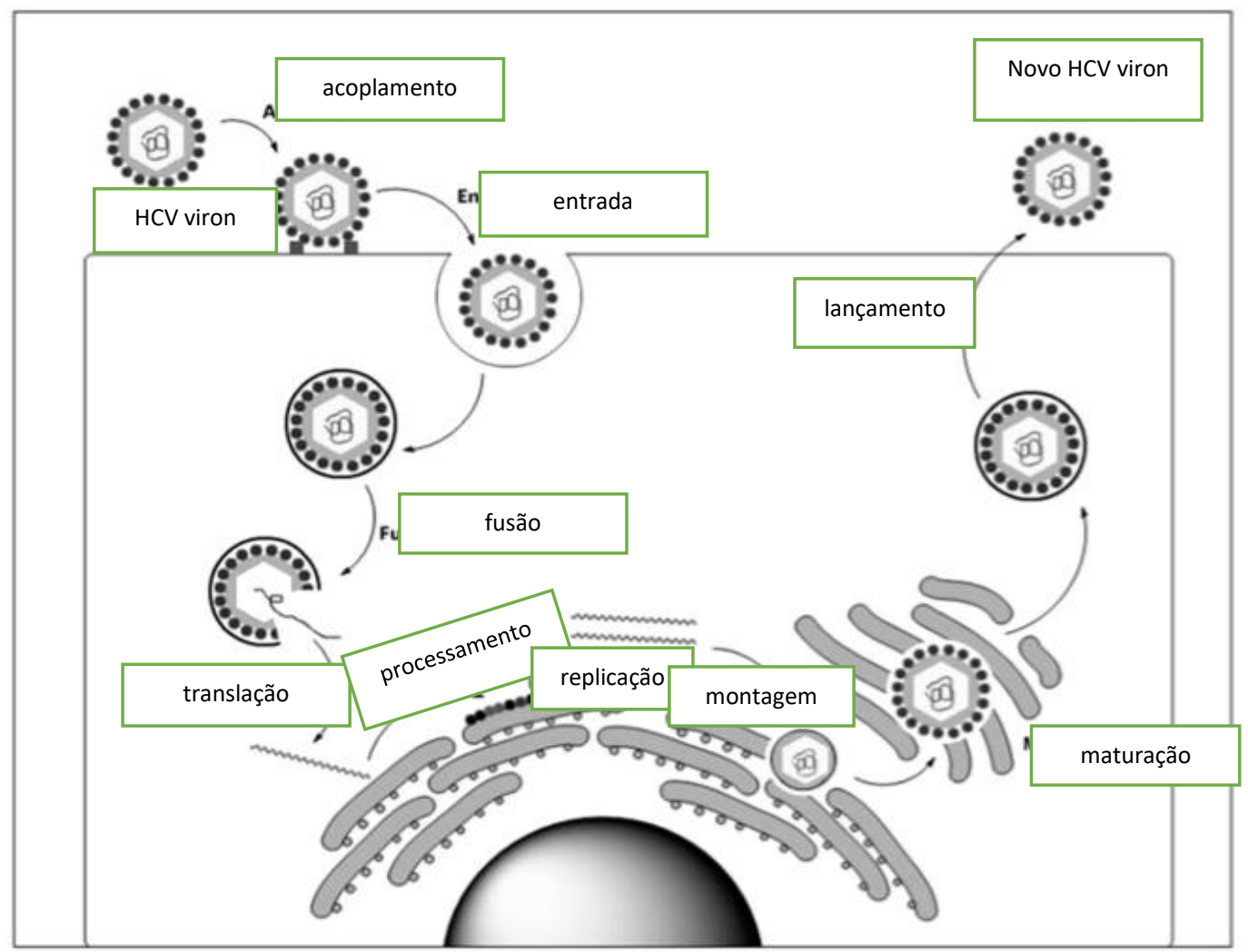

FONTE: Adaptado de Jing et al., $2017^{(15)}$.

Figura 4 - Ciclo da replicação do VHC 
O VHC apresenta sete diferentes genótipos, numerados de 1 a 7 , em algarismo arábico e 67 subtipos confirmados, que são identificados por letras minúsculas em ordem alfabética (Figura 5) ${ }^{(18)}$.

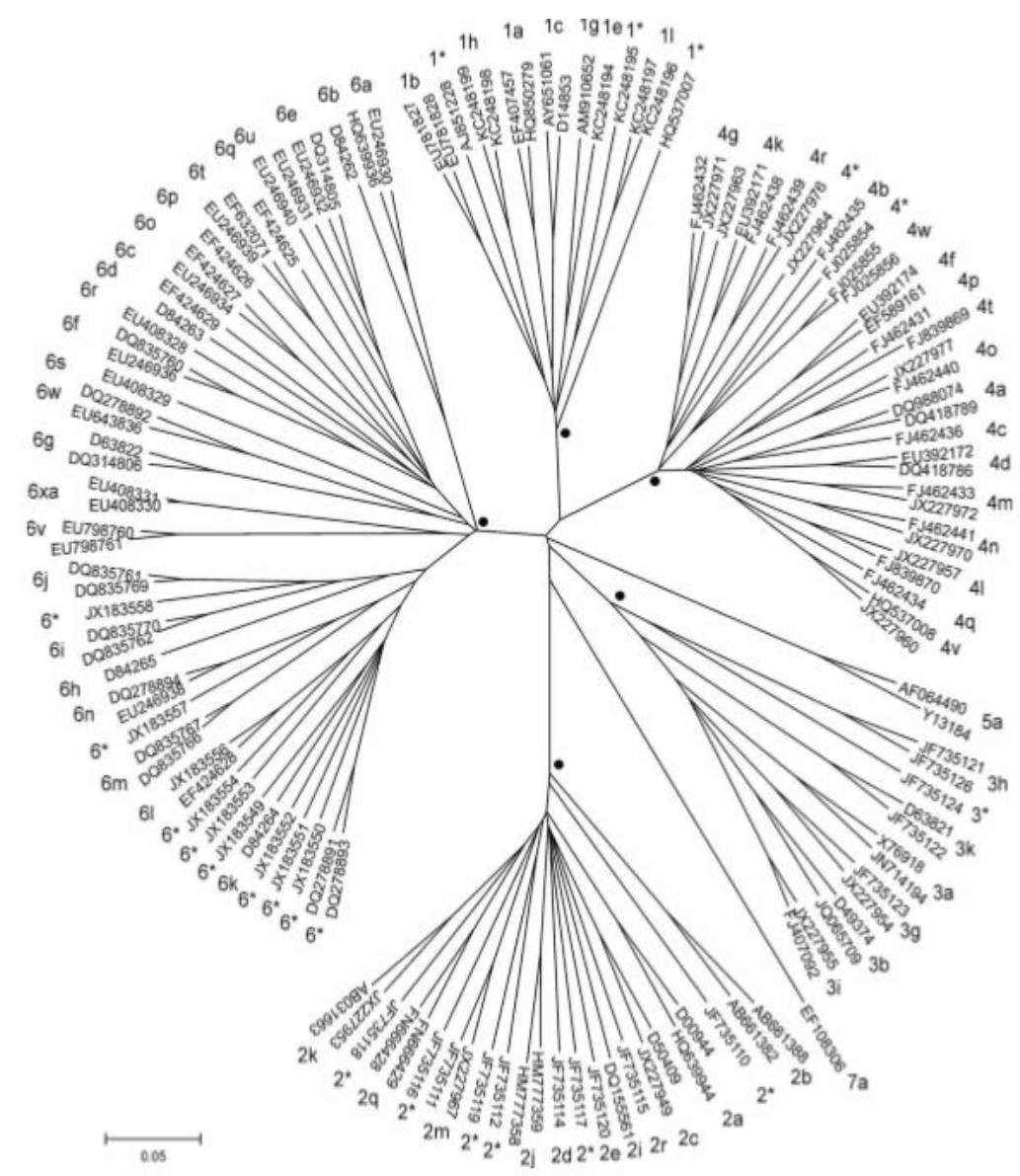

FONTE: Smith et al., 2014 ${ }^{(18)}$.

Figura 5 - Árvore filogenética representativa de 129 sequências completas

Os genótipos 1, 2 e 4 são mais encontrados no centro-oeste da África e o subtipo 4a, no Egito; o genótipo 5 é frequente no sul da África, e os genótipos 3 e 6, na China, sudeste da Ásia e na Índia ${ }^{(19)}$. No Brasil, o genótipo 1 b é predominante na Região Sudeste e no norte da Amazônia, sendo na Região Sul os mais frequentes o genótipo 1 e 3. Na Região Nordeste, especialmente em Recife (PE), há uma 
distribuição igual entre os genótipos 1 e 3; por outro lado, em Salvador (BA), essa distribuição não é uniforme, prevalecendo o genótipo $1^{(20)}$.

A exposição ao VHC pode ocorrer em várias ocasiões durante a vida. Os principais fatores de risco relacionados à transmissão do VHC são hemotransfussões, transplante de órgãos sólidos de doadores infectados, uso de drogas ilícitas injetáveis e exposição ocupacional a sangue e derivados. Na evolução da hepatite C, 60\%-80\% dos casos progridem para forma crônica, e mais de $20 \%$ progridem para cirrose hepática. A forma aguda da infecção tem resolução espontânea em mais de $45 \%$ dos casos ${ }^{(21)}$. A progressão da doença é lenta, com alta percentagem de casos que desenvolverão fibrose hepática progressiva, culminando em cirrose e/ou câncer de fígado ${ }^{(22)}$.

O diagnóstico da infecção crônica pelo VHC é baseado na presença do anticorpo (anti-HCV) detectado por imunoensaio enzimático e o teste molecular de detecção de ácido nucléico (HCV RNA) por reação em cadeia da polimerase $(\mathrm{PCR})^{(23)}$.

Alguns fatores possuem um papel na progressão da doença, dentre estes fatores podemos considerar aqueles relacionados ao vírus, ao hospedeiro e os ambientais ${ }^{(22)}$. Friedman (2008), Marcelin (2009) e Seef (2009) em seus trabalhos, relatam que nem a carga viral nem o genótipo parecem influenciar na taxa de progressão da doença $(22,24,25)$. Por outro lado existem inúmeros fatores do hospedeiro que podem influenciar na progressão da fibrose, como o sexo, idade e raça ${ }^{(26)}$. Ocorre uma maior prevalência de hepatite $\mathrm{C}$ no sexo masculino ${ }^{(22)}$, Além disso, $70 \%$ dos transplantes hepáticos ocorrem também no sexo masculino infectados com VHC ${ }^{(27)}$. Observou-se que nos pacientes infectados com idade superior a 40 
anos ocorre uma maior taxa de progressão da doença ${ }^{(28)}$, provavelmente devido ao processo natural do envelhecimento atuando no sistema imunológico e sobre o fígado ${ }^{(29)}$. Os afro-americanos com hepatite $\mathrm{C}$ crônica apresentam uma elevada taxa de evolução para o $\mathrm{CHC}$ bem como uma menor taxa de resposta à terapia quando comparados com indivíduos brancos ${ }^{(22,30)}$. Foi observado em latinos residentes nos Estados Unidos, uma progressão mais rápida para a cirrose, enquanto ocorre um curso mais benigno da doença em populações aborígenes, estes fatos vem sendo explicados pelas variações que ocorrem na resposta imune ao vírus e por influência de polimorfismos genéticos ${ }^{(22,27)}$. Dentre os fatores ambientais, o consumo de álcool está entre os principais associados à progressão da fibrose ${ }^{(25)}$. O tabagismo também tem sido implicado na elevação do risco para o $\mathrm{CHC}$ na hepatite $\mathrm{C}$ crônica ${ }^{(31-33)}$. O tabaco induz efeitos tóxicos, aumentando o processo necroinflamatório e fibrose, imunológico com o aumento da produção de citocinas pró-inflamatórias IL-1, IL-6 e TNF-alfa, além de induzir efeito oncogênico sob o fígado (em virtude da presença de produtos químicos com atividade citotóxica e genotóxica na fumaça do cigarro) ${ }^{(31)}$.

As co-infecções constituem importantes fatores de progressão da hepatite $\mathrm{C}$ crônica. A Co-infecção com o VHB resulta no desenvolvimento mais rápido de fibrose e cirrose ${ }^{(27,34)}$. Adicionalmente, a prevalência do $\mathrm{CHC}$ é cerca de quatro vezes maior nesses pacientes do que naqueles monoinfectados pelo $\mathrm{VHC}{ }^{(35)}$. Nos coinfectados com o vírus da imunodeficiência humana (HIV), observa-se que as alterações na resposta imune celular, o aumento das taxas de apoptose, leva a uma progressão mais rápida da doença hepática e ao desenvolvimento do $\mathrm{CHC}$ quando comparados com indivíduos sem a infecção pelo HIV ${ }^{(36)}$. 
O diagnóstico de diabetes Mellitus (DM), em pacientes com hepatite C crônica e cirrose, aumenta o risco de desenvolvimento de $\mathrm{CHC}{ }^{(37,38)}$. O estudo de Davila et al (2005), sugere que o DM seja um fator de risco independente para o $\mathrm{CHC}^{(39)}$. A associação entre diabetes e $\mathrm{CHC}$ pode ser explicado pelo estresse oxidativo e/ou a peroxidação dos lipídios que aumentam a possibilidade de injúria hepática ocasionando inflamação hepática e fibrose evoluindo para a cirrose ${ }^{(40)}$.

A infecção aguda pelo VHC é assintomática em 50 a $90 \%$ dos casos ${ }^{(41)}$. Excepcionalmente, ela se resolve espontaneamente. Na hepatite $\mathrm{C}$ crônica, a progressão da doença que leva algumas décadas para ocorrer, pode ser acelerada pela presença de cofatores como o consumo de álcool, DM, idade avançada no momento do contágio, Co-infecção com outros vírus hepatotrópicos ou HIV. Na dependência da presença desses cofatores os pacientes com hepatite $\mathrm{C}$ crônica, podem desenvolver cirrose em 10 a $40 \%$ dos casos ${ }^{(42)}$. A incidência estimada de surgimento do CHC nesta população é de 1 a $5 \%$ ao ano ${ }^{(43)}$.

\subsection{Carcinoma hepatocelular}

\subsubsection{Epidemiologia, prevenção e vigilância do CHC}

O CHC é a neoplasia hepática primária mais frequente. É a sexta neoplasia mais frequente no mundo e a segunda causa de morte por câncer identificado ${ }^{(4)}$. A distribuição no mundo é muito heterogênea. Existem áreas com elevada incidência como o leste da Ásia e o norte da África e outras de baixa incidência como as regiões central, leste e norte da Europa ${ }^{(44)}$ esta heterogeneidade é devido ao fato de sua prevalência estar relacionada aos diferentes fatores de risco para o desenvolvimento 
do CHC. A cirrose é um importante fator de risco, e pode ser causada por hepatite viral crônica, pelo consumo abusivo de álcool, doenças metabólicas como a hemocromatose e a doença hepática gordurosa não alcoólica (DHGNA) e deficiência de alfa 1 antitripsina ${ }^{(2)}$. Na África e no leste da Ásia o maior fator de risco associado com o surgimento do CHC é a hepatite B (60\%), enquanto que no lado oeste do mundo a hepatite $\mathrm{C}$ parece ser o maior fator de risco ${ }^{(45)}$. No Brasil, a cirrose hepática é o principal fator de risco para o surgimento do $\mathrm{CHC}$. No estudo de Carrilho et al (2010), a cirrose esteve presente em 98\% dos casos, e apesar de sua epidemiologia variar entre as diferentes regiões do Brasil, a etiologia mais frequente da cirrose hepática nos pacientes com $\mathrm{CHC}$ foi a infecção pelo vírus $\mathrm{C}$, estando presente em $58 \%$ dos casos ${ }^{(7,8)}$. O CHC é mais frequente no sexo masculino com uma relação estimada de 2-2,5:1 ${ }^{(4)}$. Alguns fatores estão associados ao aumento de risco do surgimento do $\mathrm{CHC}$, como a presença de $\mathrm{DM}^{(46,47)}$, obesidade e dislipidemia, fatores estes associados a síndrome metabólica ${ }^{(48-50)}$ bem como o tabagismo ${ }^{(51)}$. O consumo de café diminui esse risco ${ }^{(52,53)}$.

A prevenção ao CHC se faz evitando os fatores de risco, como a vacina para o VHB ${ }^{(54)}$, o consumo abusivo de álcool e a síndrome metabólica. Uma vez diagnosticado hepatite viral, o tratamento antiviral pode impedir a progressão da doença hepática e reduzir o risco do desenvolvimento do $\mathrm{CHC}^{(55)}$.

O CHC é uma das principais causas de morte nos pacientes cirróticos ${ }^{(2)}$. Sabe-se que o tratamento com intenção curativa só é possível no diagnóstico precoce do tumor ${ }^{(56)}$, portanto, é recomendado programa de vigilância com ultrassonografia (US) abdominal a cada seis meses, realizado por profissional experiente na população de alto risco ${ }^{(57,58)}$. 


\subsubsection{Diagnóstico do CHC}

Para diagnóstico de $\mathrm{CHC}$, o exame de imagem do fígado é essencial. Um nódulo acima de $10 \mathrm{~mm}$ detectado no US de um paciente cirrótico tem uma probabilidade muito alta de ser um $\mathrm{CHC}^{(59)}$. Quando diagnosticado nódulo acima de 10 mm, em paciente cirrótico, é necessário um exame de imagem dinâmico: ressonância magnética (RM) ou tomografia computadorizada (TC) com contraste. O CHC apresenta uma vascularização predominantemente arterial, diferenciando do parênquima hepático que possui uma vascularização mista: arterial e portal ${ }^{(60)}$, esta forma de vascularização permite uma diferenciação para um padrão específico de diagnóstico do CHC que é caracterizado por uma intensa captação do contraste na fase arterial (wash in), seguido de uma lavagem rápida do contraste na fase venosa portal ou tardia (wash out). Este padrão mostrou-se específico para o diagnóstico de CHC quando foi comparado com histopatológico dos explantes, peças de ressecção cirúrgica e biópsias percutâneas ${ }^{(59,61-63)}$. Se o nódulo não apresentar este padrão vascular típico para diagnóstico por imagem de um $\mathrm{CHC}$, será necessário exame histopatológico para firmar ou afastar este diagnóstico ${ }^{(59)}$. Nos nódulos menores do que $10 \mathrm{~mm}$, tanto pela dificuldade de sua caracterização adequada, bem como pela baixa probabilidade de ser de natureza maligna, a recomendação é de segmento com exame de US a cada 3-4 meses com a finalidade de avaliar um possível crescimento ${ }^{(59)}$ (Figura 6). Outros achados de imagem na RM e na TC: sinal de hiperintensidade no T2 na RM, hiperintensidade na difusão em RM, gordura intra lesional, presença de capsula, arquitetura em mosaico e hemorragia intra-lesional; ocorrem mais comumente em $\mathrm{CHC}$ do que nos nódulos regenerativos ou displásicos ${ }^{(64)}$. O Colégio Americano de Radiologia (American College of 
Radiology- ACR) propôs um sistema de padronização de dados e interpretação dos exames de RM e TC conhecido como Liver Imaging Reporting and Data System (LIRADS) que foi publicado em 2011 e sua última atualização em $2018^{(65)}$. O LIRADS categoriza os nódulos em: LR-1 (definitivamente benigno), LR-2 (provavelmente benigno), LR-3 (Probabilidade intermediária para CHC), LR-4 (Provavelmente CHC), LR-5 (definitivamente CHC) e outros tumores malignos (OM-lesões com alta probabilidade de serem neoplasias malignas diferentes de CHC) ${ }^{(66)}$.

A US com contraste não é recomendada como técnica de imagem de primeira linha. Ela pode ser utilizada quando a RM e a TC estão contra indicadas ou foram inconclusivas para o diagnóstico de $\mathrm{CHC}^{(67)}$.

Nos pacientes não cirróticos, as características do CHC na imagem são iguais aos dos pacientes cirróticos sendo que os tumores tendem a ser diagnosticados em tamanho maiores uma vez que os pacientes não estão em programa de vigilância. Mesmo assim, para o diagnóstico de $\mathrm{CHC}$ em paciente não cirrótico, é necessário o exame histopatológico uma vez que podem fazer parte do diagnóstico diferencial com outras lesões hipervasculares como os adenomas e metástases hipervasculares ${ }^{(58)}$.

A alfa 1 fetoproteína (AFP) tem um rendimento diagnóstico muito baixo ${ }^{(59,68)}$. Outras situações, como o colangiocarcinoma e metástases de origem gastrointestinal podem apresentar elevação de AFP ${ }^{(68-70)}$. 


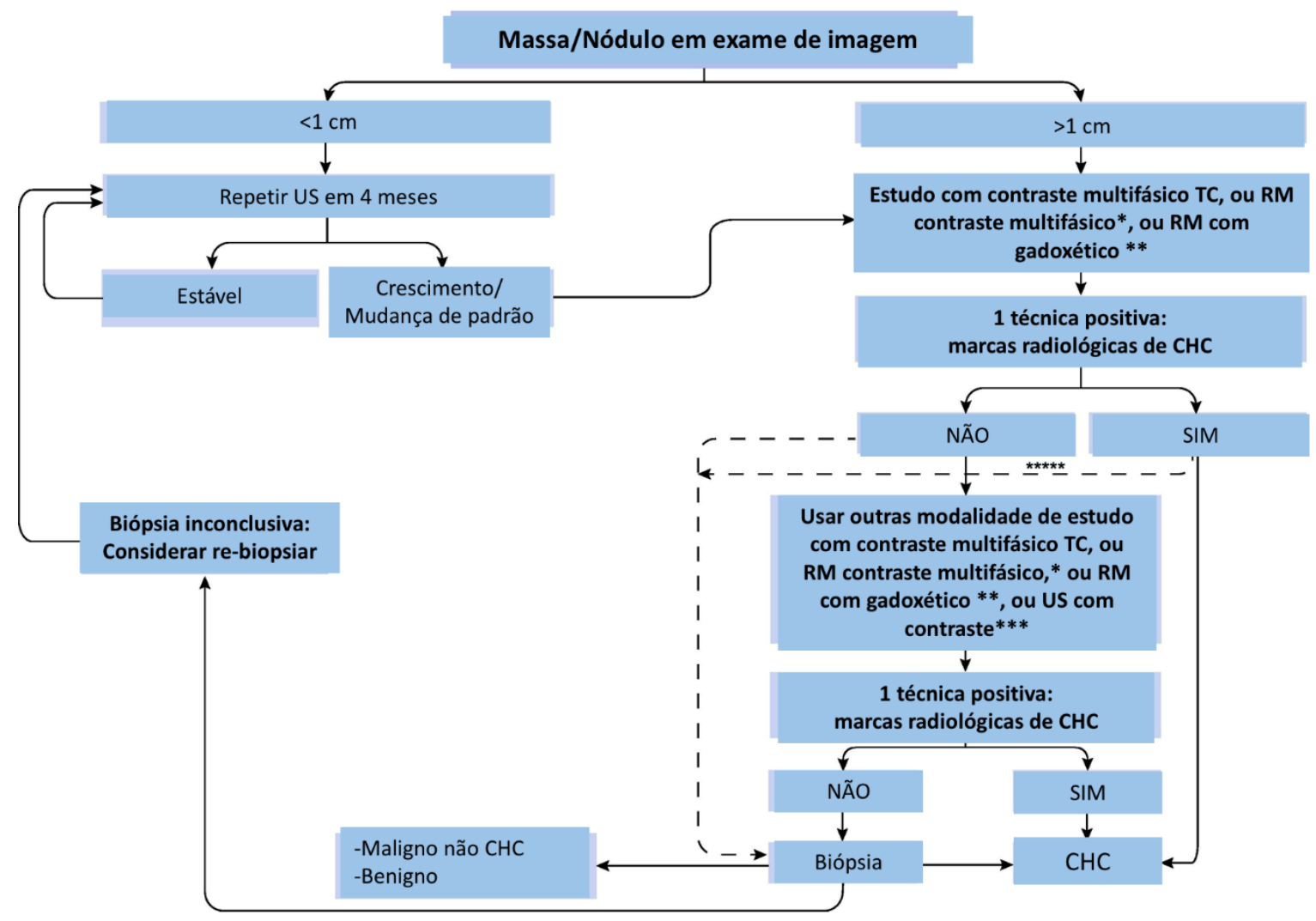

FONTE: adaptado do EASL Clinical Practice Guidelines, $2018^{(71)}$.

Figura 6 - Algoritmo de diagnóstico de nódulo em paciente cirrótico

\subsubsection{Estadiamento do CHC}

O prognóstico dos tumores sólidos depende do estágio da doença, sendo a avaliação prognóstica uma importante etapa no tratamento do paciente com câncer. Feito o diagnóstico, deve-se estudar a extensão do tumor para definir expectativa de vida, tratamento adequado e avaliar a resposta ao tratamento. Como o $\mathrm{CHC}$ aparece na maioria dos casos associado a cirrose, é imprescindível avaliar conjuntamente o grau de disfunção hepática e a extensão do tumor. Para avaliar a disfunção hepática podemos fazer uso de algumas classificações como a classificação de Child-Pugh (que utiliza a bilirrubina, albumina, INR, presença de encefalopatia e ascite) ${ }^{(72)}$, e o 
MELD (Model for End stage Liver Disease) ${ }^{(73)}$. A presença de sintomas associados ao tumor pode ser avaliada pelo Easten Cooperative Oncology Group (ECOG) performance status ${ }^{(74)}$, e pelo índice de Karnofsky ${ }^{(75)}$. Para estadiamento existem alguns sistemas de estadiamento propostos.

O sistema de estadiamento BCLC (Barcelona Clinic Liver Cancer), que foi publicado originalmente em 1999, sendo sua última atualização publicada em 2018, leva em conta todas essas variáveis: extensão do tumor, grau de função hepática e sintomas relacionados ao tumor ${ }^{(76)}$ (Figura 7). O prognóstico do paciente com CHC depende dessas características clínicas ${ }^{(77)}$. Existem ainda outras classificações utilizadas, como a CLIP (The Cancer of the liver Italian Program) ${ }^{(78)}$, CUPI (The Chinese University Prognostic Index) ${ }^{(79)}$, a HKLC (The Hong-Kong Liver Cancer) ${ }^{(80)}$ e a bm-JIS (The biomarker-combined Japan Integrated Staging) ${ }^{(81)}$. Uma classificação considerada padrão em oncologia para definir o prognóstico e o tratamento é a classificação TNM (Tumor-Nódulo-Metástases). Nos pacientes com CHC, existem algumas limitações para o uso desta classificação. Uma limitação é que para ser utilizada, necessita de informações cirúrgicas, onde apenas um percentual dos pacientes pode ser submetido a cirurgia (ressecção ou transplante). Outra limitação da classificação TNM é que não contempla os dados referentes a função hepática. 


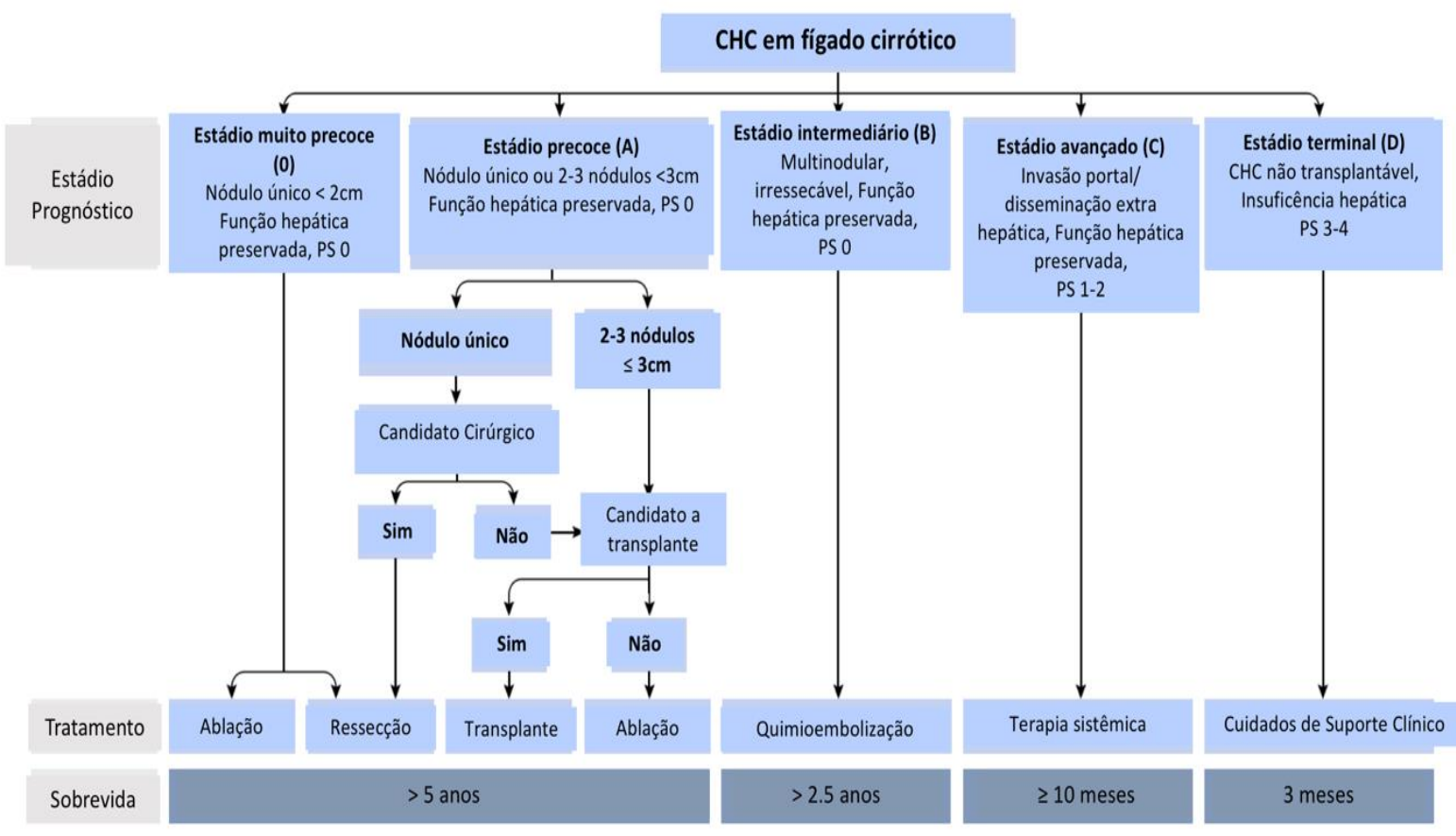

FONTE: Adaptado do EASL Clinical Practice Guidelines, $2018^{(71)}$.

Figura 7 - Algoritmo de estadiamento BCLC e estratégia de tratamento

\subsubsection{Tratamento do CHC}

Avaliada a extensão do tumor e a função hepática é possível realizar o tratamento, que pode ser classificado em cirúrgico (ressecção e transplante) e não cirúrgico. Os tratamentos cirúrgicos são utilizados no paciente em estágio inicial de doença com intenção curativa. Os tratamentos não cirúrgicos podem ser programados tanto para os estágios iniciais (terapia por ablação), estágio intermediário (quimioembolização do tumor), estágio avançado (terapia sistêmica) e cuidados de suporte clínico no estágio terminal (Figura 7).

A ressecção cirúrgica tem sua indicação nos tumores únicos que aparecem em fígado não cirrótico. No paciente com cirrose existe uma limitação para o emprego desta terapia. Nos pacientes com cirrose compensada é fundamental uma avaliação 
cuidadosa da função hepática, pelo risco de o paciente apresentar insuficiência hepática no pós-operatório. O paciente com cirrose descompensada a ressecção hepática está formalmente contraindicada ${ }^{(82)}$. Os melhores pacientes candidatos a ressecção cirúrgica são os pacientes com tumores únicos, que apresentam bilirrubina normal e ausência de hipertensão portal clinicamente relevante ${ }^{(83)}$. A taxa de recidiva do tumor na ressecção hepática pode chegar a $70 \%$ em 5 anos ${ }^{(84)}$.

As indicações de transplante hepático incluem pacientes com nódulo único $\leq$ $5 \mathrm{~cm}$ ou um máximo de 3 nódulos menores de $3 \mathrm{~cm}$, sem invasão vascular ou disseminação extra hepática (critério de Milão), obtendo uma sobrevida em 4 anos de $75 \%$ e uma taxa de recorrência de $8 \%{ }^{(85)}$. Atualmente, o CHC é a indicação de transplante hepático que mais cresce no mundo, junto com a insuficiência hepática pela doença hepática gordurosa não alcoólica ${ }^{(86)}$.

A ablação percutânea é o tratamento de escolha para os pacientes com CHC em que não é possível a ressecção hepática ou que o transplante hepático está contraindicado. As técnicas de ablação podem ser por meio de substâncias químicas (etanol ou ácido acético), ou mediante a modificação da temperatura intratumoral (radiofrequência, crioablação, micoondas ou laser) ${ }^{(87)}$. A ablação por radiofrequência e a injeção percutânea de etanol constituem as técnicas de referência. Devido a sua maior capacidade ablativa, a radiofrequência possui maior taxa de resposta do que a injeção percutânea de álcool nos tumores $>3 \mathrm{~cm}{ }^{(88)}$. Não é recomendado a radioablação em tumores subcapsulados, próximos a vesícula biliar, hilo hepático ou coração (pelo risco de complicações), e nem nos tumores que estão em contato com vasos sanguíneos. A proximidade com os vasos sanguíneos dificulta a completa ablação da lesão por apresentar um fenômeno de dissipação da energia 
térmica ${ }^{(89)}$. A taxa de recorrência do tumor que foram tratados com ablação é de $80 \%$ em 5 anos ${ }^{(90)}$.

A quimioembolização consiste na cateterização seletiva da artéria hepática seguindo pela cateterização supra seletiva das artérias que nutrem o tumor e posterior injeção do agente quimioterápico junto com uma substancia embolizante ou com microesferas sintéticas para oclusão do fluxo arterial. É o tratamento de primeira linha para o estágio B da classificação BCLC ${ }^{(91)}$. A quimioembolização está contraindicada em pacientes com descompensação da cirrose (Child-Pugh $\mathrm{B} \geq 8$, com icterícia, encefalopatia e ascite refratária), tumor extenso que ocupe ambos os lobos hepáticos, redução do fluxo portal, fístulas arteriovenosas intratáveis, anastomose bilioentérica, stent biliar e clearance de creatinina $<30 \mathrm{ml} / \mathrm{min}^{\left({ }^{(91)}\right.}$. A quimioembolização, mesmo obedecendo a seleção adequada de pacientes, pode evoluir com alguns efeitos adversos (febre, dor abdominal e íleo). Como principais complicações do procedimento podemos citar insuficiência hepática, abscesso hepático, colecistite isquêmica entre outros. Lencioni et al. (2016), em uma revisão sistemática observou uma sobrevida de 70,3\% em 1 ano, 51,8\% em 2 anos, 40,4\% em 3 anos e $32,4 \%$ em 5 anos nos pacientes submetidos a quimioembolização ${ }^{(92)}$. A quimioembolização também pode ser empregada nos pacientes em estágios iniciais do CHC que estão em fila de transplante para impedir que saiam de critério de transplante enquanto aguardam ou nos pacientes em que o transplante hepático, a ressecção hepática ou a ablação não sejam possíveis.

Um outro tratamento locorregional é a radioembolização com esferas de Yttrium-90, que possui uma boa tolerância clínica e uma sobrevida comparável a dos pacientes tratados com a quimioembolização ${ }^{(93)}$. 
A quimioterapia convencional com finalidade citotóxica não demonstra benefício significativo na sobrevida dos pacientes $\mathrm{cm}$ CHC. Com o progressivo conhecimento das alterações moleculares que condicionam a progressão do tumor, os agentes que podem atuar de forma específica nas vias moleculares alteradas vem sendo avaliados ${ }^{(94)}$. Atualmente, três drogas sistêmica, em fase III de estudo, tem mostrado benefícios na sobrevida de pacientes com CHC avançado. Estas drogas são inibidoras multi-quinase. O Sorafenibe e o lenvatinibe como drogas de primeira linha e o Regorafenibe como droga de segunda linha ${ }^{(95-97)}$.

\subsection{Fator de crescimento endotelial vascular (VEGF)}

A angiogênese é uma cascata de etapas sequenciais que leva a neovascularização dos tumores ${ }^{(98)}$. É um processo complexo onde ocorre a formação de novos vasos sanguíneos a partir de vasos preexistentes, sendo fundamental em condições fisiológicas como na reação inflamatória, reação autoimune e cicatrização tecidual, dentre outras. A patogênese das neoplasias e metástases, como exemplo, são determinadas pela resposta angiogênica. A resposta angiogênica pode ser devido a um aumento dos mediadores ou deficiência dos inibidores da angiogênese ${ }^{(99)}$.

O Fator de crescimento endotelial vascular (VEGF), também chamado de fator de permeabilidade vascular, foi inicialmente identificado em 1983 como uma proteína secretada pelas células tumorais ${ }^{(100)}$.

Como um potente fator de permeabilidade, o VEGF promove extravasamento do fibrinogênio plasmático, levando a formação de escadas de fibrina que facilita a migração celular durante invasão. Como um fator de crescimento endotelial, o VEGF 
estimula a proliferação de células endoteliais, induzindo o brotamento de novos vasos sanguíneos ao redor da massa de crescimento tumoral ${ }^{(101)}$.

A formação de novos vasos sanguíneos é iniciada por condições de hipóxia ou isquemia. Os baixos níveis de oxigênio levam ao acúmulo de Fatores Induzidos por Hipóxia (HIF-1) que estimulam a expressão de fatores de crescimento angiogênico ${ }^{(102)}$. A família VEGF é composta de seis glicoproteínas; VEGF-A, VEGF-B, VEGF-C, VEGF-D, VEGF-E e o fator de crescimento placentário. Dentro destes subtipos há múltiplas isoformas. O melhor membro que caracteriza a família VEGF é o VEGF-A ${ }^{(103)}$. O VEGF-A é o fator chave na indução da angiogênese, que pela ligação ao receptor do fator de crescimento endotelial vascular (VEGFR2) leva ao aumento da permeabilidade vascular ${ }^{(104)}$. O efeito angiogênico da VEGF é mediado por vários receptores diferentes. Os receptores da VEGF 1 e 2 (VEGFR) foram descobertos originalmente nas células endoteliais, como um receptor tirosina quinase. Os vários membros da família VEGF tem diferentes afinidades de ligação com cada receptor. O VEGFR 1 tem um importante papel no desenvolvimento da angiogênese bem como em outros processos, incluindo a migração de monócitos, recrutando as células progenitoras do endotélio e aumentando as propriedades adesivas das células "natural-Killer". O VEGFR 2 medeia a maioria dos efeitos da cascata abaixo da VEGF na angiogênese, incluindo a permeabilidade microvascular, a proliferação de célula endotelial, a migração e a sobrevida da célula tumoral ${ }^{(105)}$.

A vasodilatação é o primeiro passo na formação dos novos vasos sanguíneos. A influência da Angiopoetina 2 (Ang-2) e do VEGF dá origem à ocorrência de fenestrações, o que aumenta a permeabilidade vascular permitindo o extravasamento de proteínas plasmáticas. Estas proteínas plasmáticas servirão como uma escada para 
que as células endoteliais (CE) migrem ${ }^{(106)}$. As Angiopoetinas descritas são de dois tipos, a 1 e 2. A Ang-2 é um antagonista da Ang-1, causando a desestabilização do vaso, deslocando as $\mathrm{CE}$ de um estado estável, preso ao crescimento, para um estado proliferativo ${ }^{(107)}$. Vários fatores angiogênicos como o VEGF, o fator de crescimento do fibroblasto (FGF) e o fator de crescimento endotelial (EGF), induzem a proliferação e migração das células endoteliais através da matriz. A VE-caderina e integrinas coordenam a ligação das CE, enquanto o fator de necrose tumoral alfa (TNF- $\alpha$ ), FGF e o fator de crescimento derivado de plaquetas (PDGF), induzem a formação do tubo. As camadas de vasos circundantes compostas de pericitos precisam ser recrutadas através de um processo mediado pelos PDGF e VEGF. As células endoteliais se contraem, os pericitos são recrutados e uma nova membrana basal é gerada. A Ang-1 é responsável pela estabilização dos vasos levando a vasos sanguíneos duráveis e maduros (Figura 8) ${ }^{(106)}$. 


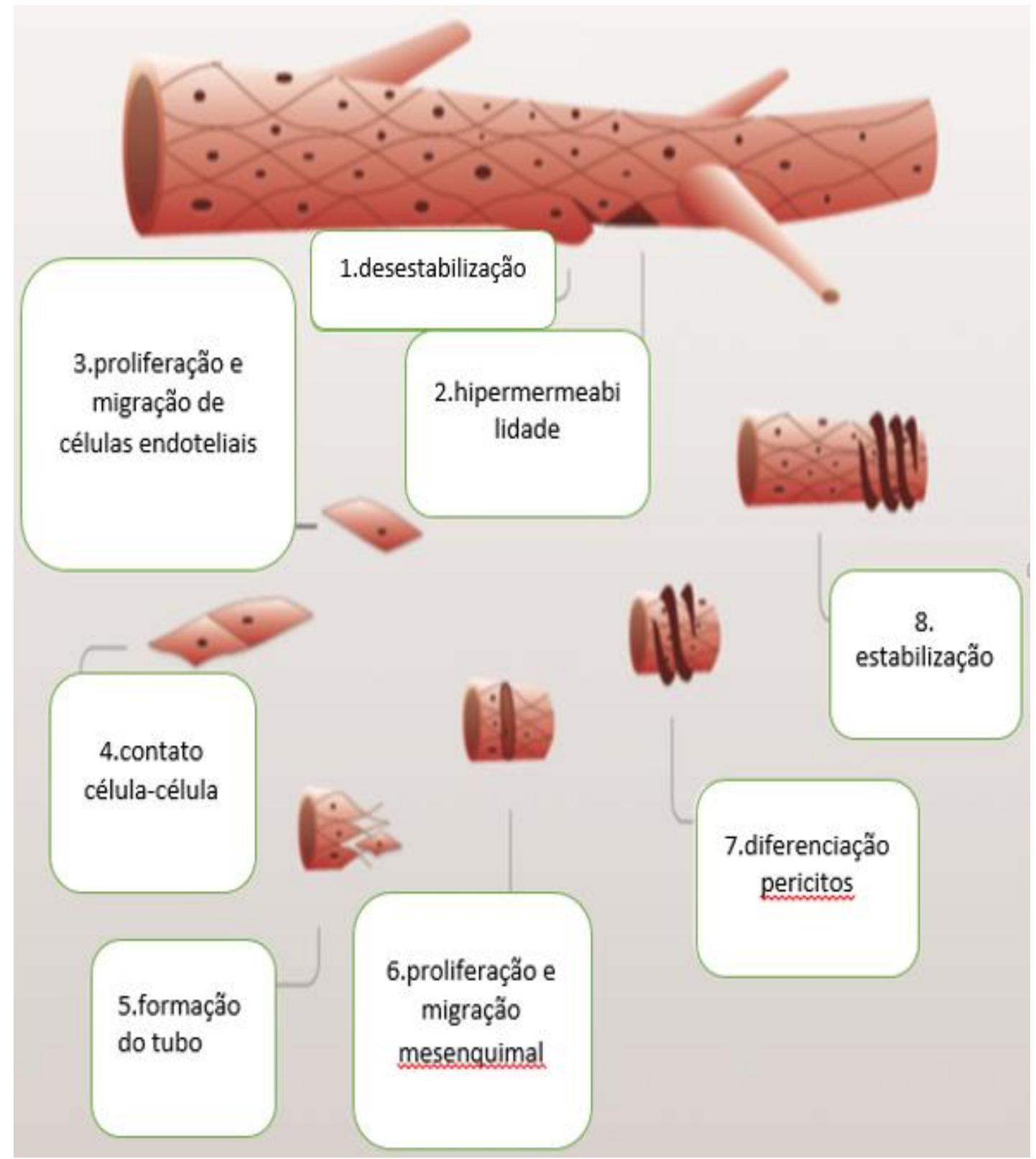

Fonte: Adaptado de Coulon et al. $2014^{(106)}$.

Figura 8 - Mecanismo da Angiogênese. 1. O primeiro passo é a desestabilização através da Ang-2 e 2. hiperpermeabilidade da parede do vaso. 3. Seguido pela proliferação e migração da CE. 4. O contato célula a célula é estabelecido através da VE-caderina e das integrinas. 5. A formação do tubo é completada via TNF-a, FGF e PDGF. 6. Após proliferação e migração mesenquimal e 7. diferenciação de pericitos. 8 . A formação dos vasos é completada após a estabilização 
O gene humano do VEGF está localizado no cromossomo $6 \mathrm{p} 21.3$ e contém 8 exóns separados por 7 íntrons ${ }^{(108)}$. O splicing alternativo resulta em quatro isoformas principais, contendo 121 (VEGF121), 165 (VEGF165), 189 (VEGF189) e 206 (VEGF206) aminoácidos ${ }^{(108,109)}$. Outras variantes têm sido observadas em menor frequência, incluindo VEGF145, VEGF183, VEGF162 e VEGF165b. Esta última variante teria um efeito inibitório na mitogênese induzida pelo VEGF ${ }^{(110)}$. O VEGF165 é a principal isoforma do VEGF-A, e é uma glicoproteína homodimérica de $45 \mathrm{KDa}^{(111)}$.

Dentro de uma espécie pode haver variabilidade na sequência do DNA. Se a variação é encontrada em uma frequência superior a $1 \%$ da população, denomina-se polimorfismo ${ }^{(112)}$. O polimorfismo C936T (rs3025039) é caracterizado por uma troca na posição 936 do gene do VEGF de uma Citosina (C) em Timina (T). O VEGF rs3025039 está localizado na região não traduzida 3'. A troca do nucleotídeo C pelo T na posição 936 do gene $V E G F$ influencia na estabilidade da transcrição do RNAm levando a uma diminuição dos níveis plasmáticos de VEGF quando comparados com indivíduos homozigotos para o alelo $\mathrm{C}^{(113)}$. No polimorfismo T460C (rs833061), o SNP está na região promotora do gene VEGF. Polimorfismos do gene VEGF localizado na região promotora pode aumentar a expressão e atividade da proteína. Este polimorfismo aumenta em $71 \%$ a atividade proteica ${ }^{(114,115)}$. O VEGF G634C (rs2010963) está localizado na região não traduzida 5'. O polimorfismo nesta região, parece estar associado com a baixa expressão da proteína VEGF ${ }^{(116)}$. 


\subsection{VEGF e CHC}

$\mathrm{O}$ crescimento do $\mathrm{CHC}$ depende da angiogênese, e tem sido demonstrado um importante papel da VEFG na angiogênese do $\mathrm{CHC}^{(117)}$. O papel da angiogênese na progressão de lesões pré-malignas para cânceres invasivos levaram os pesquisadores a estudar o papel do VEGF na história natural do CHC. A angiogênese é uma importante etapa no desenvolvimento do câncer e é necessária para o crescimento do tumor primário, invasão e metástase ${ }^{(103)}$. As células do $\mathrm{CHC}$ apresentam crescimento rápido e, consequentemente, precisam de um suprimento elevado de oxigênio e nutrientes. Assim as células tumorais induzem a formação de novos vasos sanguíneos. As lesões do CHC caracterizam-se pela hipervascularidade arterial para fornecer ao tumor sangue altamente oxigenado ${ }^{(118)}$. No entanto, estes novos vasos são formados por vasos desorganizados, com vazamento hemorrágico e tortuosos. A irregularidade dos vasos do tumor resulta em fluxo de sangue caótico com sangue pouco oxigenado. Além disso, esses vasos sanguíneos com vazamento fornecem uma passagem para as células do tumor na circulação sanguínea e, portanto, facilitam a metástase ${ }^{(106)}$. No CHC o aumento na expressão do VEGF e elevação dos níveis séricos tem sido associado com pior prognóstico ${ }^{(119)}$. Foi observado que os níveis de VEGF aumentavam progressivamente a medida que os nódulos evoluíam de displasia de baixo grau, displasia de alto grau e CHC precoce ${ }^{(120)}$. Em um estudo de análise quantitativa de 70 casos de CHC, a expressão do VEGF, demonstrada por imunohistoquímica, foi observada em 63,9\% dos CHC encapsulados, 78,3\% dos não capsulados e $90,9 \%$ dos CHC com metástases extra-hepáticas ${ }^{(121)}$. O estudo de Deli e cols. (2005) relatou uma expressão VEGF positiva, usando imunohistoquímica, em 
72 dos 105 pacientes com CHC $(68,6 \%)^{(122)}$. A expressão do VEGF no tumor com invasão venosa microscópica, está significativamente maior do que nos $\mathrm{CHC}$ sem invasão venosa microscópica ${ }^{(123)}$. Outros estudos, embora com um número pequeno de pacientes, tem evidenciado que a expressão do VEGF no CHC esta correlacionada com a probabilidade de recorrência do tumor depois da ressecção ou da ablação $^{(124,125)}$.

\subsection{Metilenotetrahidrofolato redutase (MTHFR)}

A MTHFR é a principal enzima no metabolismo do folato ${ }^{(126)}$. Junto de outras enzimas, a MTHFR participa no metabolismo do folato, pela conversão da 5,10-metilenotetrahidrofolato (5,10-metileno-THF) em 5-metiltetrahidrofolato (5metil-THF) ${ }^{(127)}$. O folato na sua forma de 5-metil-THF participa na síntese de nucleotídeos, na síntese de S-adenosil-metionina, na remetilação da homocisteína em metionina, e na metilação de DNA, proteínas, neurotransmissores e fosfolípides. A atividade normal da MTHFR pode ajudar a manter os níveis circulantes de folato e metionina prevenindo um aumento nos níveis plasmáticos de homocisteína ${ }^{(128)}$. (Figura 9). 


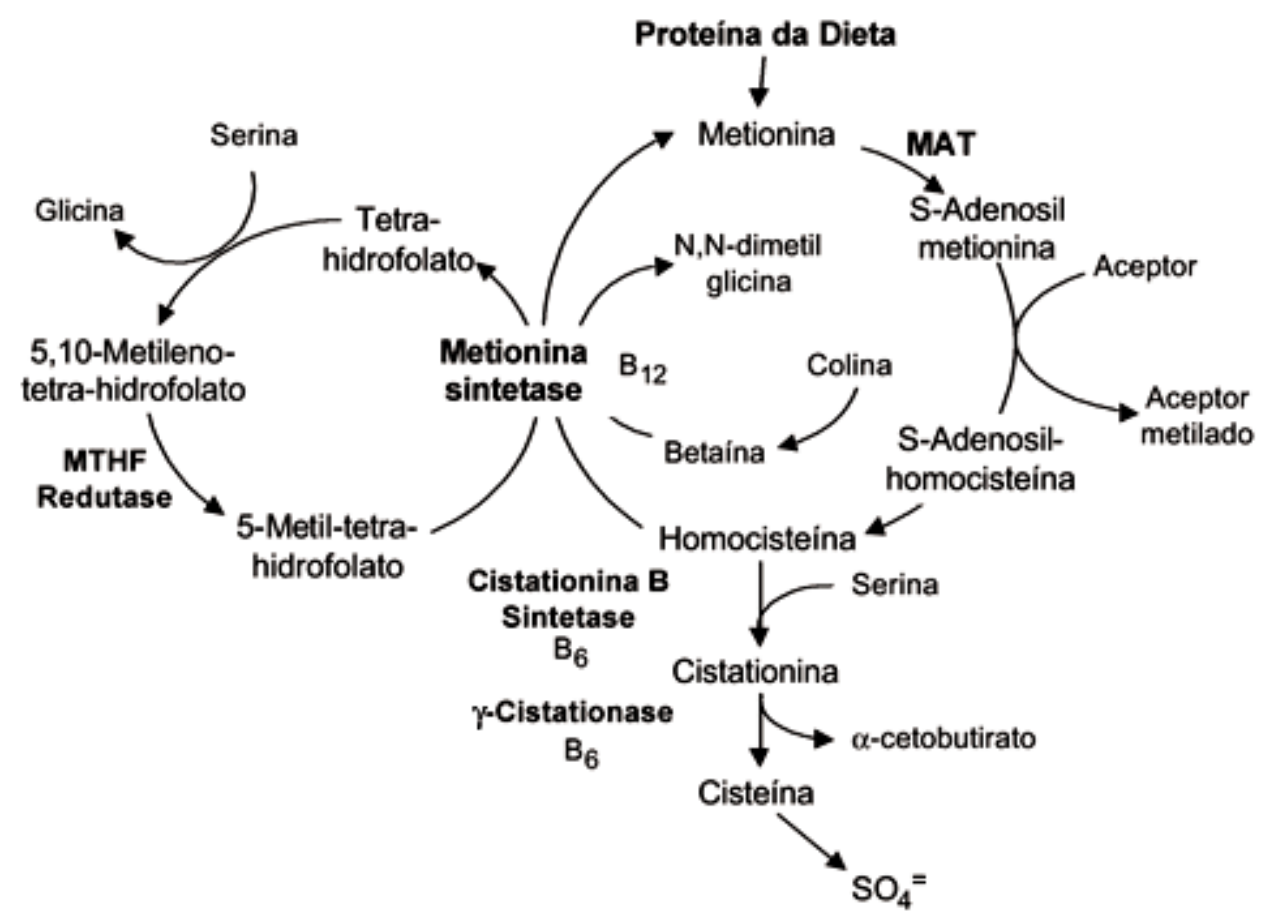

FONTE: Adaptado de Bydlowski et al., $1998^{(129)}$.

Figura 9 - Metabolismo da Homocisteína

O gene MTHFR localiza-se no cromossomo 1 (1p36.3) apresentando 11 exóns com tamanhos variando de 103 a 432 pb ${ }^{(130)}$.

Polimorfismos no gene MTHFR são descritos, a maioria deles raros ou distribuídos em populações isoladas ${ }^{(131)}$.

O polimorfismo C677T é caracterizado por uma troca na posição 677 do gene da MTHFR de uma citosina (C) em Timina $(T){ }^{(128)}$, determinando uma substituição de alanina por valina na cadeia polipeptídica, sendo a mesma relacionada a uma maior termolabilidade bem como diminuição da atividade catalítica da enzima $^{(126,132)}$, com perda de mais de $60 \%$ da atividade enzimática no homogenato celular. A frequência de alelos varia com a população estudada ${ }^{(133)}$.

Outro polimorfismo no gene MTHFR é o A1298C, onde ocorre uma troca no nucleotídeo 1298, de uma adenina (A) em citosina (C), resultando em uma 
substituição de um aminoácido do ácido glutâmico por alanina no códon 429 (Glu429Ala), o qual também pode induzir uma diminuição na atividade da $\operatorname{MTHFR}^{(134)}$.

\subsection{MTHFR e CHC}

Acredita-se que a deficiência de folato aumenta o risco de Câncer por perturbar a metilação do DNA e diminuir a síntese de reparação do DNA, conduzindo à ativação pronto-oncogênica ${ }^{(135)}$. O ácido fólico na forma de 5 'metilenotetrahidrofolato (5'-metil-THF), é essencial na conversão da metionina para sua forma ativada de S-adenosilmetionina (SAM). A SAM é a mais importante na maioria das reações bioquímicas, incluindo a metilação da citosina no DNA. Alterações ou interrupções na metilação do DNA podem aumentar a transformação maligna. Se os níveis de 5'-metil-THF estão mais baixos, leva a uma redução da metilação da citosina no DNA ${ }^{(136)}$. Esta hipometilação pode resultar em um estímulo da expressão de proto-oncogenes e induzir o câncer (Figura 10).

Na formação da molécula de DNA as pirimidinas (timina e citosina) se unem as purinas (adenina e guanina) correspondente através de ligações de hidrogênio denominadas emparelhamento de base. As pirimidinas são moléculas menores e formadas por um único anel de carbono e nitrogênio. A timina é a única molécula que só se encontra no DNA e é a principal estrutura que compõe esse ácido nucleico. A citosina compõe tanto o DNA quanto o RNA e realiza três ligações de hidrogênio com a base púrica guanina. Assim como as purinas, as pirimidinas também podem ser produzidas por síntese orgânica. Através da hidrólise de nucleotídeos são 
produzidos os nucleosídeos pirimídicos citidina, uridina e timidina. $\mathrm{O}$ folato também é essencial para a síntese de purinas e de pirimidinas. O folato na forma de $5^{\prime}, 10^{\prime}$ metileno tetrahidrofolato, atua como um doador para a enzima timidilato sintase a qual converte a desoxiuridina monofosfato (dUMP) em timidina monofosfato (TMP). A deficiência de folato bloqueia a metilação da dUMP em TMP, desta forma levando a um ciclo de reparação catastrófica ${ }^{(135,137)}$ (Figura 10).

Vários estudos demostraram que o polimorfismo C677T está associado com determinados canceres, como o câncer de próstata ${ }^{(138)}$, de pulmão ${ }^{(139)}$, coloretal $^{(140)}$, estômago ${ }^{(141)}$, bexiga ${ }^{(142)}$, esôfago ${ }^{(143)}$ e leucemia ${ }^{(144)}$. O esquema delineado na Figura 10, demonstra a possível via alternativa do aproveitamento do folato no metabolismo sob influência dos polimorfismos.

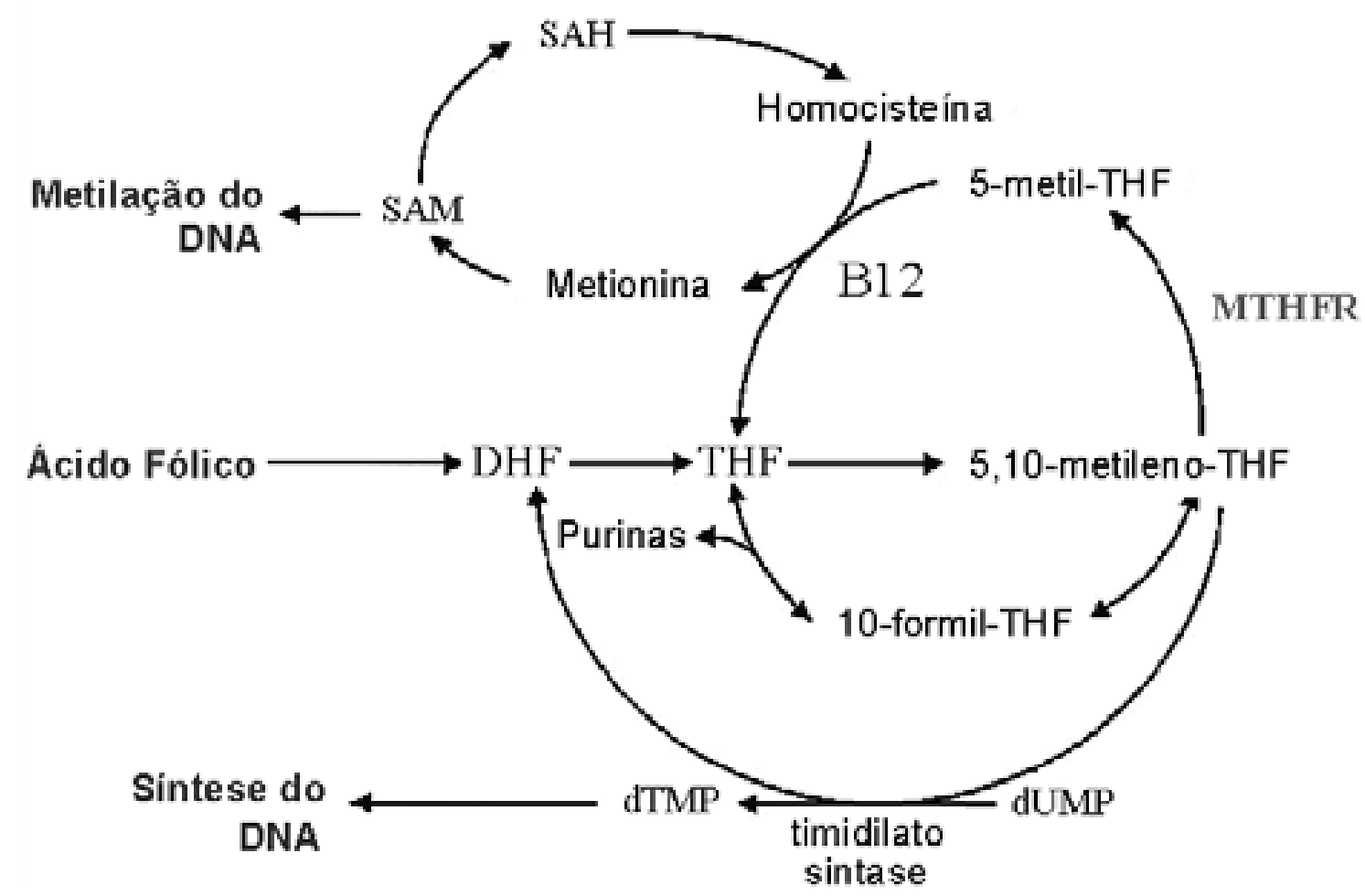

FONTE: Zanrosso et al., $2005^{(145)}$.

Figura 10 - Metabolismo do ácido fólico e função da MTHFR 
Alguns estudos avaliaram a correlação do polimorfismo C677T do gene da MTHFR com o CHC, mas os resultados foram controversos ${ }^{(146,147)}$. A meta análise de Jin e cols (2009) conclui que o polimorfismo C677T do gene da MTHFR aumenta o risco de $\mathrm{CHC}$ especialmente na população Europeia ${ }^{(148)}$.

Outros estudos tentaram evidenciar a associação entre o polimorfismo A1298C e o risco de desenvolvimento de CHC, mas a primeira meta análise publicada avaliando esta associação, conseguiu selecionar apenas seis trabalhos e conclui que este polimorfismo pode estar associado com a diminuição no risco de CHC na população asiática, afirmando contudo que devem ser realizados mais estudos com amostras maiores ${ }^{(149)}$. 
3 Objetivos 


\section{OBJETIVOS}

\subsection{Objetivo geral}

Avaliação dos polimorfismos do gene do Fator de crescimento endotelial vascular $(V E G F)$ rs2010963, rs3025039, rs833061 e polimorfismos do gene da Metilenotetrahidrofolato redutase $(M T H F R)$ rs1801131 e rs1801133 em pacientes com Carcinoma hepatocelular e hepatite $\mathrm{C}$, atendidos em centros de referência de doenças do fígado em Recife, Pernambuco.

\subsection{Objetivos específicos}

- Estimar a frequência dos polimorfismos no gene do $V E G F$ e da $M T H F R$ em pacientes com diagnóstico de carcinoma hepatocelular e infecção pelo vírus da hepatite $\mathrm{C}$.

- Correlacionar a presença dos polimorfismos no gene do VEGF e da $M T H F R$ com as características clínicas, bioquímicas e características dos nódulos hepáticos em pacientes com diagnóstico de carcinoma hepatocelular e infecção pelo vírus da hepatite C. 
4 Metodologia 


\section{METODOLOGIA}

\subsection{Casuística e delineamento do estudo}

Este é um estudo transversal de caráter analítico, onde foram incluídos, a partir de janeiro de 2014 até dezembro de 2016, 119 pacientes ambulatoriais, portadores de hepatite $\mathrm{C}$ crônica e Carcinoma hepatocelular que tinham sido ou ainda estavam em acompanhamento no ambulatório de hepatologia do Hospital Universitário Osvaldo Cruz da Universidade de Pernambuco e Instituto do Fígado e Transplantes de Pernambuco. Foram selecionados para a pesquisa, todos os pacientes acima de dezoito anos que tiveram diagnóstico de hepatite $\mathrm{C}$ crônica confirmados por PCR (HCV RNA +) e diagnóstico de Carcinoma hepatocelular por método de imagem através de exames de tomografia computadorizada do fígado e/ou ressonância nuclear magnética do fígado, que definiram diagnóstico de $\mathrm{CHC}$ utilizando como critério radiológico diagnóstico, a presença de realce intenso da lesão na fase arterial do contraste e lavagem do contraste (washout) nas fases venosas tardias estabelecidos de acordo com os critérios preconizados pela Associação Americana para o estudo de doenças do fígado (AASLD) ${ }^{(150)}$, o estadiamento dos

tumores foi feito através do BCLC (Barcelona Clinic Liver Cancer) ${ }^{(151)}$. Foram considerados critérios de exclusão pacientes com Co-infecção pelo HIV e/ou VHB, e pacientes com cirrose de outra etiologia. O presente estudo tem aprovação do comitê de ética (n. 349/14) e todos os pacientes assinaram termo de consentimento pósinformado. 
Para caracterizar a frequência dos genótipos na nossa população, foram utilizados material de banco de sangue de 128 indivíduos, com enzimas hepáticas (ALT, AST, Fosfatase Alcalina e GGT) normais, sorologias para hepatite C e B não reagentes.

Após a obtenção do termo de consentimento pós-informado foram colhidos $10 \mathrm{ml}$ de sangue periférico para o estudo genético dos pacientes incluídos na pesquisa.

\subsection{Coleta de dados clínicos e laboratoriais}

Os dados foram coletados através do questionário padrão em consulta médica, quando possível, com entrevista e exame clínico, e complementados com dados de prontuário médico, agrupados em um banco de dados e tabulados em planilha Excel. Foram registradas as características demográficas como idade, sexo, peso, altura e cálculo do índice de massa corpórea (IMC). O IMC foi calculado, conforme critério da OMS, dividindo-se o peso $(\mathrm{kg})$ pela altura ao quadrado $\left(\mathrm{m}^{2}\right)$, utilizando-se IMC > $25 \mathrm{~kg} / \mathrm{m}^{2}$ para a definição de sobrepeso e $>30 \mathrm{~kg} / \mathrm{m}^{2}$ para obesidade ${ }^{(152)}$. Foram ainda coletados os dados relacionados ao VHC (genótipo), dosagem bioquímica (transaminases, bilirrubinas, plaquetas, fosfatase alcalina, gama glutamil transferase e alfa-1 fetoproteína), todos registrados em prontuário. Através dos dados laboratoriais, exame físico e achados radiológicos, os pacientes foram classificados segundo o sistema de estadiamento do BCLC (Barcelona Clinic Liver Cancer) ${ }^{(151)}$. 


\subsection{Avaliação por imagem}

A avaliação por imagem foi realizada por meio de consulta aos laudos de exames de tomografia computadorizada do fígado e/ou ressonância nuclear magnética do fígado, com contraste em quatro fases, que definiram diagnóstico de CHC através de algoritmo diagnóstico validado em 2005 que utiliza como critério radiológico diagnóstico, a presença de realce intenso da lesão na fase arterial do

contraste e lavagem do contraste (washout) nas fases venosas tardias ${ }^{(150)}$. Todos os laudos encontravam-se anexados ao prontuário médico. Foram analisados os tamanhos e número dos nódulos hepáticos identificados por estes métodos dinâmicos de imagem.

\subsection{Coleta de Sangue e extração de DNA}

Amostras de sangue periférico $(10 \mathrm{ml})$ dos pacientes foram coletadas por punção de veia periférica em tubo contendo anticoagulante EDTA (Ácido etilenodiaminotetracético). O material coletado foi processado por centrifugação refrigerada e o volume contendo as células nucleadas (creme leucocitário), foi armazenado em tubo de micro centrífuga estéril de $1,5 \mathrm{ml} \mathrm{a}-20{ }^{\circ} \mathrm{C}$ para posterior extração de DNA.

O DNA genômico foi isolado utilizando-se o kit de extração e purificação PureLink ${ }^{\mathrm{TM}}$ Genomic DNA Mini Kit (Invitrogen-Life Technologies, Carlsbad, EUA) de acordo com instruções do fabricante. listadas a seguir. Após o descongelamento das amostras, foram transferidos $200 \mu \mathrm{L}$ do creme leucocitário para um tubo de 
micro centrífuga estéril e adicionados $20 \mu \mathrm{L}$ de Proteinase $\mathrm{K}$ e $20 \mu \mathrm{L}$ de RNaseA. Essa solução foi agitada em vórtex e incubada a temperatura ambiente por 2 minutos. Em seguida, foi adicionado $200 \mu \mathrm{L}$ de PureLink ${ }^{\mathrm{TM}}$ Genomic Lysis/Binding Buffer. Para se obter uma solução homogênea, foi efetuada agitação vigorosa em vórtex. A mistura foi incubada por 10 minutos a $55^{\circ} \mathrm{C}$ para promover a digestão protéica. Ao término da incubação, foram adicionados ao lisado $200 \mu \mathrm{L}$ de etanol 96-100\%, seguido de agitação em vórtex. O lisado foi transferido para uma coluna de sílica, acoplada a um tubo coletor de $2,0 \mathrm{~mL}$, e centrifugado a $10.000 \times \mathrm{g}$ por 1 minuto à temperatura ambiente. Em seguida, o tubo coletor foi descartado. A coluna contendo o DNA genômico fixado foi transferida para um novo tubo coletor de 2,0 mL. Foram adicionados à coluna $500 \mu \mathrm{l}$ de Wash Buffer 1, preparado previamente com etanol. A seguir, foi centrifugada a $10.000 \times \mathrm{g}$ por 1 minuto à temperatura ambiente. Novamente, o tubo coletor foi descartado e substituído. Foram adicionados à coluna $500 \mu \mathrm{l}$ de Wash Buffer 2, preparado previamente com etanol. A mistura foi centrifugada à velocidade máxima por 3 minutos à temperatura ambiente. Ao término do processamento, o tubo coletor foi descartado e substituído por um tubo de micro centrífuga estéril de 1,5 mL. Para a eluição do DNA, a solução foi incubada à temperatura ambiente por 1 minuto, acrescida de 100 a $200 \mu$ de água ultrapura estéril livre de DNase/RNase (Invitrogen) e por fim, centrifugada a velocidade máxima por 1 minuto à temperatura ambiente. A coluna foi descartada e o tubo de micro centrífuga conteve o DNA genômico purificado.

A concentração das amostras de DNA foi determinada por quantificação em espectrofotômetro NanoDrop ${ }^{T M}$ ND-1000 (NanoDrop Technologies, Inc. Wilmington, EUA) pela absorbância em luz ultravioleta a $260 \mathrm{~nm}$, utilizando-se 
como valor padrão $1 \mathrm{DO}_{260}=50 \mu \mathrm{g} / \mathrm{mL}$ de DNA. O grau de pureza foi avaliado pela razão 260/280 nm, utilizando-se apenas os DNAs cuja razão estejam entre 1,8 e 2,0.

A integridade das amostras foi verificada por eletroforese em gel de agarose $1 \%$ corado com brometo de etídio $3,0 \mu \mathrm{g} / \mathrm{mL}$ e visualizado em transluminador de luz UV em comprimento de onda $203 \mathrm{~nm}$.

O trabalho foi realizado no Laboratório de Cirurgia Experimental - LIM 37 Setor de Biologia Molecular, Disciplina de Transplante de Fígado - Departamento de Gastroenterologia da Faculdade de Medicina da Universidade de São Paulo.

\subsection{Seleção dos SNPs (single nucleotide polimorphisms)}

Para este estudo foram selecionados os SNPs potencialmente funcionais por ocorrerem próximos às regiões regulatórias dos genes e potencialmente influenciarem a expressão gênica, alterando a quantidade final da proteína codificada pelos genes.

Utilizou-se os bancos de dados dbSNP do NCBI ${ }^{(153)}$ e International HapMap Project ${ }^{(154)}$ para auxiliar na seleção dos SNPs. A distribuição dos haplótipos foi identificada com o objetivo de selecionar os SNPs mais informativos. Devido aos dados do HapMap Project e dbSNP serem derivados de populações de nãobrasileiros, os genótipos gerados no nosso estudo servirão para uma primeira análise da distribuição dos haplótipos na nossa população, o que, certamente, poderá beneficiar futuros estudos. 


\subsection{Genotipagem por TaqMan ${ }^{\circledR}$ SNP Genotyping Assays}

A genotipagem foi realizada utilizando a técnica TaqMan ${ }^{\circledR}$ SNP Genotyping Assays (Thermo Fisher Scientific, CA, EUA) através da identificação da base com uso de sondas marcadas com fluoróforos, com amplificação pela reação em cadeia da polimerase (PCR) em tempo real. Os kits TaqMan ${ }^{\circledR}$ contém primers (oligonucleotídeos) que flanqueiam a região polimórfica para amplificação dos produtos por PCR, além de duas sondas (fragmento de DNA de oligonucleotídeos de 18-22 pb) complementares à sequência alvo, sendo cada uma específica para um dos alelos descritos (polimórfico e tipo selvagem). Esta sonda apresenta na extremidade 5' um fluoróforo (dye reporter) e extremidade 3' um quencher (molécula que aceita energia do fluoróforo na forma de luz e a dissipa na forma de luz ou calor).

Enquanto as sondas estão intactas, a interação entre os dye reporters e os quenchers impede que a fluorescência seja emitida. Durante a atividade exonuclease 5' --> 3' da Taq DNA polimerase, a sonda ligada ao fragmento é clivada, causando a liberação do dye reporter e a emissão de fluorescência. Como apenas a sonda específica para um determinado alelo é capaz de se ligar a ele, apenas a fluorescência emitida por ela será detectada. Como cada sonda é marcada com uma fluorescência diferente, através da leitura da fluorescência emitida é possível determinar o genótipo da amostra. Esse processo se repete em cada ciclo e não interfere com o acúmulo de produto da PCR.

Além do dye reporter e da molécula quencher, uma molécula denominada MGB (Minor Groove Binder) também está afixada a sonda, tendo a função de elevar a sua temperatura de anelamento, permitindo ligação mais especifica, e evitando que 
ela se ligue inespecificamente a seqüência correspondente ao outro alelo. Os polimorfismos foram detectados através dos seguintes ensaios, VEGFA -634G>C (rs2010963) ensaio (C__8311614_10), VEGFA 936 C>T (rs3025039) ensaio (C_16198794_10), VEGFA -460 C $>\mathrm{T}$ (rs833061) ensaio (C__1647381_10), MTHFR C677T (rs1801133) ensaio (C__1202883_20) e MTHFR A1298C (rs1801131) ensaio (C__ 850486_20).

A fluorescência emitida na reação foi detectada em Real Time PCR Step One Plus (Applied Biosystem, Life Technologies, Foster City, EUA), que faz a discriminação alélica através da emissão de luz em comprimento de onda característico. Os genótipos serão determinados de acordo com o perfil de emissão das fluorescências ao final da reação de PCR. Para amplificação dos fragmentos desejados utilizaremos as seguintes condições de reação: 5,0 $\mu \mathrm{L}$ do master mix , 0,5 $\mu \mathrm{L}$ de Taqman Genotyping 20X, 3,5 $\mu \mathrm{L}$ de água RNase DNase Free e 1,0 $\mu \mathrm{L}$ contendo $10 \mathrm{ng}$ de DNA, somando um total de $10 \mu \mathrm{L}$ para cada reação. Foram utilizados os seguintes parâmetros de ciclagem: $30 \mathrm{seg}$ a $60{ }^{\circ} \mathrm{C}, 10 \mathrm{~min}$ a $95{ }^{\circ} \mathrm{C}$, seguidos por 50 ciclos a $92{ }^{\circ} \mathrm{C}$ por $15 \min$ e $60{ }^{\circ} \mathrm{C}$ por $1 \mathrm{~min}$.

\subsection{Análise estatística}

Os dados foram analisados utilizando o software SPSS v.17 para realização dos testes estatísticos. As frequências alélicas foram estimadas pelo método da contagem gênica com pLINK. O teste Qui-quadrado foi utilizado para verificar se a distribuição genotípica está de acordo com a hipótese do equilíbrio de HardyWeinberg. A existência de associações entre variáveis categóricas será avaliada pelos 
testes Qui-quadrado de Pearson e exato de Fisher quando apropriado. Para as variáveis quantitativas foram utilizados o teste-t ou Mann-Whitney obedecendo a regra de distribuição normal. As diferenças foram consideradas significativas para valores de $\mathrm{p}<0,05$, correção de Bonferroni para múltiplas associações foi utilizada para confirmação da associação em modelo univariado. A magnitude destas associações será estimada como Odds ratios (OR), utilizando intervalos de confiança de $95 \%$. Os valores de Odds ratio serão ajustados de acordo com as possíveis variáveis de confusão através de regressão logística multivariada. Analise de sobrevida foi realizada utilizando o teste de Logrank (Mantel-cox) para estimar a porcentagem de sobrevida relacionado aos genótipos dos SNPs estudados. 
5 Resultados 


\section{RESULTADOS}

\subsection{Características clínicas e laboratoriais}

Foram avaliados 119 pacientes portadores de infecção crônica pelo VHC e CHC acompanhados no ambulatório de nódulo do Hospital Universitário Osvaldo Cruz da universidade de Pernambuco e Instituto do Fígado e Transplantes de Pernambuco. Foram utilizados 128 indivíduos de banco de sangue com triagem sorológica para HIV, VHC, VHB, Chagas, HTLV e Sífilis para caracterizar a frequência dos genótipos na nossa população. Dentre os indivíduos com $\mathrm{CHC}$, 70,59\% foram homens e $29,41 \%$ mulheres. A média de idade dos participantes foi de 62,3 anos (variação de 46 a 86 anos). Na análise de alguns fatores de risco para neoplasia, com relação ao IMC, a média foi de 25,6 (variação de 15,2 a 38,5). Foi ainda observado a presença de diabetes mellitus em 33,61\% dos casos.

De acordo com a classificação de Child-Pugh, ficaram assim distribuídos: A 60,9\%; B 36,5\%; C 2,6\%. A avaliação do tamanho do tumor, foi feita pelo seu maior diâmetro, e nos casos de apresentação multinodular, foi mensurado aquele de maior tamanho em seu maior diâmetro, a média foi de 4,4 cm (variação de 0,5 a 13,8 cm). Apresentaram-se de forma uninodular 46,21\% dos casos e multinodular 52,10\%, não foi caracterizado dois dos 119 pacientes estudados.

Dentre os exames laboratoriais avaliados, nos indivíduos portadores de VHC e CHC, obtivemos uma média de bilirrubina total (BT) de 1,6 mg/dL (variação de 0,4 a 7,2 mg/dL), Aspartato aminotransferase (AST) média de 98,9 U/L (variação de 16 
a 237 U/L), Alanina aminotransferase (ALT) média de 90,2 U/L ( variação de 18 a 249 U/L), Gamaglutamil transpeptidase (GGT) média de 239 U/L (variação de 26 a 1629 U/L), Fosfatase alcalina (FA) média de 168,4 U/L (variação de 36 a 630 U/L), Plaquetas em número, com média de 119037 (variação de 12000 a 324000), Alfa 1 fetoproteina (AFP) média de 1492,5 ng/mL (variação 1,7 a 60.500). A frequência do genótipo 1 nesta população estudada foi de $67 \%$. A nossa amostra não apresentou diferença significativa com relação as variáveis clínicas idade, sexo, IMC e presença de DM, bem como com as variáveis laboratoriais BT, AST, ALT, GGT, FA, plaquetas e genótipo 1 do VHC quando comparados os diferentes estágios do BCLC, apresentando diferença estatística, quando avaliados o Child $\mathrm{p}=<0,0001$, o tamanho do tumor $\mathrm{p}=<0,0001$, e a apresentação uninodular ou multinodular $\mathrm{p}=<0,0001$. Observamos também diferença estatística significativa com relação a variável laboratorial AFP $\mathrm{p}=0,002$ (Tabela 1). 
Tabela 1 - Características clínicas e laboratoriais relacionadas aos pacientes com CHC e VHC, com a classificação do BCLC (Barcelona Clinic Liver Cancer)

\begin{tabular}{|c|c|c|c|c|c|}
\hline Variáveis & $\begin{array}{c}\text { HCV-CHC } \\
(n=119)\end{array}$ & $\begin{array}{c}\text { BCLC-0/A } \\
(n=60)\end{array}$ & $\begin{array}{c}\text { BCLC-B } \\
(n=32)\end{array}$ & $\begin{array}{c}\text { BCLC-C } \\
(n=25)\end{array}$ & p-value \\
\hline \multicolumn{6}{|l|}{ Clínicas } \\
\hline Idade (anos) & $62,30 \pm 8,63$ & $62,17 \pm 8,79$ & $62,5 \pm 9,13$ & $63,08 \pm 7,74$ & 0,79 \\
\hline Sexo masculino & $84(70,59 \%)$ & $40(66,67 \%)$ & $23(71,9 \%)$ & $21(84 \%)$ & 0,27 \\
\hline IMC $\left(\mathrm{kg} / \mathrm{m}^{2}\right)$ & $25,60 \pm 4,32$ & $26,1 \pm 4,79$ & $24,8 \pm 3,2$ & $25,34 \pm 4,19$ & 0,70 \\
\hline Diabetes & $40(33,61 \%)$ & $20(33,32 \%)$ & $9(28,12 \%)$ & $8(32 \%)$ & 0,87 \\
\hline CHILD A & $60,9 \%$ & $88 \%$ & $40,62 \%$ & $24 \%$ & \multirow{3}{*}{$<0,0001$} \\
\hline CHILD B & $36,5 \%$ & $10,34 \%$ & $56,25 \%$ & $72 \%$ & \\
\hline CHILD C & $2,6 \%$ & $1,66 \%$ & $3,13 \%$ & $4 \%$ & \\
\hline Tamanho tumor & $4,4 \pm 2,6$ & $2,8 \pm 1,2$ & $5,9 \pm 2,7$ & $6,15 \pm 2,96$ & $<0,0001$ \\
\hline Uninodular & $55(46,21 \%)$ & $43(71,67 \%)$ & $10(31,25 \%)$ & $2(8 \%)$ & \multirow{2}{*}{$<0,0001$} \\
\hline Multinodular & $62(52,10 \%)$ & $17(28,33 \%)$ & $22(68,75 \%)$ & $23(92 \%)$ & \\
\hline \multicolumn{6}{|l|}{ Laboratoriais } \\
\hline $\begin{array}{c}\text { BT }[\mathrm{mg} / \mathrm{dL}] \\
(\min -\max )\end{array}$ & $1,6(0,4-7,2)$ & $1,7(0,5-7,22)$ & $1,4(0,5-3,7)$ & $1,74(0,36-5,51)$ & 0,70 \\
\hline $\begin{array}{l}\text { AST (U/L) } \\
(\min -\max )\end{array}$ & $98,9(16-237)$ & $103,9(28-237)$ & $93,2(31-183,9)$ & $96(16-225)$ & 0,46 \\
\hline $\begin{array}{c}\text { ALT (U/L) } \\
(\min -\max )\end{array}$ & $90,2(18-249)$ & $100,7(18-240)$ & $84,4(26-208)$ & $75,92(18-249)$ & 0,05 \\
\hline $\begin{array}{c}\text { GGT (U/L) } \\
(\min -\max )\end{array}$ & $\begin{array}{c}239 \\
(26-1629)\end{array}$ & $\begin{array}{c}232,8 \\
(26-1133)\end{array}$ & $\begin{array}{c}184,7 \\
(41-532)\end{array}$ & $\begin{array}{c}320,61 \\
(50-1629)\end{array}$ & 0,10 \\
\hline $\begin{array}{l}\text { FA (U/L) } \\
(\min -\max )\end{array}$ & $\begin{array}{c}168,4 \\
(36-630)\end{array}$ & $\begin{array}{c}151,2 \\
(51-320)\end{array}$ & $\begin{array}{c}192,3 \\
(36-618,3)\end{array}$ & $\begin{array}{c}170,74 \\
(61-630)\end{array}$ & 0,40 \\
\hline $\begin{array}{l}\text { Plaquetas } \\
\text { (min-max) }\end{array}$ & $\begin{array}{c}119037 \\
(12000- \\
324000)\end{array}$ & $\begin{array}{c}107701,7 \\
(12000- \\
230000)\end{array}$ & $\begin{array}{c}131645,2 \\
(46000- \\
247000)\end{array}$ & $\begin{array}{c}131260,9 \\
(55000- \\
324000)\end{array}$ & 0,18 \\
\hline $\begin{array}{l}\text { AFP ng/mL } \\
(\min -\max )\end{array}$ & $\begin{array}{c}1492,5 \\
(1,7-60500)\end{array}$ & $\begin{array}{c}660 \\
(1,8-19000)\end{array}$ & $\begin{array}{c}691,9 \\
(1,7-9604)\end{array}$ & $\begin{array}{c}4468,65 \\
(1,97-60500)\end{array}$ & 0,002 \\
\hline $\begin{array}{c}\text { VHC genótipo } 1 \\
(\%)\end{array}$ & $67 \%$ & $63,32 \%$ & $50 \%$ & $52 \%$ & 0,50 \\
\hline
\end{tabular}

Abreviações: VHC- vírus da hepatite C; CHC- Carcinoma hepatocelular; BCLC- Barcelona Clinic Liver Cancer; IMC- índice de massa corpórea; BT- bilirrubina total; AST- aspartato aminotransferase; ALT- Alanina aminotransferase; GGT- Gama glutamil transpeptidase; FA- Fosfatase alcalina; AFP: alfa 1 fetoproteína; VHCvírus da hepatite $\mathrm{C}$. 
5.2 Análise da frequência dos genótipos e distribuição dos SNPs (single nucleotide polimorphisms) nos genes, MTHFR $e$ VEGF em pacientes com CHC e VHC, e indivíduos controles

A posição dos polimorfismos do MTHFR e VEGF no cromossomo, frequência esperada e observada, informações sobre o Equilíbrio de HardyWeinberg, frequência do Minor Alelo (alelo menos frequente) e do Major Alelo (alelo mais frequente), estão descritas na Tabela 2. No presente estudo, as frequências genotípicas observadas e esperadas dos SNPs do MTHFR $e$ VEGF foram consistentes com o Equilíbrio de Hardy-Weinberg, com valor de $p$ superior a 0,05 para as análises. 
Tabela 2 - Distribuição dos SNPs em pacientes com CHC e VHC, grupo controle e verificação do equilíbrio de Hardy-Weinberg (EHW)

\begin{tabular}{|c|c|c|c|c|c|c|c|c|c|}
\hline CHR & SNP & Gene & Grupo & Minor alelo & Majoralelo & Genótipos & O(HET) & E(HET) & p-Value $($ EHW) \\
\hline 1 & rs1801131 & MTHFR & $\mathrm{HCC}$ & $\mathrm{C}$ & A & $9 / 45 / 65$ & 0,3782 & 0,3893 & 0,8136 \\
\hline 1 & rs1801131 & MTHFR & Controle & $\mathrm{C}$ & $\mathrm{A}$ & $10 / 39 / 79$ & 0,3047 & 0,3547 & 0,1319 \\
\hline 1 & rs1801133 & MTHFR & $\mathrm{HCC}$ & $\mathrm{T}$ & $\mathrm{C}$ & $12 / 42 / 65$ & 0,3529 & 0,4008 & 0,2502 \\
\hline 1 & rs1801133 & MTHFR & Controle & $\mathrm{T}$ & $\mathrm{C}$ & $10 / 60 / 58$ & 0,4688 & 0,4297 & 0,4103 \\
\hline 6 & rs2010963 & VEGF & $\mathrm{HCC}$ & $\mathrm{C}$ & G & $18 / 48 / 53$ & 0,4034 & 0,4567 & 0,2282 \\
\hline 6 & rs2010963 & VEGF & Controle & $\mathrm{C}$ & $\mathrm{G}$ & $18 / 64 / 46$ & 0,5 & 0,4761 & 0,7102 \\
\hline 6 & rs3025039 & VEGF & $\mathrm{HCC}$ & $\mathrm{T}$ & $\mathrm{C}$ & $0 / 31 / 88$ & 0,2605 & 0,2266 & 0,2138 \\
\hline 6 & rs3025039 & VEGF & Controle & $\mathrm{T}$ & $\mathrm{C}$ & 0/37/91 & 0,2891 & 0,2473 & 0,07268 \\
\hline 6 & rs833061 & VEGF & $\mathrm{HCC}$ & $\mathrm{C}$ & $\mathrm{T}$ & $16 / 59 / 44$ & 0,4958 & 0,4723 & 0,6987 \\
\hline 6 & rs833061 & VEGF & Controle & $\mathrm{C}$ & $\mathrm{T}$ & $21 / 54 / 53$ & 0,4219 & 0,4688 & 0,2611 \\
\hline
\end{tabular}

Abreviações: SNP - single nucleotide polimorphisms; CRH - cromossomo; O(HET) - frequência relativa observada nos heterozigotos ; E(HET) - frequência relativa esperada nos heterozigotos; $E H W$ - Equilíbrio de Hardy-Weinberg; $M T H F R$ - metilenotetrahidrofolato redutase; $V E G F$ - fator de crescimento endotelial vascular. 


\subsection{Análise de associação com os genes MTHFR e VEGF e características do tumor em pacientes com CHC e VHC}

Com relação as características do tumor foram realizadas analises de associação genética entre os genes MTHFR e VEGF e a classificação BCLC. Não foi observada nenhuma associação estatisticamente significativa comparando a frequência dos SNPs, com a classificação BCLC no estudo de associação alélica (Tabela 3) assim como nos modelos genotípicos de associação para todas as comparações (dados não mostrados).

Tabela 3 - Análise dos SNPs dos genes MTHFR e VEGF em pacientes com CHC e VHC divididos de acordo com a classificação BCLC

\begin{tabular}{|c|c|c|c|c|c|c|c|c|c|}
\hline CHR & SNP & Gene & $\begin{array}{l}\text { Minor } \\
\text { alelo }\end{array}$ & $\begin{array}{c}\text { BCLC } \\
(B / C)\end{array}$ & $\begin{array}{c}\text { BCLC } \\
\text { (A) }\end{array}$ & $\begin{array}{l}\text { Major } \\
\text { alelo }\end{array}$ & p-value & OR & (IC 95\%) \\
\hline 1 & rs1801131 & MTHFR & $\mathrm{C}$ & 0,2193 & 0,2833 & A & 0,2595 & 0,7105 & $\begin{array}{c}(0,3917- \\
1,289)\end{array}$ \\
\hline 1 & rs1801133 & MTHFR & $\mathrm{T}$ & 0,2982 & 0,2667 & $\mathrm{C}$ & 0,5916 & 1,169 & $\begin{array}{c}(0,6611- \\
2,066)\end{array}$ \\
\hline 6 & rs2010963 & VEGF & $\mathrm{C}$ & 0,3333 & 0,3667 & G & 0,5932 & 0,8636 & $\begin{array}{c}(0,5043- \\
1,479)\end{array}$ \\
\hline 6 & rs3025039 & VEGF & $\mathrm{T}$ & 0,1316 & 0,125 & $\mathrm{C}$ & 0,8804 & 1,061 & $\begin{array}{c}(0,4928- \\
2,283)\end{array}$ \\
\hline 6 & rs833061 & VEGF & $\mathrm{C}$ & 0,4474 & 0,325 & $\mathrm{~T}$ & 0,05446 & 1,681 & $\begin{array}{c}(0,9884- \\
2,86)\end{array}$ \\
\hline
\end{tabular}

Abreviações: SNP- single nucleotide polimorphisms; ; MTHFR- metilenotetrahidrofolato redutase; $V E G F$ - fator de crescimento endotelial vascular; CHC- carcinoma hepatocelular; VHC - vírus da hepatite $\mathrm{C}$; CHR-cromossomo; OR-odds ratio; IC- intervalo de confiança.Minor alelo- alelo menos frequente, Major alelo - alelo mais frequente. 
Quando foi analisada a relação dos SNPs com a apresentação do número de tumores, observamos que os genes MTHFR e VEGF tem influência no desenvolvimento da apresentação dos tumores na forma de uninodular ou multinodular. Os alelos C (rs1801131) MTHFR e C (rs2010963) VEGF foram associados com a proteção para o desenvolvimento de $\mathrm{CHC}$ multinodular com uma frequência alélica C (rs1801131) no gene da MTHFR de 0,18 vs 0,32 para os pacientes com tumor multinodular e uninodular respectivamente, $\mathrm{p}=0.012$ OR 0.46 IC (0.25-0.85), e frequência alélica C (rs2010963) no gene da VEGF de 0.27 vs 0.43 , $\mathrm{p}=0,009$ OR 0,48 IC $(0,28-0,84)$ para os pacientes com tumor multinodular e uninodular respectivamente. Contrariamente o alelo T (rs 1801133) MTHFR foi associado com fator de risco para o desenvolvimento de $\mathrm{CHC}$ multinodular, com uma frequência alélica no gene da MTHFR de 0,33 para os pacientes com tumor multinodular, vs 0,21 para os pacientes com tumor uninodular, $\mathrm{p}=0,040$ OR 1,83 IC $(1,02-3,29)$, após a correção de bonferroni para múltiplas associações apenas o (rs2010963) no gene da VEGF mostrou-se significativo (tabela 4). 
Tabela 4 - Análise dos SNPs dos genes MTHFR e VEGF em pacientes com CHC e VHC divididos de acordo com o número de tumores

\begin{tabular}{|c|c|c|c|c|c|c|c|c|c|}
\hline CHR & SNP & Gene & Minor alelo & Multinodular & Uninodular & Major alelo & $\mathrm{p}$-value & OR & (IC 95\%) \\
\hline 1 & rs1801131 & MTHFR & $\mathbf{C}$ & 0,1855 & $\mathbf{0 , 3 2 7 3}$ & $\mathbf{A}$ & 0,01267 & 0,4681 & $(0,2561-0,8555)$ \\
\hline 1 & rs1801133 & MTHFR & $\mathbf{T}$ & $\mathbf{0 , 3 3 8 7}$ & 0,2182 & $\mathbf{C}$ & 0,04086 & $\mathbf{1 , 8 3 5}$ & $(1,022-3,297)$ \\
\hline 6 & rs2010963 & VEGF & $\mathbf{C}$ & 0,2742 & 0,4364 & $\mathbf{G}$ & $0,009456 *$ & 0,488 & $(0,2828-0,842)$ \\
\hline 6 & rs3025039 & VEGF & $\mathrm{T}$ & 0,1129 & 0,1455 & $\mathrm{C}$ & 0,4573 & 0,7477 & $(0,3468-1,612)$ \\
\hline 6 & rs833061 & VEGF & $\mathrm{C}$ & 0,4032 & 0,3636 & $\mathrm{~T}$ & 0,5344 & 1,182 & $(0,6968-2,007)$ \\
\hline
\end{tabular}

*Estatisticamente significativo após correção de bonferroni para comparações múltiplas $(\mathrm{p}<0.01)$

Abreviações: CHR-cromossomo; SNP- single nucleotide polimorphisms; ; MTHFR- metilenotetrahidrofolato redutase; VEGF- fator de crescimento endotelial vascular; CHCcarcinoma hepatocelular; VHC- vírus da hepatite C; CHR- cromossomo; OR- odds ratio; IC- intervalo de confiança. 
Com relação a análise de modelos genotípicos de associação genica entre as formas uninodular e multinodular, observamos associação estatisticamente significativa para o gene MTHFR (rs1881131) nos modelos genotípico e dominante $(p=0.036)$ e $(p=0.042$, OR 2.18 IC 1.04-4.59), respectivamente, estando o genótipo AA associado ao desenvolvimento do $\mathrm{CHC}$ na forma multinodular. Para o (rs1801133) do gene MTHFR o modelo genético dominante foi o único com associação significativa, com a presença do genótipo CT/TT associado com o desenvolvimento do CHC na forma multinodular ( $p=0,04$ OR 2,13 IC 1,01 - 4,54). Em relação ao gene VEGF (rs2010963) foi observado associação estatisticamente significativa nos modelos genotípico e recessivo, sendo os genótipos GG/GC associados com o desenvolvimento do $\mathrm{CHC}$ na forma multinodular $(\mathrm{p}=0,018)$ e ( $\mathrm{p}=0,005$, OR 4.95 IC 1.52-16.13), respectivamente (Tabela 5). 
Tabela 5 - 'Análise dos modelos de associação genética dos genes MTHFR e VEGF em pacientes com $\mathrm{CHC}$ e $\mathrm{VHC}$ divididos de acordo com o número de tumores

\begin{tabular}{|c|c|c|c|c|}
\hline Gene (SNP) & $\begin{array}{l}\text { Multinodular } \\
\text { (62) }\end{array}$ & $\begin{array}{c}\text { Uninodular } \\
(55)\end{array}$ & $\begin{array}{l}\text { Modelo de } \\
\text { associação }\end{array}$ & p-valor OR (IC 95\%) \\
\hline \multicolumn{5}{|l|}{ MTHFR } \\
\hline \multicolumn{5}{|l|}{ (rs1881131) } \\
\hline AA & $40(0,64)$ & $25(0,45)$ & $\mathrm{AA}$ vs $\mathrm{AC}$ vs $\mathrm{CC}$ & $p=0,036$ \\
\hline $\mathrm{AC}$ & $21(0,34)$ & $24(0,44)$ & $\mathrm{AA} / \mathrm{AC}$ vs CC & $\mathrm{p}=0,050 ; 7,47(0,87-64,17)$ \\
\hline $\mathrm{CC}$ & $1(0,02)$ & $6(0,11)$ & $\mathrm{AA}$ vs $\mathrm{AC} / \mathrm{CC}$ & $p=0,042,2,18(1,04-4,59)$ \\
\hline \multicolumn{5}{|l|}{ (rs1801133) } \\
\hline $\mathrm{CC}$ & $28(0,45)$ & $35(0,64)$ & CC vs CT vs TT & $\mathrm{p}=0,150$ \\
\hline CT & $26(0,42)$ & $16(0,29)$ & $\mathrm{CC} / \mathrm{CT}$ vs TT & $\mathrm{p}=0,372,0,53(0,15-1,87)$ \\
\hline TT & $8(0,13)$ & $4(0,07)$ & $\mathrm{CT} / \mathrm{TT}$ vs $\mathrm{CC}$ & $p=0,04,2,13(1,01-4,54)$ \\
\hline \multicolumn{5}{|l|}{ VEGF } \\
\hline \multicolumn{5}{|l|}{ (rs2010963) } \\
\hline GG & $32(0,52)$ & $21(0,38)$ & GG vs GC vs CC & $p=0,018$ \\
\hline $\mathrm{GC}$ & $26(0,42)$ & $20(0,36)$ & GG/GC vs CC & $\mathrm{p}=0,005,4,95(1,52-16,13)$ \\
\hline $\mathrm{CC}$ & $4(0,06)$ & $14(0,26)$ & GG vs GC/CC & $\mathrm{p}=0,192,1,73(0,82-3,61)$ \\
\hline \multicolumn{5}{|l|}{ (rs3025039) } \\
\hline $\mathrm{CC}$ & $48(0,77)$ & $39(0,71)$ & CC vs CT vs TT & $\mathrm{p}=0,525$ \\
\hline CT & $14(0,23)$ & $16(0,29)$ & $\mathrm{CC} / \mathrm{CT}$ vs TT & - \\
\hline TT & $0(0)$ & $0(0)$ & $\mathrm{CC}$ vs $\mathrm{CT} / \mathrm{TT}$ & $\mathrm{p}=0,525,1,41 \quad(0,61-3,23)$ \\
\hline \multicolumn{5}{|l|}{ (rs833061) } \\
\hline TT & $21(0,34)$ & $22(0,40)$ & TT vs TC vs CC & $\mathrm{p}=0,815$ \\
\hline $\mathrm{TC}$ & $32(0,52)$ & $26(0,47)$ & TT/TC vs CC & $\mathrm{p}=0,999,0,85(0,30-2,48)$ \\
\hline $\mathrm{CC}$ & $9(0,14)$ & $7(0,13)$ & TT vs TC/CC & $\mathrm{p}=0,565,0,77(0,36-1,63)$ \\
\hline
\end{tabular}


Avaliamos também as características clínicas do tumor e laboratoriais que apresentaram diferença estatisticamente significativa quando relacionadas com a classificação BCLC, demonstradas na tabela 1, que foram, a média do nível sérico de AFP, a classificação de Child-Pugh, a média do tamanho do tumor, e sua relação com o melhor modelo genético observado na tabela 5 para os genes MTHFR (rs18011131 e rs1801133) e VEGF (rs2010963). Contudo, não foi observada diferença significativa com nenhuma das variáveis supracitadas (Tabela 6). 
Tabela 6 - Características laboratoriais e do tumor de pacientes com CHC e VHC em relação aos genótipos dos genes MTHFR (rs18011131 e rs1801133) e VEGF (rs2010963)

\begin{tabular}{|c|c|c|c|c|c|c|c|c|c|}
\hline \multirow[b]{2}{*}{ Variável } & \multicolumn{2}{|c|}{ MTHFR rs1801131 } & \multirow[b]{2}{*}{$P$} & \multicolumn{2}{|c|}{ MTHFR rs1801133 } & \multicolumn{4}{|c|}{ VEGF rs2010963 } \\
\hline & $\underset{(n=60)}{\mathbf{A A}}$ & $\begin{array}{c}\mathrm{AC}+\mathrm{CC} \\
(\mathrm{n}=48)\end{array}$ & & $\underset{(n=60)}{C C}$ & $\begin{array}{r}\text { CT+TT } \\
(n=48)\end{array}$ & $\boldsymbol{P}$ & $\underset{(n=18)}{C C}$ & $\begin{array}{c}\text { CG+GG } \\
(n=99)\end{array}$ & $P$ \\
\hline $\operatorname{AFP}(\mathrm{ng} / \mathrm{mL})$ & $\begin{array}{c}29,5 \\
(1,73-60.500)\end{array}$ & $\begin{array}{c}60,9 \\
(1,80-4770)\end{array}$ & 0,65 & $\begin{array}{c}47,5 \\
(1,73-20302)\end{array}$ & $\begin{array}{c}26,4 \\
(1,97-60.500)\end{array}$ & 0,45 & $\begin{array}{c}16,7 \\
(1,80-530)\end{array}$ & $\begin{array}{c}36,7 \\
(1,73-60.500)\end{array}$ & 0,14 \\
\hline Child-Pugh & $\underset{(n=64)}{\mathbf{A A}}$ & $\begin{array}{c}\mathrm{CA}+\mathrm{CC} \\
(\mathrm{n}=51)\end{array}$ & & $\begin{array}{c}\mathrm{CC} \\
(n=62)\end{array}$ & $\begin{array}{c}\text { CT+TT } \\
(n=53)\end{array}$ & & $\begin{array}{c}\mathrm{CC} \\
(\mathrm{N}=17)\end{array}$ & $\begin{array}{c}\mathbf{C G}+\mathbf{G G} \\
(\mathrm{n}=98)\end{array}$ & \\
\hline A & $41(64 \%)$ & $29(57 \%)$ & \multirow{2}{*}{0,43} & $39(63 \%)$ & $31(58 \%)$ & \multirow{2}{*}{0,62} & $9(53 \%)$ & $59(60 \%)$ & \multirow{2}{*}{0,57} \\
\hline $\mathrm{B} / \mathrm{C}$ & $23(36 \%)$ & $22(43 \%)$ & & $23(37 \%)$ & $22(42 \%)$ & & $8(47 \%)$ & $39(40 \%)$ & \\
\hline BCLC & $\underset{(n=65)}{\mathbf{A A}}$ & $\begin{array}{c}\mathrm{CA}+\mathrm{CC} \\
(\mathrm{N}=52)\end{array}$ & & $\begin{array}{c}C C \\
(N=63)\end{array}$ & $\begin{array}{l}\text { CT+TT } \\
(\mathrm{N}=54)\end{array}$ & & $\begin{array}{c}C C \\
(\mathrm{~N}=18)\end{array}$ & $\begin{array}{c}\mathbf{C G}+\mathbf{G G} \\
(\mathbf{N}=99)\end{array}$ & \\
\hline $\mathrm{A}$ & $31(48 \%)$ & $29(56 \%)$ & \multirow{2}{*}{0,38} & $34(54 \%)$ & $26(48 \%)$ & \multirow{2}{*}{0,53} & $10(55 \%)$ & $50(50 \%)$ & \multirow{2}{*}{0,79} \\
\hline $\mathrm{B} / \mathrm{C}$ & $34(52 \%)$ & $23(44 \%)$ & & $29(46 \%)$ & $28(52 \%)$ & & $8(45 \%)$ & $49(50 \%)$ & \\
\hline $\begin{array}{l}\text { Tamanho do } \\
\text { tumor* } \\
\text { CHC (cm) }\end{array}$ & $3,7(1,3-13,8)$ & $4,0(0,5-13)$ & 0,96 & $3,9(0.5-9,0)$ & $3,75(1,3-13,8)$ & 0,76 & $3,2(1,6-13)$ & $3,9(0,5-13,8)$ & 0,63 \\
\hline
\end{tabular}

* Pacientes com tumores multinodulares foi considerado o tamanho do maior tumor 
Na análise de regressão logística binária, ajustada para as variáveis sexo e idade, observamos que, para o gene do VEGF (rs2010963), os genótipos GG/GC é fator de risco independente no desenvolvimento do CHC da forma multinodular $\mathrm{p}=0,013,4,78(1,38$ 16,67) (Tabela 7).

Tabela 7 - Análise de regressão logística para predizer ocorrência de tumores multinodulares em 117 pacientes com CHC e VHC

\begin{tabular}{lcccc}
\hline Variáveis & p-value & OR & \multicolumn{2}{c}{$\mathbf{9 5 \%}$ I.C. } \\
\hline Idade & 0,868 & 1,004 & 0,958 & 1,053 \\
Sexo Masc. & 0,098 & 2,099 & 0,873 & 5,049 \\
MTHFR (rs1801131- AA) & 0,335 & 1,506 & 0,655 & 3,465 \\
MTHFR (rs1801133 - CC) & 0,132 & 0,537 & 0,240 & 1,205 \\
VEGF (rs2010963 - GG/GC) & $\mathbf{0 , 0 1 3}$ & $\mathbf{4 , 7 8}$ & $\mathbf{1 , 3 8}$ & $\mathbf{1 6 , 6 7}$ \\
\hline
\end{tabular}

Abreviações: CHC- carcinoma hepatocelular; VHC- vírus da hepatite C; OR- odds ratio; ICintervalo de confiança; MTHFR- metilenotetrahidrofolato redutase; VEGF- fator de crescimento endotelial vascular 


\subsection{Análise da frequência alélica dos genes $M T H F R$ e $V E G F$ nas populações de Recife, Europeia e Africana}

A Tabela 8 compila as frequências alélicas da população obtida nesse estudo de indivíduos de banco de sangue e das populações do 1000 genomes Europeia (EUR) e Africa (AFR) para critério de comparação.

Tabela 8 - Frequência alélica dos genes MTHFR e VEGF nas populações de Recife (REC) estudada, Europeia (EUR) e Africana (AFR)

\begin{tabular}{cccccccc}
\hline Gene & SNP & Cromossomo & Troca & $\begin{array}{c}\text { Alelo } \\
\text { polimórfico }\end{array}$ & $\begin{array}{c}\text { Frequência } \\
\text { REC } \\
\text { (MAF)* }\end{array}$ & $\begin{array}{c}\text { Frequência } \\
\text { EUR(MAF) } \\
* *\end{array}$ & $\begin{array}{c}\text { Frequência } \\
\text { AFR(MAF) } \\
* *\end{array}$ \\
\hline MTHFR & rs1801131 & $1 \mathrm{p} 36.22$ & A1298C & $\mathrm{C}$ & 0,23 & 0,31 & 0,15 \\
MTHFR & rs1801133 & $1 \mathrm{p} 36.22$ & C677T & $\mathrm{T}$ & 0,31 & 0,36 & 0,09 \\
VEGF & rs2010963 & $6 \mathrm{p} 21.1$ & G634C & $\mathrm{C}$ & 0,39 & 0,31 & 0,32 \\
VEGF & rs3025039 & $6 \mathrm{p} 21.1$ & $\mathrm{C} 936 \mathrm{~T}$ & $\mathrm{~T}$ & 0,14 & 0,12 & 0,08 \\
VEGF & rs833061 & $6 \mathrm{p} 21.1$ & $\mathrm{~T} 460 \mathrm{C}$ & $\mathrm{C}$ & 0,37 & 0,50 & 0,32 \\
\hline
\end{tabular}

** De acordo com 1000 genomes

* Indivíduos do estudo ....

Abreviações: MTHFR- metilenotetrahidrofolato redutase; VEGF - fator de crescimento endotelial vascular; REC- Recife; EUR- Europeia; AFR- Africana; SNP - single nucleotide polimorphisms. MAF- Minor allele frequency (frequência do alelo menor) 


\subsection{Análise de sobrevida dos pacientes com CHC e VHC, estratificados pelos genótipos dos genes MTHFR (rs1801131), MTHFR (rs1801133) e VEGF (rs2010963)}

$\mathrm{Na}$ Análise de sobrevida foram avaliados 92 pacientes com $\mathrm{CHC}$ e VHC, estratificados pelos genótipos dos genes MTHFR (rs1801131), MTHFR (rs1801133) e VEGF (rs2010963), genes estes, que demostraram associação estatisticamente significativa, com relação a forma de apresentação do tumor, se uninodular ou multinodular.

$\mathrm{Na}$ análise do gene MTHFR (rs180133), em que o alelo T confere risco do desenvolvimento da forma multinodular, não foi observada relação estatisticamente significativa ( $\mathrm{p}=0,968)$ (Figura 11). No gene MTHFR (rs1801131), em que o alelo C confere proteção para a forma multinodular, também não foi observada relação estatisticamente significativa ( $\mathrm{p}=0,774$ ) (Figura 12). E no gene VEGF (2010963), onde o alelo $\mathrm{C}$ confere proteção para a forma multinodular, não foi observada relação estatisticamente significativa $(\mathrm{p}=0,882)$ (Figura 13$)$, com relação a análise de sobrevida. 


\section{MTHFR (rs1801133)}

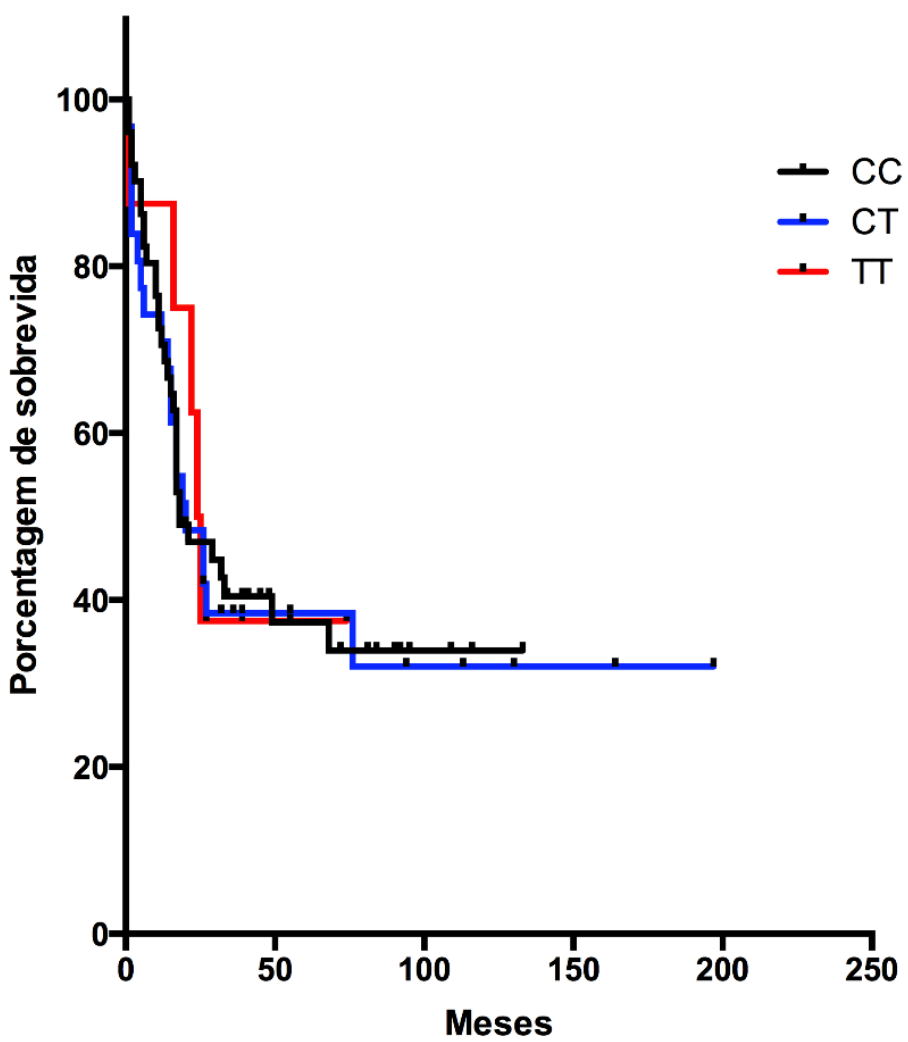

Figura 11 - Análise de sobrevida de 92 pacientes com $\mathrm{CHC}$ infectados pelo vírus da hepatite $\mathrm{C}$ estratificados pelos genótipos do gene MTHFR (rs181133), o teste de Logrank (Mantel-cox) foi realizado, contudo não foi observada uma relação estatisticamente significativa $\mathrm{p}=0,968$ 
MTHFR (rs1801131)

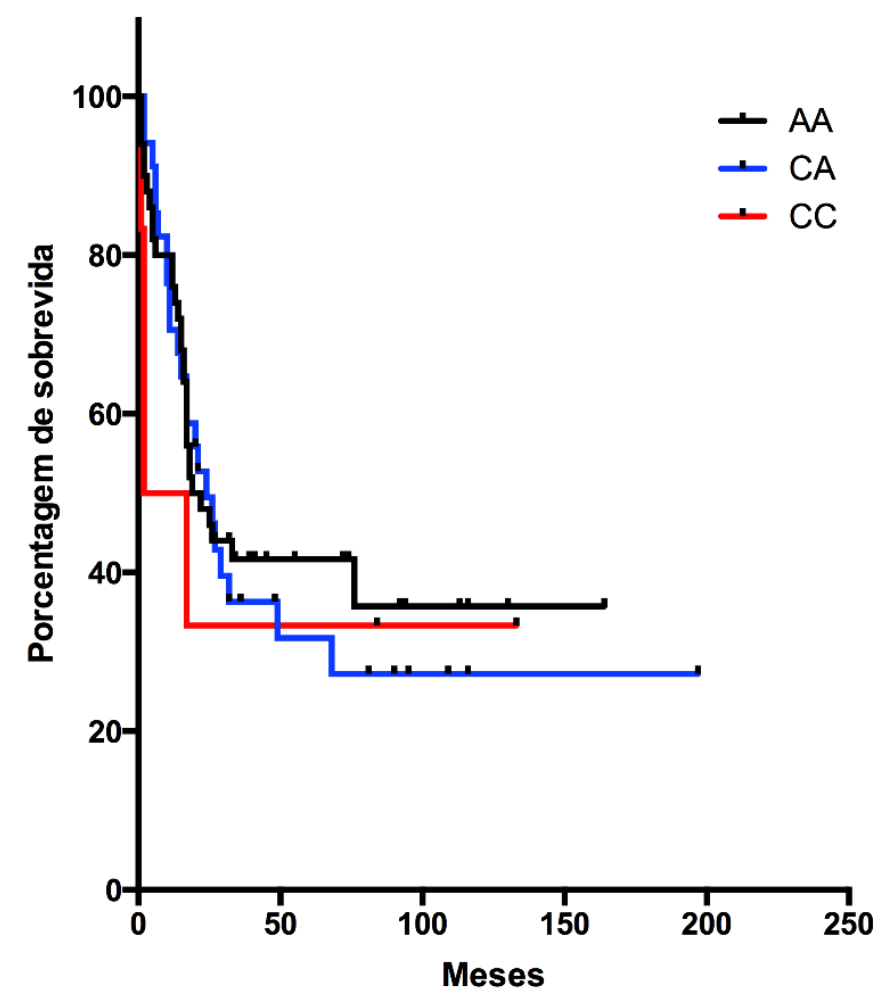

Figura 12 - Análise de sobrevida de 92 pacientes com CHC infectados pelo vírus da hepatite C estratificados pelos genótipos do gene MTHFR (rs181131), o teste de Logrank (Mantel-cox) foi realizado, contudo não foi observada uma relação estatisticamente significativa $\mathrm{p}=0,774$ 
VEGF (rs2010963)

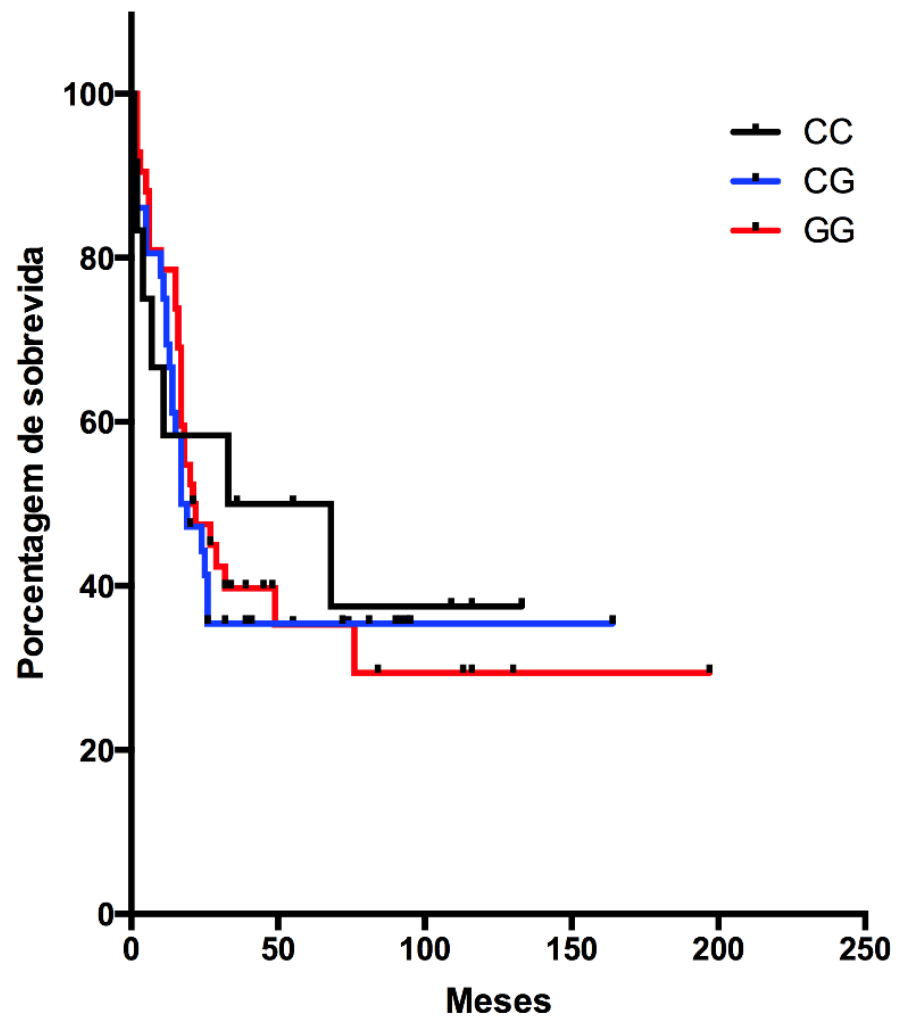

Figura 13 - Análise de sobrevida de 92 pacientes com $\mathrm{CHC}$ infectados pelo vírus da hepatite $\mathrm{C}$ estratificados pelos genótipos do gene VEGF (rs2010963), o teste de Logrank (Mantel-cox) foi realizado, contudo não foi observada uma relação estatisticamente significativa $p=0,882$ 
6 Discussão 


\section{DISCUSSÃO}

O presente estudo teve como interesse, estimar a frequência dos polimorfismos do gene do fator de crescimento endotelial vascular (VEGF) rs2010963, rs3025039, rs833061 e da metilenotetrahidrofolato redutase (MTHFR) rs1801131 e rs 1801133 em pacientes com carcinoma hepatocelular infectados com o vírus da hepatite $\mathrm{C}$ na população atendida em centros de referência em hepatologia na cidade do Recife, e avaliar a presença de associação entre estes polimorfismos e características clínicas, laboratoriais e do tumor, utilizando ainda, nas análises, as classificações de Child-Pugh, BCLC (Barcelona Clinic Liver Cancer) e sobrevida dos pacientes.

Neste estudo, todos os pacientes que foram avaliados, eram cirróticos, e o diagnóstico de CHC foi dado por método de imagem, através de algoritmo validado em 2005 que utiliza como critério radiológico, a presença de realce intenso da lesão na fase arterial do contraste e lavagem do contraste (washout) nas fases venosas tardias ${ }^{(150)}$, exceto um paciente que foi transplantado pela disfunção hepática, e o diagnóstico de CHC foi dado como achado do explante. Dos 119 pacientes estudados, 70 (59\%) foram homens, com idade média de 62,3 anos, dados condizentes com o estudo epidemiológico de Carrilho F.J. et al. (2010) que avaliou 1.405 pacientes de todas as regiões do Brasil ${ }^{(8)}$. A variável laboratorial alfa 1 fetoproteina, também apresentou um aumento estatisticamente significativo, no seu valor médio, de acordo com o aumento na graduação de estadiamento do BCLC $(\mathrm{p}=0,002)$. 
A AFP é uma glicoproteína sérica de cadeia simples, detectada pela primeira vez em 1963. Possui um peso molecular de $70 \mathrm{kDa}$ e é produzida principalmente no hepatócito fetal, nas células do trato gastrointestinal fetal e no saco vitelino. Foi inicialmente descrita como específica para o $\mathrm{CHC}$ e carcinoma de células embrionárias. Ela tem meia vida de aproximadamente 4 a 5 dias e sua função fisiológica é desconhecida ${ }^{(69)}$. Em indivíduos saudáveis, a síntese de AFP para no nascimento ${ }^{(70)}$. Liu C et al. (2013), em estudo de uma coorte chinesa retrospectiva, observaram que os altos níveis de alfa 1 fetoproteína, estavam correlacionados com o tamanho maior do tumor, invasão vascular e a baixa diferenciação do tumor ${ }^{(155)}$. Corroborando com nosso achado de AFP mais alta nos estágios mais avançados do BCLC, onde gradualmente vai ocorrendo aumento do tumor, podendo ocorrer aumento do número de nódulos e invasão vascular, bem como doença extra-hepática.

A Angiogênese é um processo fundamental que envolve a fisiologia normal dos órgãos, o desenvolvimento de tecidos de reparação e uma variedade de processos patológicos ${ }^{(99)}$. O VEGF pode estimular diretamente o crescimento de novos vasos sanguíneos ${ }^{(156)}$ e tem um importante papel na angiogênese do $\mathrm{CHC}^{(120)}$. O estudo de Yao (2005), sugere que o nível sérico do VEGF se correlaciona com o estágio do tumor e o comportamento mais agressivo do $\mathrm{CHC}{ }^{(157)}$. Alterações nos níveis plasmáticos do VEGF podem estar relacionados com a presença de polimorfismos no gene do $V E G F$, alguns estudos correlacionam polimorfismos no $V E G F$ e o aparecimento de $\mathrm{CHC}^{(115,158)}$.

Neste estudo, ao fazer as análises de associação genética com a classificação BCLC, não foi encontrado associação estatisticamente significativa entre os grupos BCLC (B/C) e (A). O Estudo de Baitello et al. (2016) avaliou o polimorfismo no 
gene do VEGF (C936T- rs3025039) em 102 pacientes com diagnóstico de CHC, da população de São Paulo, e correlacionou com a classificação de BCLC, mas também não encontrou associação ${ }^{(159)}$. Wu et al. (2013) mostraram uma associação do CHC em pacientes com VHB, com o polimorfismo no gene do VEGF (rs833061), mas não fez a correlação com o BCLC ${ }^{(115)}$. Contudo, Kong et al. (2007) avaliaram 416 pacientes coreanos, com diagnóstico de $\mathrm{CHC}$ de diferentes etiologias e analisou 19 polimorfismos no gene do VEGF. Na avaliação do gene VEGF (rs2010963), o genótipo GG esteve associado com o aumento do tamanho do tumor e ainda com estágio mais avançado do BCLC ( $\mathrm{p}=0,025)$, porém não encontrou associação com o número de nódulos ${ }^{(116)}$.

O presente estudo observou que os genótipos GG/GC (rs2010963) do gene VEGF apresentou significância estatística tanto na análise univariada assim como na multivariada como fator de risco para o desenvolvimento do $\mathrm{CHC}$ na forma multinodular. De fato, esse SNP (rs2010963) está localizado na região não traduzida 5'(5'-UTR) regulatória do gene VEGF $(-634){ }^{(116)}$, já é demostrado que essa variante é capaz de afetar o padrão de expressão genica e consequentemente alterar a síntese da proteína ativa do VEGF. O polimorfismo nessa região (genótipo CC) tem sido associado com diminuição da expressão do gene VEGF, e dessa forma, os genótipos GG/GC estariam associados com uma maior expressão do gene e consequentemente aumento da angiogênese levando a uma tumorogênese mais acentuada repercutindo em formas multinodulares ${ }^{(160)}$. Park et al. (2000) observaram que os níveis de VEGF aumentavam progressivamente a medida que os nódulos evoluíam de displasia de baixo grau, displasia de alto grau e CHC precoce ${ }^{(120)}$. O estudo de Deli e cols. (2005) relatou uma expressão VEGF positiva, usando imunohistoquímica, em 72 dos 105 
pacientes com CHC $(68,6 \%)^{(122)}$. A expressão do VEGF no tumor com invasão venosa microscópica está significativamente maior do que nos $\mathrm{CHC}$ sem invasão venosa microscópica ${ }^{(123)}$. Outros estudos, embora com um número pequeno de pacientes, têm demostrado um a associação do genótipo GG (rs2010963) com neoplasia de tumores sólidos como, câncer coloretal $^{(161)}$ e osteossarcoma ${ }^{(162)}$,

A relação entre o polimorfismo no gene $M T H F R$ (rs 1801133) e o CHC vem sendo estudada, mas os resultados são controversos ${ }^{(146,147)}$. Jin et al. (2009) conduziram uma meta análise que evidenciou que o polimorfismo no gene $M T H F R$ (rs1801133), aumenta o risco de $\mathrm{CHC}$ especialmente nos pacientes europeus com doença hepática crônica. Nesta avaliação dez estudos mostraram que o genótipo TT aumenta o risco de CHC quando comparado ao genótipo CT. Porém conclui-se que esta associação necessita de mais estudos em outras etnias ${ }^{(148)}$. O estudo de Kwak et al. (2008), realizado em população coreana, não mostrou associação entre os polimorfismos nos genes MTHFR (rs1801133) e MTHFR (rs1801131) e o risco de $\mathrm{CHC}^{(163)}$

Analisamos os SNPs do gene MTHFR (rs1881131 e rs1801133) nos pacientes com CHC e VHC com relação a todas as variáveis clínicas, porém só encontramos resultado estatisticamente significativo, com relação à forma de apresentação do tumor, se uninodular ou multinodular no modelo univariado sendo o genótipo AA do rs1801131 e os CT/TT do rs1801133 relacionados com o risco para forma multinodular. Estudos funcionais sobre variantes do gene MTHFR demostraram que a variante rs1801133-TT tem sido relacionada com a diminuição da atividade da enzima responsável pela reparação do DNA e consequentemente do surgimento do CHC (146, 147, 163-165), adicionalmente em uma meta-analise, foi observado que o 
genótipo CC do rs1881131 está associado como fator de proteção em pacientes com hepatocarcinoma ${ }^{(166)}$ e em outras neoplasias ${ }^{(167)}$.

O estudo de Kuo et al. (2014), na população de Taiwan, não encontrou diferença estatística quando avaliou o gene $M T H F R$ (rs1801133) e sua relação com o número de nódulo ${ }^{(168)}$. Os resultados divergentes encontrados nas diferentes populações sugerem que os SNPs sofrem interferência de fatores ambientais e da composição étnica da população, demonstrado nos resultados dos estudos em diferentes populações. Neste estudo foi demostrado uma diferença entre as SNPs estudadas em relação ao MAF encontrado em população europeia e africana, esse fato sugere um componente genético heterogêneo importante que pode influenciar em fenótipos clínicos específicos da nossa população.

Na análise de sobrevida, o estudo de Kong et al. (2007) avaliou a relação do polimorfismo do gene VEGF (rs2010963), em 416 pacientes coreanos, e evidenciou um aumento da sobrevida associada ao genótipo $\mathrm{CC}(\mathrm{p}=0,023){ }^{(116)}$. Quando da análise de sobrevida, foi utilizado dados de 92 pacientes com CHC e VHC, estratificados pelos genótipos dos genes MTHFR (rs1801131), MTHFR (rs1801133) e VEGF (rs2010963). Nesta nossa casuística, não foi observado relação estatisticamente significante. Provavelmente o tamanho amostral pequeno limitou o poder desta análise.

Este estudo foi o primeiro a analisar características do tumor em pacientes com HCC infectados com HCV associando polimorfismos dos genes MTHFR e VEGF em uma população etnicamente miscigenada revelando importantes achados sobre a influência desses polimorfismos na forma de apresentação dos tumores. Contudo, mais estudos são necessários para confirmar essa hipótese em outras 
populações com outras etiologias e com estratificação para a apresentação do tumor, além de estudos funcionais do impacto dessas variantes na produção da molécula ativa. Portanto, esse tipo de abordagem poderá trazer avanços na conduta clínica dos pacientes com $\mathrm{CHC}$ infectados com $\mathrm{VHC}$ e consequentemente irá impactar no prognostico e medidas terapêuticas. 


\section{Conclusões}




\section{CONCLUSÕES}

1. Este estudo analisou a relação dos genes MTHFR e VEGF nos pacientes com CHC e VHC com relação a todas as variáveis clínicas, e encontramos que em ambos genes, MTHFR (rs1801131) e VEGF (rs2010963) os alelos C conferem proteção para o desenvolvimento do $\mathrm{CHC}$ na sua forma multinodular, enquanto que no gene MTHFR (rs1801133) o alelo T confere risco para o desenvolvimento de CHC na forma multinodular.

2. Ao fazer análise de regressão logística, apenas o alelo $\mathrm{C}$ da $V E G F$ (rs2010963) é fator de proteção independente para o desenvolvimento da forma multinodular do carcinoma hepatocelular.

3. Não foi evidenciada associação dos genes MTHFR (rs1801131), MTHFR (rs1801133) e VEGF (rs2010963) na análise de sobrevida na população estudada. 


\section{Anexos}


ANEXO A- Aprovação do Comitê de Ética em Pesquisa.

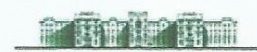 \\ MEDICINA \\ TSP \\ COMITÊ DE ÉTICA EM PESQUISA
}

\title{
APROVAÇÃO
}

O Comitê de Ética em Pesquisa da Faculdade de Medicina da Universidade de São Paulo, em sessão de 05/11/2014, APROVOU o Protocolo de Pesquisa n 349/14 intitulado: "AVALIAÇÃO DOS POLIMORFISMOS NO GENE DA CICLOOXIGENASE 2 (COX-2), NO GENE DO FATOR DE CRESCIMENTO ENDOTELIAL VASCULAR (VEGF) E DA METILENOTETRAHIDROFOLATO REDUTASE (MTHFR) EM PACIENTES COM CARCINOMA HEPATOCELULAR E VIRUS DA HEPATITE $C \%$ apresentado pelo Departamento de GASTROENTEROLOGIA.

Cabe ao pesquisador elaborar e apresentar ao CEPFMUSP, os relatórios parciais e final sobre a pesquisa (Resolução do Consellho Nacional de Saúde $n^{\circ} 466 / 12$ ).

Pesquisador (a) Responsável: Flair José Carrillho

Pesquisador (a) Executante: Sylene Coutinho Rampche de Carvalho

CEP-FMUSP, 05 de Novembro de 2014.

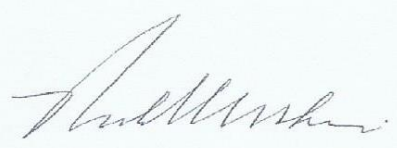

Prof. Dr. Paulo Eurípedes Marchiori Vice-Coordenador Comitê de Ética em Pesquisa

Comitê de Ética em Pesquisa da Faculdade de Medicina e-mail: cep.fm@usp.br 
ANEXO B- Termo de consentimento livre e esclarecido.

HOSPITAL UNIVERSITÁRIO OSWALDO CRUZ

DA FACULDADE DE MEDICINA DA UNIVERSIDADE DE PERNAMBUCO

TERMO DE CONSENTIMENTO LIVRE E ESCLARECIDO

\section{I- DADOS DE IDENTIFICAÇÃO DO SUJEITO DA PESQUISA OU RESPONSÁVEL LEGAL}

1- Nome do paciente.

Documento de Identidade $\mathrm{N}^{\circ}$ Sexo:

Data de Nascimento: ................

Endereço:

Bairro:. Cidade.

CEP. Telefone(

2- Responsável legal:

Natureza (grau de parentesco, tutor, curador etc).

Documento de Identidade:

Sexo

Data de Nascimento:

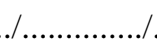

Endereço:

Bairro: Cidade.

CEP. Telefone(

\section{II - DADOS SOBRE A PESQUISA CIENTÍFICA}

1. TÍTULO DO PROTOCOLO DE PESQUISA: Avaliação dos polimorfismos A1195G, G765C, T8473C do gene da ciclooxigenase 2 (Cox-2), polimorfismos C2578A, G634C, C460T, C936T do gene do Fator de crescimento endotelial vascular (VEGF) e polimorfismos C677T e C1298A da Metilenotetrahidrofolato redutase (MTHFR) em pacientes com Carcinoma hepatocelular e vírus da hepatite C

2. PESQUISADORA: Sylene Coutinho Rampche de Carvalho

CARGO/FUNÇÃO: Médica INSCRIÇÃO CONSELHO REGIONAL Nº 11715

UNIDADE DO HUOC/UPE: AMBULATÓRIO HEPATOLOGIA

3. AVALIAÇÃO DO RISCO DA PESQUISA:

$$
\text { RISCO MÍNIMO }
$$

(Probabilidade de que o indivíduo sofra algum dano como consequência imediata ou tardia do estudo) 


\section{III - REGISTRO DAS EXPLICAÇÕES DO PESQUISADOR AO PACIENTE OU SEU REPRESENTANTE LEGAL SOBRE A PESQUISA CONSIGNADO:}

\section{Justificativa e objetivos da pesquisa}

O câncer resulta da combinação de alterações genéticas e elementos externos.

O VHC, é na nossa população, uma importante etiologia para a cirrose hepática culminando com o CHC. O mecanismo de carcinogênese no $\mathrm{CHC}$, como em outros tipos de câncer permanece ainda não muito claro. Embora o CHC ocorra em fígados que são afetados pela doença de base como cirrose pela hepatite $\mathrm{C}$, acredita-se que alterações genéticas sejam a base desta patologia. Alguns estudos vem sendo conduzidos para investigar a associação entre polimorfismos genéticos e o risco de CHC, mas os resultados são controversos.

Convidamos o(a) Senhor(a) a participar de uma pesquisa que tem por objetivo avaliar os polimorfismos A1195G, G765C, T8473C do gene da ciclooxigenase 2 (Cox-2), polimorfismos C2578A, G634C, C460T, C936T do gene do Fator de crescimento endotelial vascular (VEGF) e polimorfismos C677T e C1298A da Metilenotetrahidrofolato redutase (MTHFR) em pacientes com Carcinoma hepatocelular e vírus da hepatite C. Com essa avaliação será possível identificar fator de risco genético para o desenvolvimento de câncer gástrico em pacientes portadores de hepatite C. Este estudo será conduzido pela pesquisadora executante Sylene Coutinho Rampche de Carvalho, no Hospital Universitário Osvaldo Cruz de Pernambuco, localizado na Rua Arnóbio Marques 310- Santo Amaro- Recife- PE - CEP: 50100-130 Campus Universitário- Tel 81-34230501.

Solicitamos que leia cuidadosamente este termo de consentimento e faça qualquer pergunta para esclarecer todas as dúvidas antes de concordar em participar deste estudo.

\section{2- Procedimentos que serão utilizados e propósitos, incluindo a identificação dos procedimentos} que são experimentais:

A pesquisa consistirá num estudo completo do seu fígado abrangendo perguntas gerais, perguntas relacionadas à hábitos alimentares, breve exame físico, colheita de sangue para exames laboratoriais. Também serão realizadas medidas denominadas antropométricas que consistem em peso, altura, circunferência de abdome.

O sangue coletado será enviado para o laboratório de pesquisa no setor de biologia molecular na Faculdade de Medicina da Universidade de São Paulo.

\section{3- Desconforto e riscos esperados:}

A entrevista e o exame físico deverão ter uma duração média de 15-20 minutos, os desconfortos da colheita de sangue serão os mesmos de qualquer exame laboratorial, incluindo desconforto no local da punção. A avaliação nutricional com determinação de medidas antropométricas também não acarreta desconfortos.

\section{4- Benefícios que poderão ser obtidos:}

As alterações diagnosticadas durante o estudo serão documentadas e esta informação poderá trazer benefícios à sua pessoa sob a forma de orientação ambulatorial mais eficaz. Não há garantia dos benefícios que possam resultar da sua participação neste estudo, exceto o acompanhamento ambulatorial. Por outro lado, o conhecimento adquirido neste estudo poderá beneficiar outras pessoas.

\section{5-Procedimentos alternativos que possam ser vantajoso para o indivíduo:}

$\mathrm{O}(\mathrm{A}) \operatorname{Sr}(\mathrm{a})$ tem a alternativa de não participar desta pesquisa caso não o deseje. 


\section{IV - ESCLARECIMENTOS DADOS PELO ORIENTADOR SOBRE GARANTIAS DO SUJEITO DA PESQUISA CONSIGNADO:}

1. Acesso, a qualquer tempo, às informações sobre procedimentos, riscos e benefícios relacionados à pesquisa, inclusive para dirimir eventuais dúvidas. As informações do questionário e de sua avaliação estarão à sua disposição sempre que desejar, e o(a) $\operatorname{Sr}(a)$ tem toda liberdade de fazer perguntas caso tenha alguma dúvida.

2. Liberdade de retirar seu consentimento a qualquer momento e de deixar de participar do estudo, sem que isto traga prejuízo à continuidade da assistência. $\mathrm{O}(\mathrm{A}) \mathrm{Sr}(\mathrm{a})$ poderá se retirar da pesquisa a qualquer momento, sem precisar se justificar, e continuar a gozar de todos os direitos como paciente.

3. Salvaguarda da confidencialidade, sigilo e privacidade: As informações aqui reunidas serão sigilosas e somente serão divulgadas para a equipe de saúde que cuida do seu caso, a fim de que seu atendimento seja o melhor possível, ou para estudos e publicações científicas, sendo que neste caso seu nome e sua identidade não serão conhecidos.

4. A disponibilidade de assistência no ambulatório de Hepatologia, por eventuais danos à saúde.

5. Viabilidade de indenização por eventuais danos à saúde decorrentes da pesquisa: $\mathrm{O}$ acesso ao projeto é de forma voluntária e não está prevista nenhuma idenização. O paciente expressa ainda sua concordância e vontade em se submeter aos exames referidos, assumindo a responsabilidade e risco pelos eventuais efeitos indesejáveis que venham ocorrer em decorrência do mesmo.

\section{INFORMAÇÓES DE NOMES, ENDEREÇOS E TELEFONES DOS RESPONSÁVEIS PELO ACOMPANHAMENTO DA PESQUISA, PARA CONTATO EM CASO DE INTERCORRÊNCIAS CLÍNICAS E REAÇÕES ADVERSAS.}

Dra Sylene Coutinho Rampche de Carvalho Fone: 34654959

Comitê de ética do Hospital Universitário Osvaldo Cruz Fone: 21011536

\section{CONSENTIMENTO PÓS-ESCLARECIDO}

Declaro que, após convenientemente esclarecido pelo pesquisador e ter entendido o que me foi explicado, consinto em participar do presente Protocolo de Pesquisa, bem como autorizo a saída de minha amostra de sangue coletada para processamento da pesquisa na Faculdade de Medicina da Universidade de São Paulo.

Recife,

assinatura do sujeito da pesquisa ou responsável legal

assinatura da testemunha

assinatura do pesquisador (carimbo ou nome legível) 


\section{Referências}




\section{REFERÊNCIAS}

1. Shiffman ML. Natural history and risk factors for progression of hepatitis $\mathrm{C}$ virus disease and development of hepatocellular cancer before liver transplantation. Liver Transpl. 2003;9(11):S14-20.

2. Sangiovanni A, Prati GM, Fasani P, Ronchi G, Romeo R, Manini M, Del Ninno E, Morabito A, Colombo M. The natural history of compensated cirrhosis due to hepatitis C virus: A 17-year cohort study of 214 patients. Hepatology. 2006;43(6):1303-10.

3. Rehermann B, Nascimbeni M. Immunology of hepatitis B virus and hepatitis C virus infection. Nat Rev Immunol. 2005;5(3):215-29.

4. WHO. Globocan 2012. Disponível em:

globocan.iarc.fr/Pages/fact_sheets_population.aspx2012 [cited 2018 09/08].

5. Parkin DM, Bray F, Ferlay J, Pisani P. Global cancer statistics. Cancer J Clin. 2005;55:74-108.

6. Ioannou GN, Splan MF, Weiss NS, McDonald GB, Beretta L, Lee SP. Incidence and predictors of hepatocellular carcinoma in patients with cirrhosis. Clin Gastroenterol Hepatol. 2007;5(8):938-45, 45 e1-4.

7. Kikuchi L, Chagas AL, Alencar RS, Paranagua-Vezozzo DC, Carrilho FJ. Clinical and epidemiological aspects of hepatocellular carcinoma in Brazil. Antivir Ther. 2013;18(3 Pt B):445-9.

8. Carrilho FJ, Kikuchi L, Branco F, Goncalves CS, Mattos AA; Brazilian HCC Study Group. Clinical and epidemiological aspects of hepatocellular carcinoma in Brazil. Clinics (São Paulo). 2010;65(12):1285-90. 
9. Berlau J, Glei M, Pool-Zobel BL. Colon cancer risk factors from nutrition. Anal Bioanal Chem. 2004;378(3):737-43.

10. Patil VM, Gupta SP, Samanta S, Masand N. Current perspective of HCV NS5B inhibitors: a review. Curr Med Chem. 2011;18(36):5564-97.

11. Choo QL, Kuo G, Weiner AJ, Overby LR, Bradley DW, Houghton M. Isolation of a cDNA clone derived from a blood-borne non-A, non-B viral hepatitis genome. Science. 1989;244:359-62.

12. Hijikata M, Kato N, Ootsuyama Y, Nakagawa M., Shimotohno k. Gene mapping of the putative structural region of the hepatitis $\mathrm{C}$ virus genome by in vitro processing analysis. Biochemistry. 1991;88:5547-51.

13. Kaito M, Watanabe S, Tsukiyama-Kohara K, Yamaguchi K, Kobayashi Y, Konishi M, Yokoi M, Ishida S, Suzuki S, Kohara M. Hepatitis C virus particle detected by immunoelectronmicroscopic study. J Gen Virol. 1994;75(7):1755-60.

14. Penin F, Dubuisson J, Rey FA, Moradpour D, Pawlotsky J. Structural biology of hepatitis C virus. Hepatology. 2004;39(1):5-19.

15. Jing G, Lee J, Lee K. Chemical genetics-based development of small molecules targeting hepatitis C virus. Arch Pharm Res. 2017;40(9):1021-36.

16. Bartenschlager R, Lohmann V. Novel cell culture systems for the hepatitis C virus. Antiviral Res. 2001;52(1):1-17.

17. Barone AA. Hepatite por VHC - Aspectos virológicos e suas implicações práticas. I Consenso da Sociedade Brasileira de Infectologia para o Manuseio e Terapia da hepatite C. São Paulo: Sociedade Brasileira de Infectologia; 2008. p.20-3.

18. Smith DB, Bukh J, Kuiken C, Muerhoff AS, Rice CM, Stapleton JT, Simmonds P. Expanded classification of hepatitis C virus into 7 genotypes and 67 
subtypes: updated criteria and genotype assignment web resource. Hepatology. 2014;59:318-27.

19. Simmonds P, Bukh J, Combet C, Del’eage G, Enomoto N, Feinstone S, Halfon P, Inchausp’e G, Kuiken C, Maertens G, Mizokami M, Murphy DG, Okamoto H, Pawlotsky J, Penin F, Sablon E, Shin-I T, Stuyver L J, Thiel H, Viazov S, Weiner AJ, Widell A. Consensus Proposals for a Unified System of Nomenclature of Hepatitis C Virus Genotypes. Hepatology. 2005;42(4):962-73.

20. Pereira LM, Spinelli V, Ximenes RA, Cavalcanti MS, Melo R, Jucá N, Mizokami M, McFarlane IG. Chronic hepatitis C infection: influence of the viral load, genotypes, and GBV-C/HGV coinfection on the severity of the disease in a Brazilian population. J Med Virol. 2002;67(1):27-32.

21. Alter HJ, Conry-Cantinela C, Melpolder J, De Tan, Van Raden M, Herion D, Lau D, Hoofnagle JH. Hepatitis C in asymptomatic blood donors. Hepatology. 1997;26(3 (suppl 1)):29-33.

22. Seeff LB. The history of the "natural history" of hepatitis C (1968-2009). Liver Int. 2009;29(Suppl 1):89-99.

23. Chevaliez S, Pawlotsky JM. Diagnosis and management of chronic viral hepatitis: antigens, antibodies and viral genomes. Best Pract Res Clin Gastroenterol. 2008;22(6):1031-48.

24. Friedman SL. Mechanisms of hepatic fibrogenesis. Gastroenterology. 2008;134(6):1655-69.

25. Marcellin P. Hepatitis B and hepatitis C in 2009. Liver Int. 2009;29(Suppl $1): 1-8$.

26. Di Bisceglie AM. Natural history of hepatitis C: its impact on clinical management. Hepatology. 2000;31(4):1014-8. 
27. Missiha SB, Ostrowskim M, Heathcote EJ. Disease progression in chronic hepatitis C: modifiable and nonmodifiable factors. Gastroenterology. 2008;134(6):1699-714.

28. Harris DR, Gonin R, Alter HL, Wright EC, Buskell ZJ, Hollinger FB, Seeff LB; National Heart, Lung and Blood Institute Study Group. The relationship of acute transfusion-associated hepatits to the development of cirrhosis in the presence of alcohol abuse. Ann Intern Med. 2001;134(2):120-4.

29. Seef LB. Natural history of chronic hepatitis C. Hepatology. 2002;36(5):S35S46.

30. Wiley TE, Brown J, Chan J. Hepatitis C infection in African Americans:Its natural history and histological progression. Am J Gastroenterol. 2002;97(3):700-6.

31. Pessione F, Ramond MJ, Njapoum C, Duchatelle V, Degott C, Erlinger S, Rueff B, Valla DC, Degos F. Cigarette smoking and hepatic lesions in patients with chronic hepatitis C. Hepatology. 2001;34(1):121-5.

32. El-Zayadi AR. Heavy smoking and liver. World J Gastroenterol. 2006;12(38):6098-101.

33. Scognamiglio P, Galati V, Navarra A, Longo MA, Aloisi MS, Antonini MG, Puoti M, Almasio PL, Ippolito G, Girardi E. Impact of hepatitis C virus infection on lifestyle. World J Gastroenterol. 2007;13(19):2722-6.

34. Chu C, Lee S. Hepatitis B virus/hepatitis C virus coinfection:epidemiology, clinical features, viral interactions and treatment. J Gastroenterol Hepatol. 2008;23(4):512-20.

35. Cheruvu S, Marks K, Talal AH. Understanding the pathogenesis and management of hepatitis B/HIV and hepatitis B/ hepatitis $\mathrm{C}$ virus coinfection. . Clin Liver Dis. 2007;11(4):917-43. 
36. Roe B, Hall WW. Cellular and molecular interactions in coinfection with hepatitis C vírus and human immunodeficiency vírus. Expert Rev Mol Med. 2008;10(e30):1-19.

37. Veldt BJ, Chen W, Heathcote EJ, Wedemeyer H, Reichen J, Hofmann WP, Knegt RJ, Zeuzem S, Manns MP, Hansen BE, Schalm SW, Janssen HLA. Increased risk of hepatocellular carcinoma among patients with hepatitis c cirrhosis and diabetes mellitus. Hepatology. 2008;47(6):1856- 62.

38. Chen CI, Yang HI, Yang WS, Liu CJ, Chen PJ, You SL, Wang LY, Sun CA, Lu SN, Chen DS, Chen CJ. Metabolic factors and risk of hepatocellular carcinoma by chronic hepatitis B/C infection. A follow up study in Taiwan. Gastroenterology. 2008;135(1):111-21.

39. Davila JA, Morgam RO, Shaib Y, McGlynn KA, El-Serag HB. Diabetes increases the risk of hepatocellular carcinoma in the United States: a population based case control study. Gut. 2005;54(4):533-9.

40. Yu MC, Yuan JM. Environmental factors and risk for hepatocellular carcinoma. Gastroenterology. 2004;127(5 Suppl 1):S72-8.

41. Santantonio T, Wiegand J, Gerlach JT. Acute hepatitis C: current status and remaining challenges. J Hepatol. 2008;49(4):625-33.

42. Afdhal NH. The natural history of hepatitis C. Semin Liver Dis. 2004;24(Suppl 2):3-8.

43. Thompson CJ, Rogers G, Hewson P, Wright D, Anderson R, Cramp M, Jackson S, Ryder S, Price A, Stein K. Surveillance of cirrhosis for hepatocellular carcinoma: systematic review and economic analysis. Health Technol Assess. 2007;11(34):1-206. 
44. Venook AP, Papandreou C, Furuse J, Guevara LL. The incidence and epidemiology of hepatocellular carcinoma: a global and regional perspective. Oncologist. 2010;15(4):5-13.

45. Akinyemiju T, Abera S, Ahmed M, Alam N, Alemayohu M A, Allen C, AlRaddadi R, Alvis-Guzman N, Amoako Y, Artaman A, Ayele TA, Barac A, Bensenor I, Berhane A, Bhutta Z, Castillo-Rivas J, Chitheer A, Choi JY, Cowie B, Dandona L, Dandona R, Dey S, Dicker D, Phuc H, Ekwueme DU, Zaki MS, Fischer F, Fürst T, Hancock J, Hay SI, Hotez P, Jee SH, Kasaeian A, Khader Y, Khang YH, Kumar A, Kutz M, Larson H, Lopez A, Lunevicius R, Malekzadeh R, McAlinden C, Meier T, Mendoza W, Mokdad A, Moradi-Lakeh M, Nagel G, Nguyen Q, Nguyen G, Ogbo F, Patton G, Pereira DM, Pourmalek F, Qorbani M, Radfar A, Roshandel G, Salomon JA, Sanabria J, Sartorius B, Satpathy M, Sawhney M, Sepanlou S, Shackelford K, Shore H, Sun J, Mengistu DT, Topór-Mądry R, Tran B, Ukwaja, Vlassov V, Vollset SE, Vos T, Wakayo T, Weiderpass E, Werdecker A, Yonemoto N, Younis M, Yu C, Zaidi Z, Zhu L, Murray CJL, Naghavi M, Fitzmaurice C; Global Burden of Disease Liver Cancer Collaboration. The burden of primary liver cancer and underlying etiologies from 1990 to 2015 at the global, regional, and national level results from the Global Burden of Disease Study 2015. JAMA Oncol. 2017;3:1683-91.

46. Kim K, Choi S, Park SM. Association of fasting serum glucose level and type 2 diabetes with hepatocellular carcinoma in man with chronic hepatitis B infection: a large cohort study. Eur J Cancer. 2018;102:103-13.

47. Schlesinger S, Aleksandrova K, Pischon T, Jenab M, Fedirko V, Trepo E, Overvad K, Roswall N, Tjønneland A, Boutron-Ruault MC, Fagherazzi G, Racine A, Kaaks R, Grote VA, Boeing H, Trichopoulou A, Pantzalis M, Kritikou M, Mattiello A, Sieri S, Sacerdote C, Palli D, Tumino R, Peeters PH, Bueno-de-Mesquita HB, Weiderpass E, Quirós JR, Zamora-Ros R, Sánchez MJ, Arriola L, Ardanaz E, Tormo MJ, Nilsson P, Lindkvist B, Sund M, Rolandsson O, Khaw KT, Wareham N, Travis RC, Riboli E, Nöthlings U. Diabetes mellitus, insulin treatment, diabetes duration, and risk of biliary tract cancer and hepatocellular carcinoma in a European cohort. Ann Oncol. 2013;24(9):2449-55. 
48. Regimbeau JM, Colombat M, Mognol P, Durand F, Abdalla E, Degott C, Degos F, Farges O, Belghiti J. Obesity and diabetes as a risk factor for hepatocellular carcinoma liver. Transplantation. 2004;10(2):S69-S73.

49. Ratziu V, Bonyhay L, Di Martino V, Charlotte F, Cavallaro L, SayeghTainturier MH, Giral P, Grimaldi A, Opolon P, Poynard T. Survival, liver failure, and hepatocellular carcinoma in obesity-related cryptogenic cirrhosis. Hepatology. 2002;35(6):1485-93.

50. Dyson J, Jaques B, Chattopadyhay D, Lochan R, Graham J, Das D, Aslam T, Patanwala I, Gaggar S, Cole M, Sumpter K, Stewart S, Rose J, Hudson M, Manas D, Reeves H L. Hepatocellular cancer: the impact of obesity, type 2 diabetes and a multidisciplinary team. J Hepatol. 2014;60:110-7.

51. Marrero JA, Fontana RJ, Fu S, Conjeevaram HS, Su GL, Lok AS. Alcohol, tobacco and obesity are synergistic risk factors for hepatocellular carcinoma. J Hepatol. 2005;42:218-24.

52. Bravi F, Bosetti C, Tavani A, Gallus S, La Vecchia C. Coffee reduces risk for hepatocellular carcinoma: an updated meta-analysis. Clin Gastroenterol Hepatol. 2013;11:1413-21.

53. Bravi F, Tavania A, Bosetti C, Boffetta P, La Vecchia C. Coffee and the risk of hepatocellular carcinoma and chronic liver disease: a systematic review and metaanalysis of prospective studies. Eur J Cancer Prev. 2017;26(5):368-77.

54. Chang MH, You SL, Chen CJ, Liu C J, Lee CM, Lin SM, Chu HC, Wu TC, Yang SS, Kuo HS, Chen DS; Taiwan Hepatoma Study Group Collaborators (24). Decreased incidence of hepatocellular carcinoma in hepatitis B vaccinees: a 20- year follow-up study. J Natl Cancer Inst. 2009;101(19):1348-55.

55. Morgan RL, Baack B, Smith BD, Yartel A, Pitasi M, Falck-Ytter Y. Eradication of hepatitis $\mathrm{C}$ virus infection and the development of hepatocellular 
carcinoma: a meta-analysis of observational studies. Ann Intern Med. 2013;158(5 Pt $1): 329-37$.

56. Forner A, Llovet JM, Bruix J. Hepatocellular carcinoma. Lancet. 2012;379(9822):1245- 55 .

57. Sangiovanni A, del Ninno E, Fasani P, de Fazio C, Ronchi G, Romeo R, Morabito A, Franchis R, Colombo M. Increased survival of cirrhotic patients with a hepatocellular carcinoma detected during surveillance. Gastroenterology. 2004;126(4):1005-14.

58. EASL. EASL Clinical Practice Guideline: Management of hepatocellular carcinoma. J Hepatol. 2018;69(1):182-236.

59. Forner A, Vilana R, Ayuso C, Bianchi L, Soli M, Ayuso JR, Boix L, Sala M, Varela M, Llovet JM, Brú C, Bruix J. Diagnosis of hepatic nodules $20 \mathrm{~mm}$ or smaller in cirhosis: Prospective validation of the noninvasive diagnostic criteria for hepatocellular carcinoma. Hepatology. 2008;47(1):97-104.

60. Roskams T, Kojiro M. Pathology of early hepatocellular carcinoma: conventional and molecular diagnosis. Semin Liver Dis. 2010;30(1):17-25.

61. Torzilli G, Minogawa M, Takayama T, Inau K, Hui AM, Kubota K, Ohtomo K, Makuuchi M. Accurate preoperative evaluation of liver mass lesions without fineneedle biopsy. Hepatology. 1999;30:889-93.

62. Levy I, Greig PD, Gallinger S, Langer B, Sherman M. Resection of hepatocellular carcinoma without preoperative tumor biopsy. Ann Surg. 2001;234(2):206-9.

63. Burrel M, Llovet JM, Ayuso C, Iglesias C, Sala M, Miquel R, Caralt T, Ayuso JR, Solé M, Sanchez M, Brú C, Bruix J; Barcelona Clinic Liver Cancer 
Group. MRI angiography is superior to helical CT for detection of HCC prior to liver transplantation: an explant correlation. Hepatology. 2003;38(4):1034-42.

64. Rimola J, Forner A, Tremosini S, Reig M, Vilana R, Bianchi L, RodríguezLope C, Solé M, Ayuso C, Bruix J. Non-invasive diagnosis of hepatocellular carcinoma $\leq 2 \mathrm{~cm}$ in cirrhosis. Diagnostic accuracy assessing fat, capsule and synal intensity at dynamic MRI. J Hepatol. 2012;56:1317-23.

65. ACR. Liver Imaging Reporting and Data System Version 2018. Disponível em: https://www.acr.org/Clinical-Resources/Reporting-and-Data-Systems/LIRADS/CT-MRI-LI-RADS-v20182018 [cited 2018 09/09].

66. Darnell A, Forner A, Rimola J, Reig M, Criado A G, Ayuso C, Bruix J. Liver imaging reporting and data system with $\mathrm{mr}$ imaging: evaluation in nodules $20 \mathrm{~mm}$ or smaller detected in cirrhosis at screening US. Radiology. 2015;275:698-707.

67. Furlan A, Marim D, Cabassa P, Taibbi A, Brunelli E, Agnello F, Lagalla R, Brancatelli G. Enhancement pattern of small hepatocelular carcinoma (HCC) at contrast-enhanced US (CEUS), MDCT and MRI: Intermodality agreement and comparasion of diagnostic sensitivity between 2005 and 2010 American Association for the study of liver Diseases (AASLD). Eur J Radiol. 2012;81:2099-105.

68. Kim SE, Lee HC, Shim JH, Park HJ, Kim KM, Kim PN, Shin YM, Yu ES, Chung YH, Suh DJ. Noninvasive diagnostic criteria for hepatocellular carcinoma in hepatic masses > 2cm in a hepatitis B virus-endemic area. Liver Int. 2011;31:146876.

69. Mueller SB, Micke O, Herbst H, Schaefer U, Willich N. Alpha-fetoproteinpositive carcinoma of the pancreas: a case report. Anticancer Res. 2005;25(3A):1671-4. 
70. Ishikawa K, Sasaki A, Haraguchi N, Yoshikawa Y, Mori M. A case of an alfa-fetoprotein-producing intrahepatic cholangiocarcinoma suggests probable cancer stem cell origin. Oncologist. 2007;12(3):320-4.

71. EASL. Clinical Practice Guidelines: Management of hepatocellular carcinoma. J Hepatol. 2018;69(1):182-236.

72. Pugh RN, Murray-Lyon IM, Dawson JL, Pietroni MC, Williams R. Transection of the oesophagus for bleeding oesophageal varices. Br J Surg. 1973;60(8):646-9.

73. Kamath PS, Wiesner RH, Malinchoc M, Kremers W, Therneau TM, Kosberg CL, D'Amico G, Dickson ER, Kim WR. A model to predict surverval in patients with end stage liver disease. Hepatology. 2001;33(2):464-70.

74. Sorensen JB, Klee M, Palshof T, Hansen HH. Performance status assessment in cancer patients. An inter-observer variability study. Br J Cancer. 1993;67(4):7735.

75. Verger E, Salamero M, Conill C. Can Karnofsky performance status be transformed to the Eastern Cooperative Oncology Group Scoring Scale and vice versa? . Eur J Cancer. 1992;28A(8-9):1328-30.

76. Llovet JM, Brú C, Bruix J. Prognosis of hepatocellular carcinoma: the BCLC staging classification. Semin Liver Dis. 1999;19(3):329-38.

77. Cabibbo G, Enea M, Attanasio M, Bruix J, Craxı A, Camma C. A metaanalysis of survival rates of untreated patients in randomized clinical trials of hepatocellular carcinoma. Hepatology. 2010;51(4):1274-83.

78. CLIP Investigators . A new prognostic system for hepatocellular carcinoma: a retrospective study of 435 patients: The Cancer of the Liver Italian Program (CLIP) Investigators. Hepatology. 1998;28(3):751-5 
79. Leung TW, Tang AM, Zee B, Lau WY, Lai PB, Leung KL, Lau JT, Yu SC, Johnson PJ. Construction of the Chinese University Prognostic Index for hepatocellular carcinoma and comparasion with the TNM staging system, the Okuda staging system, and the Cancer of the Liver Italian Program staging system: a study based on 926 patients. Cancer. 2002;94(6):1760-9.

80. Yau T, Tang VYF, Yao T-J, Fan S-T, Lo C-M, Poon R TP. Development of Hong Kong Liver Cancer staging system with treatment stratification for patients with hepatocellular carcinoma. Gastroenterology. 2014;146(7):1691-700.

81. Kitai A, Kudo M, Minami Y, Haji S, Osaki Y, Oka H, Seki T, Kasugai H, Sasaki Y, Matsunaga T Validation of a new prognostic staging system for hepatocellular carcinoma: a comparison of the biomarker-combined Japan Integrated Staging Score, the Conventional Japan Integrated Staging Score and the BALAD Score. Oncology. 2008;75(Suppl 1):83-90.

82. Llovet JM, Schwartz M, Mazzaferro V. Resection and liver transplantation for hepatocellular carcinoma. Semin Liver Dis. 2005;25(2):181-200.

83. Ishizawa T, Hasegawa K, Aoki T, Takahashi M, Inoue Y, Sano K, Imamura H, Sugawara Y, Kokudo N, Makuuchi M. Neither multiple tumors nor portal hypertension are surgical contraindications for hepatocellular carcinoma. Gastroenterology. 2008;134(7):1908-16.

84. Hasegawa K, Kokudo N, Makuuchi M, Izumi N, Ichida T, Kudo M, Ku Y, Sakamoto M, Nakashima O, Matsui O, Matsuyama Y. Comparison of resection and ablation for hepatocellular carcinoma: A cohort study based on a Japanese nationwide survey. J Hepatol. 2013;58(4):724-9.

85. Mazzaferro V, Regalia E, Doci R, Andreola S, Pulvirenti A, Bozzetti F, Montalto F, Ammatuna M, Morabito A, Gennari L. Liver transplantation for the treatment os small hepatocellular carcinomas in patients with cirrhosis. N Engl J Med. 1996;334(11):693-9. 
86. Kim WR, Lake JR, Smith JM, Skeans MA, Schladt DP, Edwards EB, Harper AM, Wainright JL, Snyder JJ, Israni AK, Kasiske BL. OPTN/SRTR 2015 Annual Data Report: Liver. Am J Transplant. 2017;17(Suppl 1):174-251.

87. Lencioni R, Crocetti L. Local-regional treatment of hepatocellular carcinoma. Radiology. 2012;262(1):43-58.

88. Lencioni R, Cioni D, Crocetti L, Franchini C, Pina CD, Lera J, Bartolozzi C. Early-stage hepatocellular carcinoma in patients with cirrhosis: long-term results of percutaneous image-guided radiofrequency ablation. Radiology. 2005;234(3):961-7.

89. Shiina S, Teratani T, Obi S, Tateishi R, Fujishima T, Ishikawa T, Koike Y, Yoshida H, Kawabe T, Omata M. A randomizaded controlled trial of radiofrequency ablation with ethanol injection for small hepatocellular carcinoma. Gastroenterology. 2005;129(1):122-30.

90. Shiina S, Tateishi R, Arano T, Uchino K, Enooku K, Nakagawa H, Asaoka Y, Sato T, Masuzaki R, Kondo Y, Goto T, Yoshida H, Omata M, Koike K. Radiofrequency ablation for hepatocellular carcinoma: 10-year outcome and prognostic factors. Am J Gastroenterol. 2012;107(4):569-77.

91. Raoul J, Sangro B, Forner A, Mazzaferro V, Piscaglia F, Bolondi L, Lencioni R. Evolving strategies for the management of intermediate-stage hepatocellular carcinoma: Available evidence and expert opinion on the use of transarterial chemoembolization. Cancer Treat Rev. 2011;37(3):212-20.

92. Lencioni R, de Baere T, Soulen MC, Riling WS, Geschwind J-FH. Lipiodol transarterial chemoembolization for hepatocellular carcinoma: A systematic review of efficacy and safety data. Hepatology. 2016;64(1):106-16.

93. Sangro B, Carpanese I, Cianni R, Golfieri R, Gasparini D, Ezziddin S, Paprottka PM, Fiore F, Van Buskirk M, Bilbao JI, Ettorre GM, Salvatori R, Giampalma E, Geatti O, Wilhelm K, Hoffmann RT, Izzo F, Iñarrairaegui M, Maini 
CL, Urigo C, Cappelli A, Vit A, Ahmadzadehfar H, Jakobs TF, Lastoria S; European Network on Radioembolization with Yttrium-90 Resin Microspheres (ENRY). Survival after ytrium-90 resin microsphere radioembolization of hepatocellular carcinoma across Barcelona clinic liver cancer stages: a European evaluation. Hepatology. 2011;54(3):868-78.

94. Villanueva A, Llovet JM. Therapies for hepatocellular carcinoma. Gastroenterology. 2011;140(5):1410-26.

95. Llovet JM, Ricci S, Mazzaferro V, Hilgard P, Gane E, Blanc J-F, de Oliveira AC, Santoro A, Raoul JL, Forner A, Schwartz M, Porta C, Zeuzem S, Bolondi L, Greten TF, Galle PR, Seitz JF, Borbath I, Häussinger D, Giannaris T, Shan M, Moscovici M, Voliotis D, Bruix J; SHARP Investigators Study Group. Sorafenib in advanced hepatocellular carcinoma. N Engl J Med. 2008;359(4):378-90.

96. Bruix J, Qin S, Merle P, Granico A, Huang YH, Bodoky G, Pracht M, Yokosuka O, Rosmorduc O, Breder V, Gerolami R, Masi G, Ross PJ, Song T, Bronowicki JP, Ollivier-Hourmand I, Kudo M, Cheng AL, Llovet JM, Finn RS, LeBerre MA, Baumhauer A, Meinhardt G, Han G; RESORCE Investigators. Regorafenib for patients with hepatocellular carcinoma who progressed on sorafenib treatment (RESORCE): a randomisided, double-bind, placebo-controlled, phase 3 trial. Lancet. 2017;389(10064):56-66.

97. Kudo M, Finn RS, Qin S, Han K-H, Ikeda K, Piscaglia F, Baron A, Park JW, Han G, Jassem J, Blanc JF, Vogel A, Komov D, Evans TRJ, Lopes C, Ductus C, Guo M, Saito K, Kraljevic S, Tamai T, Ren M, Cheng A-L. Lenvatinib vs sorafenib in first-line treatment of patients with unresectable hepatocellular carcinoma: a randomised phase 3 non-inferiority trial. Lancet. 2018:391(10126):1163-73.

98. Fidler IJ, Yano S, Zhang RD, Fujimaki T, Bucana CD. The seed and soil hypothesis: vascularisation and brain metástases. Lancet Oncol. 2002;3(1):53-7.

99. Folkman J, Shing Y. Angiogenesis. J Biol Chem. 1992;267(16):10931-4. 
100. Senger DR, Galli SJ, Dvorak AM, Perruzzi CA, Harvey VS, Dvorak HF. Tumor cells secrete a vascular permeability fator that promotes accumulation of ascites fluid. Science. 1983;219(4587):983-5.

101. Kaseb AO, Hanbali A, Cotant M, Hassan MM, Wollner I, Philip PA.

Vascular endothelial growth factor in the management of hepatocellular carcinoma: a review of literature. Cancer. 2009;115(21):4895-906.

102. Lee EH, Kao WW, Schwarz RI. Cell density regulates prolyl 4-hydroxylase activity independent of mRNA levels. Matrix Biol. 2001;19(8):779-82.

103. Ferrara N, Gerber HP, Le Couter J. The biology of VEGF and its receptors. Nat Med. 2003;9:669-76.

104. Kroll J, Waltenberger J. Regulation of the endothelial function and angiogenesis by vascular endothelial growth factor-A (VEGF-A). Z Kardiol. 2000;89(3):206-18.

105. Lamszus K, Ulbricht U, Matscheke J, Brockmann MA, Fillbrandt R, Westphal M. Levels of soluble vascular endotelial growth fator (VEGF) receptor 1 in astrocytic tumors and its relation to malignancy, vascularity and VEGF-A. Clin Cancer Res. 2003;9(4):1399-405.

106. Coulon S, Heindryckx F, Geerts A, Steenkiste CV, Colle I, Vlierberghe HV. Angiogenesis in chronic liver disease and its complications. Liver Int. 2011;31(2):146-62.

107. Kim I, Moon SO, Koh KN, Kim H, Uhm CS, Kwak HJ, Kim NG, Koh GY. Molecular cloning, expression, and characterization of angiopoietin-related protein. Angiopoietin-related protein induces endothelial cell sprouting. J Biol Chem. 1999;274(37):26523-8. 
108. Tischer E, Mitchell R, Hartman T, Silva M, GospodarowiczS D, Fiddes J C, Abrahamll JA. The human gene for vascular endothelial growth factor. Multiple protein forms are encoded through alternative exon splicing. J Biol Chem. 1991;266(18):11947-54.

109. Devorak HF, Brown LF, Detmar M, Dvorak AM. Vascular permeability factornascular endothelial growth factor, microvascular hyperpermeability, and angiogenesis. Am J Pathol. 1995;146(5):1029-39.

110. Woolard J, Wang WY, Bevan HS, Qiu Y, Morbidelli L, Jones ROP, Cui TG, Sugiono M, Waine E, Perrin R, Foster R, Bell JD, Shields JD, Whittles CE, Mushens RE, Gillatt DA, Ziche M, Harper SJ, Bates DO. VEGF165b, an inhibitory vascular endothelial growth factor splice variant: mechanism of action, in vivo effect on angiogenesis and endogenous protein expression. Cancer Res. 2004;64(21):7822-35.

111. Ferrara N. Vascular endothelial growth factor: basic science and clinical progress. Endocr Rev. 2004;25(4):581-611.

112. Balasubramanian SP, Cox A, Brown NJ, Reed MW. Candidate gene polymorphisms in solid cancers. Eur J Surg Oncol. 2004;30(6):593-601.

113. Solovey A, Gui L, Ramakrishnan S, Steinberg MH, Hebbel R P. Sickle cell anemia as a possible state of enhanced anti-apoptotic tone: Survival effect of vascular endothelial growth factor on circulating and unanchored endothelial cells. Blood. 1999;93(11):3824-30.

114. He Y, Ni J, Chen S, Jiang Y, Jia S, Gao Y. The vascular endothelial growth factor-2549 insertion/deletion polymorphism is not associated with susceptibility to hepatocellular carcinoma in Chinese. DNA Cell Biol. 2010;29(7):393-6.

115. Wu X, Xin Z, Zhangetal W, Wu X, Xin Z, Zhang W, Wu J, Chen K, Wang H, Zhu X, Pan L, Li Z, Li H, Liu Y. Polymorphisms in the VEGFA promoter are 
associated with susceptibility to hepatocellular carcinoma by altering promoter activity. Int J Cancer. 2013;133(5):1085-93.

116. Kong SY, Park JW, Lee JA, Park JE, Park KW, Hong EK, Kim CM. Association between vascular endothelial growth factor gene polymorphisms and survival in hepatocellular carcinoma patients. Hepatology. 2007;46(2):446-55.

117. Mise M Arii S, Higashituji H, Furutani M, Niwano M, Harada T, Ishigami S I, Toda Y, Nakayama H, Fukumoto M, Fujita J, Imamura M. Clinical significance of vascular endothelial growth factor and basic fibroblast growth factor gene expression in liver tumor. Hepatology. 1996;23(3):455-64.

118. Yamamoto T, Kaneda K, Hirohashi K, Kinoshita H, Sakurai M. Sinusoidal capillarization and arterial blood supply continuously proceed with the advance of the stages of hepatocarcinogenesis in the rat. Jpn J Cancer Res. 1996;87(5):442-50.

119. Pang RWC, Joh JW, Johnson PJ, Monden M, Pawlik TM, Poon RP. Biology of hepatocellular carcinoma. Ann Surg Oncol. 2008;15(4):962-71.

120. Park YN, Kim YB, Yang KM, Park C. Increased expression of vascular endothelial growth factor and angiogenesis in the early stage of multistep hepatocarcinogenesis. Arch Pathol Lab Med. 2000;124(7):1061-5.

121. Yao DF, Wu XR, Zhu Y, Shi GS, Dong ZZ, Yao DB, Wu W, Qiu LW, Meng XY. Quantitative analysis of vascular endotelial growth fator, microvascular density and their clinicopathologic featurres in human hepatocellular carcinoma. Hepatobiliary Pancreat Dis Int. 2005;4(2):220-6.

122. Deli G, Jin CH, Mu R, Yang S, Liang Y, Chen D, Makuuchi M. Immunohistochemical assessment of angiogenesis in hepatocellular carcinoma and surrounding cirrhotic liver tissues. World J Gastroenterol 2005;11(7):960-3. 
123. Huang GW, Yang LY, Lu WQ. Expression of hypoxia-inducible factor 1 alpha and vascular endothelial growth factor in hepatocellular carcinoma: impact on neovascularization and survival. World J Gastroenterol. 2005;11(11):1705-8.

124. Cui J, Dong BW, Liang P, Yu DJ. Effect of c-myc, Ki-67, MMP-2 and VEGF expression on prognosis of hepatocellular carcinoma patients undergoing tumor resection. World J Gastroenterol. 2004;10(10):1533-6.

125. Wang ZL, Liang P, Dong BW, Yu XL, Yu DJ. Prognostic factors and recurrence of small hepatocellular carcinoma after hepatic resection or microwave ablation: a retrospective study. J Gastrointest Surg. 2008;12(2):327-37.

126. Guenther BD, Sheppard CA, Tran P, Rozen R, Matheus RG, Ludwig ML. The structure and properties of methylenetetrahydrofolate reductase from Escherichia coli suggest how folate ameliorates human hyperhomocysteinemia. Nat Struct Biol. 1999;6(4):359-65.

127. Frost P, Blom HJ, Melos R, Goyette P, Sheppard CA, Matthews RG, Boers GJ, den Heijer M, Kluijtmans LA, Heuvel LP, Van den Rozen R. A candidate genetic risk fator for vascular disease: a common mutation in methylenetetrahydrofolate reductase. Nat Genet. 1995;10(11):111-3.

128. Botto LD, Yang Q. 5-10-Methylenetetrahydrofolate reductase gene variants and congenital anormalies: a HuGE review. Am J Epidemiol. 2000;151(9):862-77.

129. Bydlowski SP, Magnanelli AC, Chamone DA. Hyperhomocysteinemia and vaso-occlusive diseases. Arq Bras Cardiol. 1998:71(9):69-76.

130. Goyette P, Summer JS, Milos R, Duncan MV, Rosenblatt DS, Mathews RG, Rozen R. Human methylenetetrahydrofolate reductase: isolation of cDNA mapping and mutation identification. Nat Genet. 1994;7(2):195-200. 
131. Sibani S, Christensen B, O’Ferrall E, Saadi I, Hiou-Tim F, Rosenblatt DS, Rozen R. Characterization of six novel mutations in methylenetetrahydrofolate reductase (MTHFR) gene in patients with homocystinuria. Hum Mutat. 2000;15(3):280-7.

132. Frosst P, Blom HJ, Milos R. Govette P, Sheppard CA, Matthews RG, Boers GJ, den Heijer M, Kluijtmans LA, van den Heuvel LP, Rozen R. A candidate genetic risk fator for vascular disease: a commom mutation in methylenotetrahydrofolate reductase. Nat Genet. 1995;10(1):111-3.

133. Neves L.B, Macedo DM, Lopes AC. Homocisteína. J Bras Patol Med Lab. 2004;40(5):311-20.

134. van der Put NM, Gabreels F, Stevens EM, Smeitink JA, Trijbels FJ, Eskes TK, van den Heuvel LP, Blom HJ. A second common mutation in the methylenetetrahydrofolate reductase gene: an additional risk factor for neural-tube defects? Am J Hum Genet. 1998;62(5):1044-51.

135. Duthie SJ. Folic acid deficiency and cancer: mechanisms of DNA instability. Br Med Bull. 1999;55(3):578-92.

136. Giovannucci E, Stampfer Mj, Colditz GA, Rimm EB, Trichopoulos D, Rosner BA, Speizer FE, Willett WC. Folate, methionine and alcohol intake and risk of colorectal adenoma. J Natl Cancer Inst. 1993;85(11):875-84.

137. Duthie SJ. Folate and cancer: how DNA damage, repair andmethylation impact on colon carcinogenesis. J Inherit Metab Dis. 2011;34(1):101-9.

138. Bai JL, Zheng MH, Xia X, Ter-Minassian M, Chen YP, Chen F. MTHFR C677T polymorphism contributes to prostate cancer risk among Caucasians: A metaanalysis of 3511 cases and 2762 controls. Eur J Cancer. 2009;45(8):1443-9. 
139. Langsenlehner T, Renner W, Yazdani-Biukê B, Langsenlehner U.

Methylenetetrahydrofolate reductase (MTHFR) and breast cancer risk: a nested-casecontrol study and a pooled meta analysis. Breast Cancer Res Treat. 2008;107(3):45960

140. Le Marchand L, Wilkens LR, Kolonel LN, Henderson BE. The MTHFR C677T polymorphism and colorectal câncer: the multiethinic cohort study. Cancer Epidemiol Biomarkers Prev. 2005;14(5):1198-203.

141. Mu LN, Cao W, Zhang ZF, Yu SZ, Jiang QW, You NC, Lu QY, Zhou XF, Ding BG, Chang J, Chan CW, Wei GR, Cai L. Polymorphisms of 5-10methylenetetrahydrofolate reductase (MTHFR), fruit and vegetables intake, and risk of stomacle cancer. Biomarkers. 2007;12(1):61-75.

142. Karagas MR, Park S, Nelson HH, Andrew AS, Mott L, Schned A, Kelsey KT. Methylenetetrahydrofolate reductase (MTHFR) variants and bladder cancer: a population based case-control study. Int J Hyg Environ Health. 2005;208(5):321-7.

143. Yang CX, Matsuo K, Ito H, Shinoda M, Hatooka S, Hirose K, Wakai K, Saito T, Suzuki T, Maeda T, Tajima K. Gene-environment interactions between alcohol drinking and the MTHFR C677T polymorphism impact on esophageal cancer risk: results of a case-control study in Japan. Carcinogenesis. 2005;26(7):1285-90.

144. Krajinovic M, Lamoth S, Labuda D, Lemieux-Blanchard E, Theoret Y, Moghrabi A, Sinnett D. Role of MTHFR genetic polymorphisms in the susceptibility to childhood acute lymphoblastic leucemia. Blood 2004;103(1):252-7.

145. Zanrosso CW, Emereciano M, Figueiredo A, Reis M, Cordeiro SNS, Splendore A, Oliveira MS. Influência da metileno-tetrahidrofolato redutase na patogênese das leucemias agudas infantis. Revista Brasileira de Cancerologia. 2005;51(4):289-95. 
146. Fabris C, Toniutto P, Falleti E, Fontanini E, Cussigh A, Bitetto D, Fornasiere E, Fumolo E, Avellini C, Minisini R, Pirisi M. MTHFR C677T polymorphism and risk of HCC in patients with liver cirrhosis: role of male gender and alcohol consumption. Alcohol Clin Exp Res. 2009;33(1):102-7.

147. Ventura P, Rosa MC, Abbati G, Marchini S, Grandone E, Vergura P, Tremosini S, Zeneroli ML. Hyperhomocysteinaemia in chronic liver diseases: role of disease stage, vitamin status and methylenetetrahydrofolate reductase genetics. Liver Int. 2005;25(1):49-56.

148. Jin F, Qu LS, Shen XZ. Association between the methylenetetrahydrofolate reductase $\mathrm{C} 677 \mathrm{~T}$ polymorphism and hepatocellular carcinoma risk: a meta-analysis. Diagnostic pathology. 2009;4:39.

149. Qin X, Peng Q, Chen Z, Deng Y, Huang S, Xu J, Li H, Li S,Zhao J. The association between MTHFR gene polymorphisms and hepatocellular carcinoma risk: a meta-analysis. PloS one. 2013;8(2):e56070.

150. Bruix J, Sherman M; American Association for the Study of Liver D. Management of hepatocellular carcinoma: an update. Hepatology. 2011;53(3):10202.

151. Forner A, Reig M, de Lope CR, Bruix J. Current strategy for staging and treatment: the BCLC update and future prospects. Semin Liver Dis 2010;30:61-74.

152. WHO. Report of a WHO Consultation on Obesity. Obesity: preventing and managing the global epidemic. . Geneva: World Health Organization; 2000. Contract No. 894.

153. dbSNP. Disponível em: http://www.ncbi.nlm.nih.gov/sites/entrez?db=snp [cited 2013 12/02/2013]. 
154. International HapMap Project. Disponível em: http://hapmap.ncbi.nlm.nih.gov/ [cited 2013 12/02].

155. Liu C, Xiao GQ, Yan LN, Li B, Jiang L, Wen TF, Wang WT, Xu MQ, Yang JY. Value of $\alpha$-fetoprotein in association with clinicopathological features of hepatocellular carcinoma. World J Gastroenterol 2013;19(11): 1811-9.

156. Leung DW, Cachianes G, Kuang WJ, Goeddel DV, Ferrara N. Vascular endothelial growth factor is a secreted angiogenic mitogen. Science. 1989;246(4935):1306-9.

157. Yao DF, Wu XR, Zhu Y, Shi GS, Dong ZZ, Yao DB, Wu W, Qiu LW, Meng XY. Quantitative analysis of vascular endothelial growth factor, microvascular density and their clinicopathologic features in human hepatocellular carcinoma. Hepatobiliary Pancreat Dis Int. 2005;4(2):220-6.

158. Giacalone A, Montalto G, Giannitrapani L, Balasus D, Terranova A, Cervello M, Soresi M, Marasa L. Association between single nucleotide polymorphisms in the cyclooxygenase-2, tumor necrosis factor- $\alpha$, and vascular endothelial growth factor-A genes, and susceptibility to hepatocellular carcinoma. OMICS. 2011;15(3):193-6.

159. Baitello ME, Tenani GD, Ferreira RF, Nogueira V, Pinhel MA, Silva RC, Silva RF, Fucuta PD, Godoy MF, Souza DR. VEGF polymorphisms related to higher serum levels of protein identify patients with hepatocellular carcinoma. Can J Gastroenterol Hepatol. 2016;2016:9607054.

160. Ratnasari N, Nurdjanah S, Sadewa AH, Hakimi M. The role of Vascular endothelial growth factor $-634 \mathrm{G} / \mathrm{C}$ and its solube receptor on chronic liver disease and hepatocellular carcinoma. Arab J Gastroenterol. 2016;17(2):61-6.

161. Guo Q, Dai SB, Shen F, Yu D, Shen ST, Zhang Q, Huang JX, Wu ZD. VEGF +405G/C (rs2010963) polymorphisms and digestive system cancer risk: a metaanalysis. Tumour Biol. 2014;35(5):4977-82. 
162. Tie Z, Bai R, Zhai Z, Zhang G, Zhang H, Zhao H, Zhou D, Liu W. Single nucleotide polymorphisms in VEGF gene are associated with an increased risk of osteosarcoma. Int J Clin Exp Pathol. 2014;7(11):8143-9.

163. Kwak SY, Kim UK, Cho HJ, Lee HK,Kim HJ, Kim NK, Hwang SG. Methylenetetrahydrofolate reductase (MTHFR) and methionine synthase reductase (MTRR) gene polymorphisms as risk factors for hepatocellular carcinoma in a Korean population. Anticancer Res. 2008;28(5A):2807-11.

164. Cui LH, Song Y, Si H, Shen F, Shin MH, Kim HN, Choi JS. Folate metabolism-related gene polymorphisms and susceptibility to primary liver cancer in North China. Med Oncol. 2012;29(3):1837-42.

165. D'Amico M, Pasta L, Sammarco P. MTHFR C677TT, PAI1 4G-4G, V Leiden Q506, and prothrombin G20210A in hepatocellular carcinoma with and without portal vein thrombosis. J Thromb Thrombolysis. 2009;28(1):70-3.

166. Qi YH, Yao LP, Cui GB, Liang J, Shao QJ, Yan LF, Du P. Meta-analysis of MTHFR C677T and A1298C gene polymorphisms: association with the risk of hepatocellular carcinoma. Clin Res Hepatol Gastroenterol. 2014;38(2):172-80.

167. Zhuo X, Ling J, Zhou Y, Zhao H, Song Y, Tan Y. Polymorphisms of MTHFR C677T and A1298C association with oral carcinoma risk: a meta-analysis. Cancer Invest. 2012;30(6):447-52.

168. Kuo CS, Huang CY, Kuo HT, Cheng CP, Chen CH, Lu CL, Yang FL, Huang RFS. Interrelationships among genetic C677T polymorphism of 5,10methylenetetrahydrofolate reductase, biochemical folate status, and lymphocytic p53 oxidative damage in association with tumor malignancy and survivals of patients with hepatocellular carcinoma. Mol Nutr Food Res. 2014;58(2):329-42. 